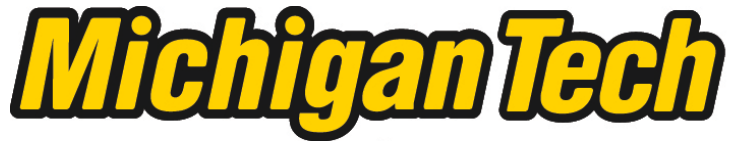 \\ Michigan Technological University Create the Future Digital Commons @ Michigan Tech
}

Quickbird satellite imagery for riparian management : characterizing riparian filter strips and detecting concentrated flow in an agricultural watershed

Sarah Volkman

Michigan Technological University

Follow this and additional works at: https://digitalcommons.mtu.edu/etds

Part of the Civil and Environmental Engineering Commons

Copyright 2005 Sarah Volkman

\section{Recommended Citation}

Volkman, Sarah, "Quickbird satellite imagery for riparian management : characterizing riparian filter strips and detecting concentrated flow in an agricultural watershed ", Master's Thesis, Michigan Technological University, 2005.

https://doi.org/10.37099/mtu.dc.etds/279

Follow this and additional works at: https://digitalcommons.mtu.edu/etds

3 Part of the Civil and Environmental Engineering Commons 


\title{
QUICKBIRD SATELLITE IMAGERY FOR RIPARIAN MANAGEMENT: CHARACTERIZING RIPARIAN FILTER STRIPS AND DETECTING CONCENTRATED FLOW IN AN AGRICULTURAL WATERSHED
}

\author{
By \\ SARAH VOLKMAN
}

\begin{abstract}
A THESIS
Submitted in partial fulfillment of the requirements for the degree of

MASTER OF SCIENCE IN ENVIRONMENTAL ENGINEERING
\end{abstract}

MICHIGAN TECHNOLOGICAL UNIVERSITY

2005

Copyright @ Sarah Volkman 2005 
This thesis, "Quickbird Satellite Imagery for Riparian Management: Characterizing Riparian Filter Strips and Detecting Concentrated Flow in an Agricultural Watershed," is hereby approved in partial fulfillment of the requirements for the Degree of MASTER OF SCIENCE IN ENVIRONMENTAL ENGINEERING.

\section{DEPARTMENT:}

Civil and Environmental Engineering

Signatures:

Thesis Advisor

Typewritten Name

Department Chair

Typewritten Name

Date 


\begin{abstract}
Riparian ecology plays an important part in the filtration of sediments from upland agricultural lands. The focus of this work makes use of multispectral high spatial resolution remote sensing imagery (Quickbird by Digital Globe) and geographic information systems (GIS) to characterize significant riparian attributes in the USDA's experimental watershed, Goodwin Creek, located in northern Mississippi. Significant riparian filter characteristics include the width of the strip, vegetation properties, soil properties, topography, and upland land use practices. The land use and vegetation classes are extracted from the remotely sensed image with a supervised maximum likelihood classification algorithm. Accuracy assessments resulted in an acceptable overall accuracy of 84 percent. In addition to sensing riparian vegetation characteristics, this work addresses the issue of concentrated flow bypassing a riparian filter. Results indicate that Quickbird multispectral remote sensing and GIS data are capable of determining riparian impact on filtering sediment. Quickbird imagery is a practical solution for land managers to monitor the effectiveness of riparian filtration in an agricultural watershed.
\end{abstract}




\section{ACKNOWLEDGEMENTS}

I greatly appreciate the guidance given to me by my advisor, Dr. Brian Barkdoll and National Sedimentation Laboratory correspondent, Dr. Ronald Bingner, in the development of this research. I am also especially thankful for the field work help and technical guidance provided by Vance Justice from the National Sedimentation Laboratory. In addition, valuable GIS support was provided by Darlene Wilcox. Funding was supported by the USDA-ARS National Sedimentation Laboratory and Michigan Technological University. Finally, I'd like to thank my committee members; Dr. Brian Barkdoll, Dr. David Watkins, Dr. John Gierke, and Dr. Ann Maclean, for their time and valuable input into this research. 


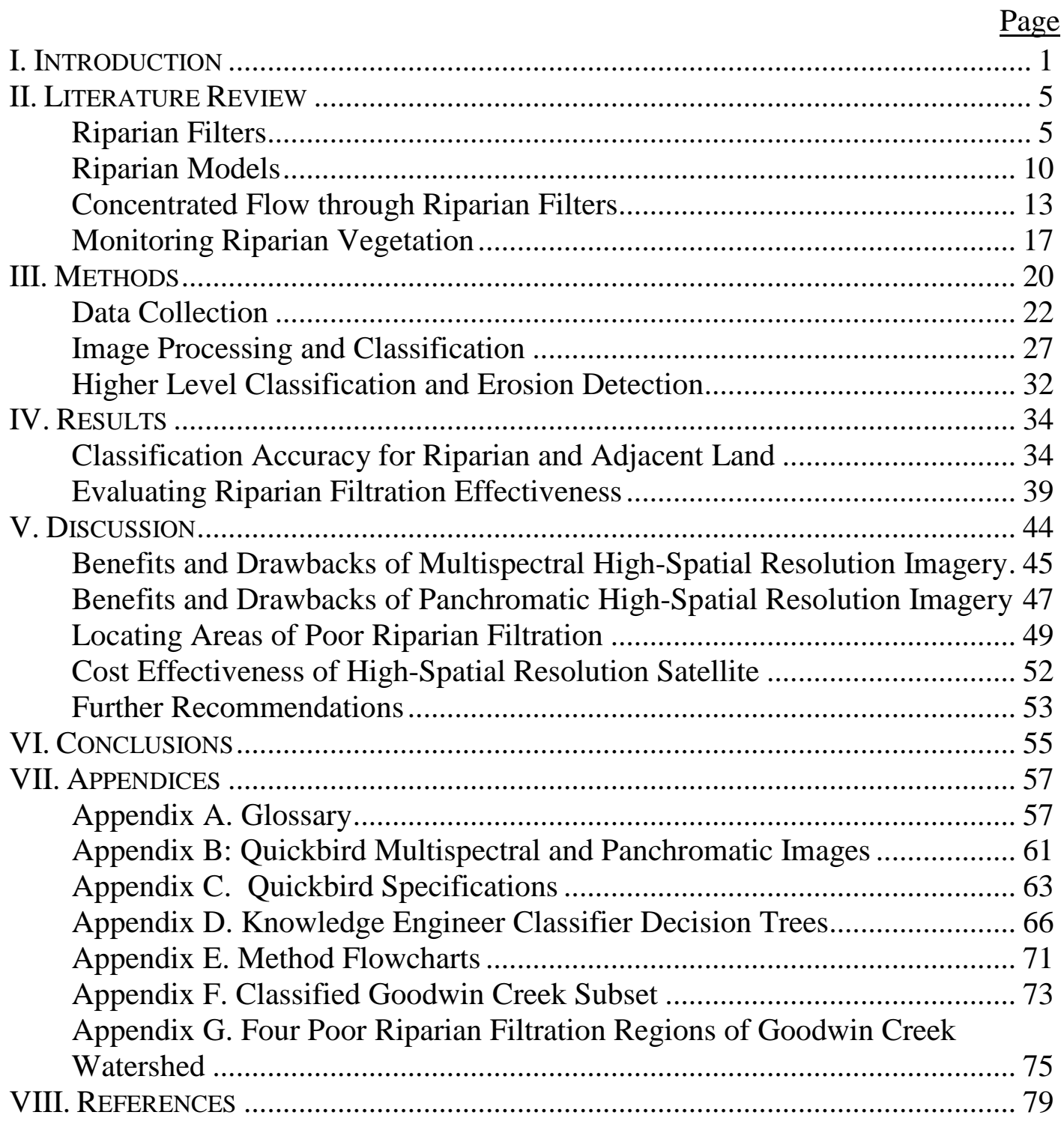




\section{LIST OF FIGURES}

Figure 1. Buffer widths and corresponding benefits (adapted from English et al., 2002)

Figure 2. Ideal field-buffer contact for maximum sediment trapping efficiency ....... 15

Figure 3. Active filter area when concentrated flow occurs through a field or buffer 15

Figure 4. Image shows the appearance of 30-m, 10-m, 2.44-m, and 0.61-m spatial resolutions. The resolutions indicate that the $30 \mathrm{~m}$ resolution of Landsat TM imagery is too coarse to capture buffers measuring less than $30 \mathrm{~m}(100 \mathrm{ft})$. ..... 19

Figure 5. Location of Goodwin......................................................................... 20

Figure 6. Equipment used for Goodwin Creek field data collection. The data collected in the field was later used as training and accuracy data for supervised classification of the Quickbird satellite image.

Figure 7. Scatter of stratified random field plots for training and accuracy data within the extent of the Quickbird coverage. ............................................................. 24

Figure 8. A flowchart summarizing changes and adaptations made to the classification scheme in order to produce a classification of higher accuracy. .. 30

Figure 9. General description of Knowledge Engineer's decision tree. The tree states that the hypothesis is true, given rule A and rule B exist, and the rules exist given that at least one of the conditions is present. 32

Figure 10. Riparian image delineated and clipped from entire Quickbird extent. Riparian area was defined as the land between pasture or agriculture and the stream. The inset image shows the level of detail, and displays the progressive change of riparian vegetation.

Figure 11. Adjacent fields grouped into polygons, and their crop row directions were digitized (soybean= green, cotton= yellow). The figure also shows the riparian delineation and 10-m topographic contours. Concentrated flow is shown as red lines entering the riparian zone from the adjacent field.

Figure 12. Riparian area identified as having poor qualities is also receiving concentrated flow from a cotton field. Pictured here, is concentrated flow coming from a field entering into a "red" riparian zone. It is surrounded by trees or shrubs with no dispersion vegetation, steep slopes, and poor soil properties (blue and teal).

Figure 13. Four riparian regions within Goodwin Creek that have been identified by Knowledge Engineer decision trees as having poor sediment filtration, dispersion or settling properties, and are accepting incoming concentrated flow.

Figure 14. Kudzu covered riparian area with steep slopes, not detected with

Knowledge Classifier. The steep slopes observed in the field did not appear in the 10-m DEM and slope calculation. In effect, this classification method is not

suitable for detecting narrow, steep channel erosion. 43

Figure 15. Erosion visible in panchromatic image and field due to lack of vegetation. 
Figure 16a: Sediment transport through vegetated riparian zone (according to Barfield

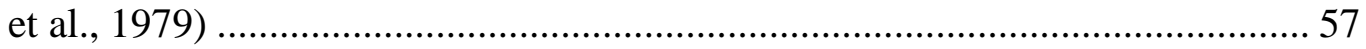

Figure 17b. Quickbird multispectral image, showing blue, green and infrared bands

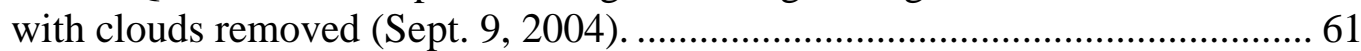

Figure 18b. Quickbird panchromatic image (Sept. 9, 2004).................................. 62

Figure 19d. Knowledge Engineers classification of areas with poor riparian filtration (red). The areas include poor filtering vegetation, slopes greater than $15 \%$, and poor soil infiltration properties (type C \& D).

Figure 20d. Knowledge Engineer's classification of riparian areas with healthy grass (green), but other poor qualities including poor soil infiltration properties and slopes greater than $15 \%$. The classification was also limited to 24 meters from the streamline.

Figure 21d. Knowledge Engineer's classification of riparian areas with healthy grass (dark green), with poor qualities that limit its ability to disperse entering runoff including poor soil infiltration properties and slopes greater than $15 \%$. The classification was also limited to greater than 24 meters from the streamline. .. 68

Figure 22d. Knowledge Engineer's classification of riparian areas with shrubs and trees (blue) used to increase the settling time of dispersed flow, but with other poor qualities including poor soil infiltration properties and slopes greater than 15\%. The classification was also limited to 24 meters from the streamline..... 69

Figure 23d. Knowledge Engineer's classification of riparian areas with shrubs and trees (teal blue), used to increase the settling time of dispersed flow, but with other poor qualities including poor soil infiltration properties and slopes greater than $15 \%$. The classification was also limited to greater than 24 meters from the streamline. 70

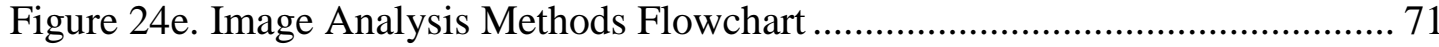

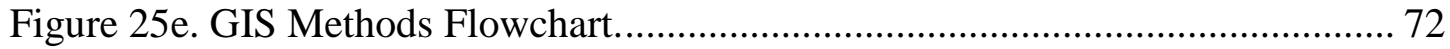

Figure 26f. Goodwin Creek Watershed classified image. Classification is a result of the Maximum Likelihood algorithm run in ERDAS Imagine. Holes in the classification are from clipping out cloud coverage. 73

Figure 27f: 1987 land use classification used by the USDA Sedimentation Laboratory and created from a 30-m Landsat TM image. Classification includes only four classes: Cropland, Pasture/Idle Land, Water, and Woods.

Figure 28g. Poor riparian region one. Concentrated flow from soybean field and roadside flow into kudzu riparian area with a slope greater than $15 \%$ and poor soil infiltration.

Figure 29g. Poor riparian region two. Concentrated flow coming from cotton field into Kudzu covered riparian zone with a slope greater than $15 \%$ and poor soil infiltration.

Figure $30 \mathrm{~g}$. Poor riparian region three. Concentrated flow coming from cotton field into forested riparian area with insufficient width and with no grass to disperse the flow, slope greater than $15 \%$ and poor soil infiltration.

Figure $31 \mathrm{~g}$. Poor riparian region four. Concentrated flow from hayfield into kudzu riparian area with a slope greater than $15 \%$ and poor soil infiltration. Note that the classifier did not denote the entire area as poor. This is due to the 10-meter resolution of the DEM used to calculate slope. 


\section{LIST OF TABLES}

Table 1. Relative effectiveness of different riparian vegetation types for providing specific benefits (Dosskey et al., 1998) ........................................................ 8

Table 2. Results from Dosskey et al. (2002) on contributing factors of concentrated

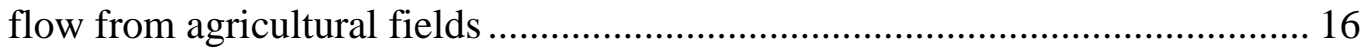

Table 3. Vegetation classes and associated properties used to classify the riparian and upland areas of Goodwin Creek Watershed (FGDC, 1997)............................ 26

Table 4. Best minimum separability matrix using Transformed Divergence for the final classification scheme (performed with ERDAS Imagine software package).

Table 5. Contingency Error Matrix using Maximum Likelihood algorithm for the final classification scheme (made with ERDAS Imagine software).

Table 6. Error matrix for final vegetation classes produced from the Maximum Likelihood Classifier.

Table 7. Summary of the Error Matrix for Vegetation Classes using Supervised Maximum Likelihood Classification ............................................................. 36

Table 8. Vegetation area in three zones from the stream (Welsch, 1991)................. 37

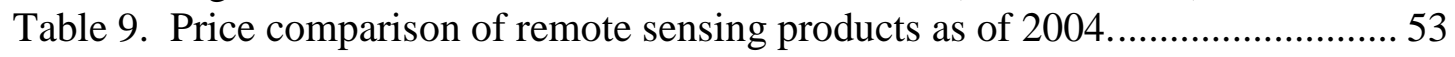

Table 10. Identification of riparian land characteristics to aid in identifying areas of ineffective riparian filtration.................................................................... 55

Table 11. Identification of adjacent land use characteristics to aid in identifying areas that contribute to ineffective riparian filtration............................................... 56

Table 12a: Characteristics of Spectral Bands in Quickbird Images (Digital Globe, 2004; Jensen, 1996)

Table 13a: Summary of available remotely sensed data types (adapted from Franklin \& Dickson, 2001; Brohman and Bryant, 2003) 59

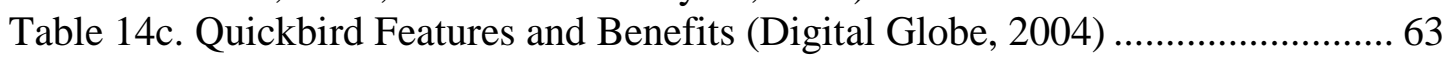

Table 15c. Quickbird Design and Specifications (Digital Globe, 2004) ................... 64

Table 16c. Quickbird Design and Specifications continued (Digital Globe, 2004) ... 65 


\section{ACRONYMS}

AGNPS: Agriculture Non-Point Source

AnnAGNPS: Annualized Agriculture Non-Point Pollution Source

DEM: Digital Elevation Model

ERDAS: Earth Resources Data Analysis System

GIS: Geographic Information Systems

GPS: Global Positioning System

LIDAR: Light Detection and Ranging

MLC: Maximum Likelihood Classifier

NRCS: Natural Resource Conservation Service

REMM: Riparian Ecosystem Management Model

USDA: United States Department of Agriculture

USLE: Universal Soil Loss Equation

VFSMOD: Vegetated Filter Strip Model 


\section{Introduction}

The U.S. Department of Agriculture conducted a recent evaluation of one million kilometers of rivers and streams. Results indicated that in $44 \%$ of those streams, sedimentation and excess nutrients were the most significant causes of degradation-- with most of the sediment sources being agricultural land (Langendoen et al., 1998). This is especially true in agricultural watersheds along the Mississippi River, where erosion is excessive based on a history of agriculture coupled with poor conservation practices (Blackmarr, 1995). The damage of excess sedimentation begins in small streams, and accumulates as those streams enter larger rivers. An example of the severe effect is seen where the Mississippi River enters the Gulf of Mexico causing the infamous Dead Zone (Gowda, 1998). Riparian land is increasingly susceptible to clearing for agriculture and other land use; such events result in land and water quality degradation. Monitoring of these natural resources is required to ensure their effectiveness and proper management.

The impact of riparian land use on water quality has been an important topic in land management practices in recent years. Scientists are beginning to realize the many benefits riparian areas extend to water quality in creeks, streams, and rivers (Daniels and Gilliam, 1996). A specific benefit that is especially important in agricultural watersheds is the use of riparian areas as filters between upland non-point pollution sources and waterways. At the same time, other scientists question the effectiveness of riparian filters when agricultural runoff is not necessarily controlled and dispersed into the filters; essentially forming concentrated runoff and bypassing the filter. Whether a riparian filter 
functions as an effective sediment trap can be determined by monitoring the width of vegetation, vegetation properties, soil properties, and upland land use practices.

If riparian filters have significant shortcomings in their ability to filter runoff, sediment reaching the streams will then have severe detrimental effects on water quality. Therefore, scientists have searched for methods to detect riparian characteristics and model riparian processes to assist in land management and decision making. In the past, researchers digitized aerial photographs to monitor riparian vegetation. This method proved to be time consuming and inefficient for large study areas and limited in the ability to conduct frequent monitoring (EPA \& FTG, 2004; RESAC, 2003; Franklin and Dickson, 2001; Coulter et al., 2000; Black et al., 2003). Fortunately, remote sensing of the ecosystem has made significant advances over the past twenty years in monitoring vegetation. SPOT and Landsat TM satellites, launched in the 1980s, have been used extensively to characterize land use and vegetation. However, their coarse spatial resolution (10-30 meters) limits their use in monitoring riparian areas, which are often narrow strips of land with diverse vegetation. New advances have led to multispectral high-spatial resolution (HSR) imaging that includes IKONOS (Space Imaging Corp.), Quickbird (Digital Globe), and digital aerial photography. High spatial resolution images range from 0.3 meters to 4 meters and can detect riparian spatial conditions with greater precision than that of the Landsat TM or SPOT images.

Since the IKONOS satellite became available in 2001, several studies have used it to map riparian zones (Klemas, 2001; Rolem and Lingnau, 2002; Khorram et al., 2003; Goetz et 
al., 2003). The Quickbird satellite is the most recent commercially-available satellite imagery and has an even finer resolution than the IKONOS multispectral and panchromatic images. Because of Quickbird's recent launch, very few studies have utilized Quickbird satellite imagery to characterize riparian terrain.

Nonetheless, mapping riparian vegetation is only the first step in using the potential of remote sensing technology. Applying the information gathered from remotely-sensed images to current riparian and watershed models is a significant step in understanding riparian functions. The question this study addresses is whether sufficient characteristics of riparian filter strips and its adjacent land can be obtained from a multispectral highresolution image. In particular, will these characteristics be adequate so that the effectiveness of active filter areas be detected? Key terms within the research question need to be defined to narrow the scope of the question. A riparian filter strip is defined as a strip of land separating the water body from land use that could act as a non-point pollution source. The vegetated riparian land strip has the ability to reduce sedimentation by intercepting surface runoff and dispersing the runoff, allowing filtration and sediment deposition within the riparian filter strip. The active filter area is defined as the area within the gross buffer area that has contact with the actual field runoff (Dosskey et al, 2002). Significant riparian characteristics for this study are defined as the spatial phenomena of riparian filters related to the spatial activity of the filter area. These phenomena include: riparian distance from the channel, vegetation classes, soil characteristics that affect runoff infiltration, topography that influences flow direction and accumulation, and evidence of the strip receiving surface runoff. Finally, adjacent 
land characteristics include spatial phenomena of land use along the filter that influence where surface runoff contacts the active filter area. These phenomena include: land use type (pasture, idle land, cultivated cotton, soybeans, or corn), topography, location of topographic swales, soil type, crop row direction and if rows lead to topographic swales where runoff may exit, as well as any other land shaping features that influence runoff direction.

This work intends to develop procedures using Quickbird imagery and geographic information systems (GIS) to characterize the riparian area in the USDA's experimental watershed, Goodwin Creek, located in northern Mississippi. Furthermore, knowledge of the riparian characteristics will predict if runoff is formed into concentrated flow and bypasses the filter strip, decreasing its effectiveness. Specific goals include, (1) defining what riparian characteristics need to be detected, (2) determining an appropriate classification system that would encapsulate the riparian features considered necessary to observe riparian effectiveness, (3) perform an accuracy assessment of the classified image, and finally (4) predict where concentrated flow is short-circuiting the riparian filter.

The procedures for using remote sensing in this study are meant to provide a method that is not as time-consuming or costly as alternative or traditional methods. Other remote sensing technologies, such as hyperspectral imagery, LIDAR (Leckie et al, 2003), or microwave imagery (Mertes, 2002; van Oevelen and Sterk, 2001) may provide more 
riparian information, but have high-computational requirements and high costs, thus not fitting into the scope of this study.

\section{Literature Review}

There are a multitude of documents concerning the impact of riparian zones and how they affect water quality, as well as endless possibilities of using remote sensing to gather vegetation data. As today's technology rapidly improves, the potential to use remote sensing as a way to more accurately understand ecosystem processes is steadily increasing. The following section will present the approach researchers have used to evaluate riparian filter's characteristics, how remote sensing techniques have contributed to date, and how new technology will assist in a more accurate assessment. Terms with a superscript number after them are defined in the glossary in Appendix A.

\section{Riparian Filters}

Within a riparian area, one or more ecotones ${ }^{1}$ can exist, providing different functions through different portions of the strip. In naturally-occurring riparian areas, an edge effect is often created due to the changing hydrological and soil conditions as the distance from the stream increases. Horizontal diversity generally progresses from water to aquatic plants, to forbs ${ }^{1}$ and shrubs, to deciduous trees, and then conifer trees (McKee et al., 1996). However, within the Goodwin Creek watershed and other agricultural watersheds, the horizontal progression has been disturbed due to land use practices. Given the existence of disturbed or undisturbed riparian areas within a watershed, it is unfair to 
define riparian boundaries with arbitrarily set distances; rather they should be defined by ecological edges (Malanson, 1993). A summary of the different functions of a riparian area in relation to its distance from the water source is shown in Figure 1.

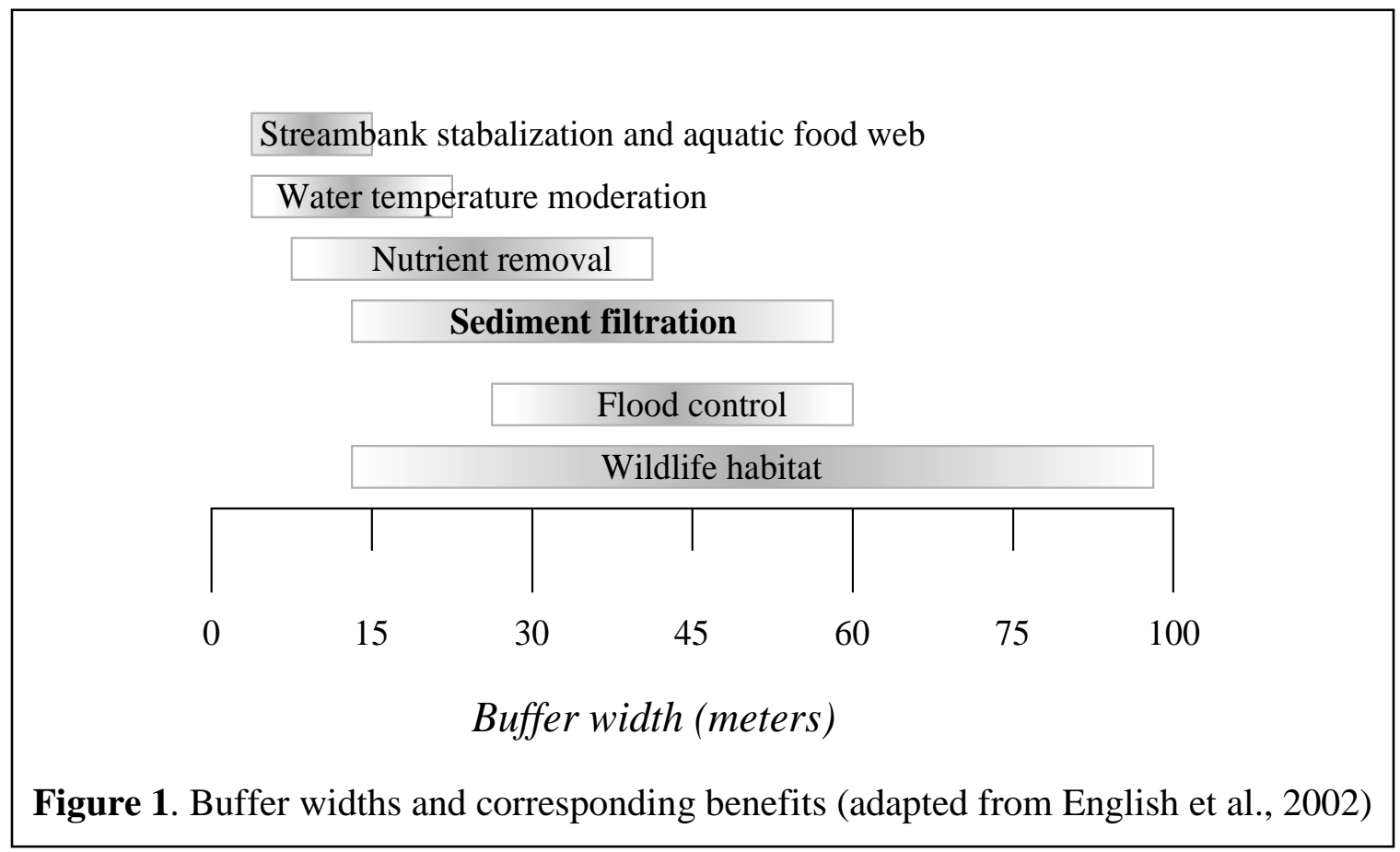

A riparian filter's influence in sediment interception as well as nutrient absorption ${ }^{1}$ has been well documented (Karr and Schlosser, 1978; Lowrance et al, 1986; Dillaha et al., 1989; Malanson, 1993; McKee et al., 1996, English et al., 2002; Prosser et al, 2002a). Riparian filters are defined as strips of vegetation separating a water body from land use that could act as a non-point pollution source. Riparian filters reduce runoff volume and velocity largely due to the filter's hydraulic roughness ${ }^{1}$, and consequent increase of infiltration (Munoz-Carpena et al., 1999). The buffer's roughness in turn, decreases transport capacity, allowing sediment to deposit in the filter rather than the body of water. 
An efficient filter is characterized by having the proper vegetation present, appropriate width, and no concentrated flow bypassing the buffer. In controlled plot studies, these properties lead to buffers that have the capacity to remove 50 percent of nutrients and pesticides, 60 percent of certain pathogens, and 75 percent of sediment (Natural Resources Conservation Service, 2001).

Central riparian characteristics that affect riparian filtration include (1) width, (2) soil type, (3) slope, (4) amount and type of vegetation, and (5) upland, bordering land use practices (English, 2002). The way each of these properties influence riparian filtration functions has traditionally been studied on small plots and field-sized study areas. The first property, width, has been examined by recent literature, and the appropriate width is debatable (Bren, 1998; Bagdon et al., 2000). The width of the buffer needs to be wide enough to distribute most of the flow as was shown in Figure 1, as well as allow for heterogeneity within the riparian area (Malanson, 1993). This width typically varies from 10 to 50 meters and depends on the source area, topography, the strip's hydraulic characteristics, and vegetation type (Munoz-Carpena et al., 1999). Soil properties also influence the rate of infiltration and determine the effectiveness of the buffer, as well as the source of the flow. If soil hydrologic groups ${ }^{1} \mathrm{C}$ and $\mathrm{D}$ are present, it often requires the riparian filters to be wider due to their poor ability to infiltrate. In addition, the crop type and farming management practices both influence how the flow enters the buffer (Souchere et al., 1998; English, 2002). 
The vegetation type and density in riparian areas has also been studied, and some conclusions have been made on ideal riparian conditions. Table 1 provides an overall summary of appropriate vegetation type and its degree of influence (low, medium, and high) on riparian effectiveness for a variety of riparian benefits.

Table 1. Relative effectiveness of different riparian vegetation types for providing specific benefits (Dosskey et al., 1998)

\begin{tabular}{lccc} 
& \multicolumn{3}{c}{ Vegetation Type } \\
\cline { 2 - 4 } Benefit & Grass & Shrub & Tree \\
\hline Stabilize bank erosion & low & high & high \\
Filter sediment & high & low & low \\
Filter nutrients pesticides, microbes & & & \\
$\quad$-sediment-bound & high & low & low \\
$\quad$-soluble & medium & low & medium \\
Aquatic habitat & low & medium & high \\
Wildlife habitat & & & \\
$\quad$-range/pasture/prairie wildlife & high & medium & low \\
$\quad$-forest wildlife & low & medium & high \\
Economic products & medium & low & medium \\
Visual diversity & low & medium & high \\
Flood protection & low & medium & high \\
\hline
\end{tabular}

As shown in Table 1, grass is more important than shrubs and trees in dispersing flow and trapping sediment. Trees, on the other hand, are better suited as a nutrient sink and bank stabilizer (Welsch, 1991). Essentially, anything that confines or deflects flow around vegetation will increase flow velocity (i.e. clumpy vegetation, tree trunks, roots, and topographic hollows) (Prosser et al., 2002a). Therefore, dense short grass $(10-15 \mathrm{~cm})$ is better than clumpy vegetation for trapping sediment. In forest soils where undergrowth is sparse, runoff flows quickly along preferred pathways around trunks and roots. Consequently, a forest filter needs to be wider than grass filter for it to trap sediment 
efficiently, or else flow must be dispersed in a flood plain prior to entering the forested region (Prosser, 2002b).

Ideally, if a riparian strip were divided into three zones, the First Zone closest to the water would be limited to the purpose of bank stability, with a minimum width of 4.5 meters. All concentrated flow would be dispersed before entering the First Zone, and livestock would be excluded. In the Second Zone, concentrated flow would also be dispersed prior to entering, and the primary purpose of this zone would be to provide the necessary contact time for the filtering process. In order to allow for enough settling time the width should be no less than 18 meters. The predominant vegetation would be trees and shrubs, and livestock would also be excluded from this area. Finally, in Zone Three, the purpose would be sediment filtration and nutrient uptake, and the vegetation (grass and forbs) would be dense and wide enough (6-meters) to disperse any concentrated flow (Welsch, 1991).

In addition, the USDA and Natural Resource Conservation Service (2001) have noted that riparian filtration is more significant and effective on seasonal streams or first and second-order streams ${ }^{1}$ that occur in the uplands of the watershed. This is due to both the natural presence of steep slopes in upland watershed regions and the absence of a flood plain, a property more common to larger streams. Riparian buffers placed along bigger, higher-ordered streams can still benefit wildlife habitats and stream bank protection. 


\section{Riparian Models}

There have been several efforts in modeling filter strips in order to determine their filtering effectiveness. In most cases, similar concepts to ones used in watershed models are applied, but the change occurring with time as runoff flows through a buffer strip and sediment is accumulated is accounted for in riparian modeling. As scientists' understanding of riparian filter strips improve, so have the models. This has also caused more complicated models requiring extensive inputs.

Wilson et al. (1981) modified and combined GRASSF, SEDIMOT II and a simple algorithm for the outflow hydrograph for up to three different slope changes in a filter. However, Munoz-Carpena et al. (1999) point out that this method does not account for time dependent infiltration within the buffer strip and changes in flow derived from sediment deposition, two important functions in a riparian buffer sediment transfer processes.

Tim et al. (1995) showed that in order to model a buffer strip, not only are hydrologic and hydraulic characteristics relevant but so are the buffer's physical characteristics (i.e. width and location in the agricultural setting). To perform this integrated approach, AGNPS (ㅁgriculture №n-Point $\underline{\text { Source}) ~(Y o u n g ~ e t ~ a l ., ~ 1989) ~ c o m b i n e d ~ w i t h ~ A R C / I N F O ~}$ GIS software were chosen to predict sediment yield. Tim et al. (1995) chose AGNPS because of the need for a spatially-distributed model that predicted runoff and sediment transfer considering on- and off-field management practices. Secondly, AGNPS had the ability to incorporate the complex hydraulic processes of buffer zones. AGNPS allowed 
the user to predict the impact of buffer strips on sediment yield by making changes to parameters within a buffer. According to Tim et al. (1995), parameters that change in a buffer include the Manning roughness coefficient for overland flow, the USLE C factor, the soil condition constant, and the SCS curve number for runoff.

Two zone-based riparian models that have recently been developed are VFSMOD (Vegetated Filter $\underline{\text { Strip }} \underline{\text { Model) }}$ (Munoz-Carpena et al., 1999) and REMM (iiparian

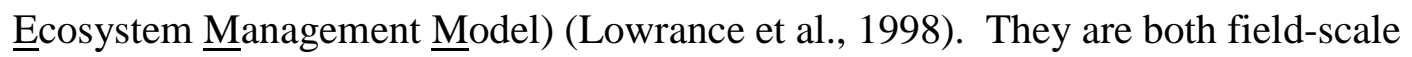
models that attempt to describe principal mechanisms in a riparian filter. MunozCarpena et al. (1999) developed VFSMOD, a field-scale, mechanistic, storm-based model that combines three submodels to describe the riparian processes. Two of the submodels describe the hydrology component and consist of a Petrov-Galerkin quadratic finite element overland flow based on the kinematic wave approximation and a modified Green-Ampt infiltration model for unsteady rainfall. A hydrograph representing runoff from the adjacent field serves as the input, along with soil type, slope, surface roughness, filter length, storm pattern, and field inflow. The sediment transport submodel is based on the original zone mechanism from Barfield et al. (1979). Barfield et al.'s zones ${ }^{1}$ account for sediment deposition processes within a filter of constant vegetation height. By linking the submodels, the hydrology model provides complex effects of rainfall, infiltration, and flow delay to the sediment model, and the sediment model provides information on surface conditions in each zone of the buffer. The new surface conditions are then fed back into the hydrology model for the next time step. 
REMM (Lowrance et al., 1998) is another zone-based riparian modeling tool that is often used in conjunction with AGNPS or AnnAGNPS. The previously mentioned Barfield et al. (1979) zones propose a constant vegetation height, whereas REMM's zones range from forested to grassy areas. The three-zone concept allows the user to vary slope, vegetation, soil characteristics and management in each zone. Model outputs are computed based on the USLE, an AGNPS algorithm for sediment routing, and the modified Bagnold stream power equations for effective transport capacity (Bagnold, 1966). After simulation, outputs for each zone include water table depth, surface runoff, and total sediment yield at the input to the buffer, both between each zone and at the buffer outlet to the water body. REMM reflects the specifications recommended by the U.S. Forest Service and the USDA-Natural Resource Conservation Service (USDANRCS, 1995).

In summary, riparian buffer strips have many processes occurring in them that scientists are continually trying to model to predict sediment yield more accurately. Furthermore, there are other features influencing buffer dynamics that researchers are considering and implementing in their programs. Inputs into these models can often be tedious, especially in an expansive riparian area. A tool for monitoring riparian areas would be advantageous in the further development of these models. One aspect of riparian function that will be discussed in the next section is whether the flow into and within the buffer is dispersed or concentrated, and its associated effects on the buffer's efficiency. 


\section{Concentrated Flow through Riparian Filters}

If concentrated flow exists in the buffer strip, the sediment and nutrient trapping efficiency decreases. Yet many field studies verifying riparian models do not account for concentrated flow, thereby computing the maximum trapping efficiency (Figure 2). In reality, concentrated flow forms where the topography is hilly or sediment build-up in the buffer causes flow to run parallel to the buffer (Dillaha et al., 1989). According to a study conducted by Eisenhaurer et al. (1997), it is common for concentrated flow to exit a field into a buffer strip when natural berms develop along the field-buffer boundary. Consequently, proper maintenance and design are imperative for a buffer to effectively reduce pollutants (Bagdon et al., 2000).

Daniels and Gilliam (1996) analyzed runoff at field edges and various places in the buffer. Some of the conclusions made were that ephemeral ${ }^{1}$ riparian channels need continuous vegetation to be effective, and under a forested canopy, this may not be possible. Upland ephemeral channels with nothing to impede the flow do not reduce sediment unless there is not enough flow to reach the main stream. Concentrated flow needs to be dispersed onto a flood plain to reduce energy and velocity of the flow.

Dillaha et al. (1989) performed several tests on experimental field plots to evaluate effectiveness of buffer strips. In one set of plots, a cross slope of four percent was present because it caused concentrated flow along the side of the plot. This was incorporated into the study because it was a concern on farms when buffers have natural drainage-ways running through them. Dillaha et al. (1989) concluded that the greater the 
slope-lengths, the higher the probability concentrated flow will occur in drainageways within the field and then cross the filter strips.

Souchere et al. (1998) examined whether slope and aspect or tillage direction determined the direction of the water flow, and thereby predicted where concentrated flow may occur in agricultural fields. According to Souchere et al., most runoff studies only consider topography, slope and aspect. However, when evaluating an agricultural watershed with shallow slopes, man-made agricultural factors influence the water pathways. This factor may be important in determining if and where concentrated flow forms as it enters the buffer strip. Souchere et al. found that if the slope is less than approximately 7 percent and the angle between the aspect and tillage direction lay between 20 and 60 degrees, then tillage directs the water flow. On the other hand, if the slope is greater than 8 percent and the aspect-tillage angle is between 40 and 90 degrees then the slope directs the flow; or, if the slope is low but the aspect-tillage angle is 70 to 90 degrees then slope determines flow as well.

Dosskey et al. (2002) also acknowledges that concentrated flow through a buffer limits its capabilities. Rather, Dosskey et al. (2002) wanted to find the concentrated flow patterns through a buffer in field-scale conditions instead of the test plots used in previous studies. Concentrated flow usually occurred within fields where runoff flowed into topographic swales ${ }^{1}$ before entering the buffer zone. Row direction parallel to the buffer zones and short berms at field margins appeared to promote flow into the field swales. If concentrated flow is observed in a field, only adding buffer area will not improve the buffer's efficiency. Conversely, introducing better runoff distribution would improve 
sediment retention without having to take away farming land needlessly. If the incidence of concentrated flow were not as great, then adding new buffer area would be a likely solution to improving the buffer efficiency.

In their field studies, Dosskey et al. (2002) attempted to identify the active buffer area (Figure 3) within the gross buffer area based upon visual observations of microrelief, sediment and debris deposition and orientation, and erosion patterns on the ground surface.

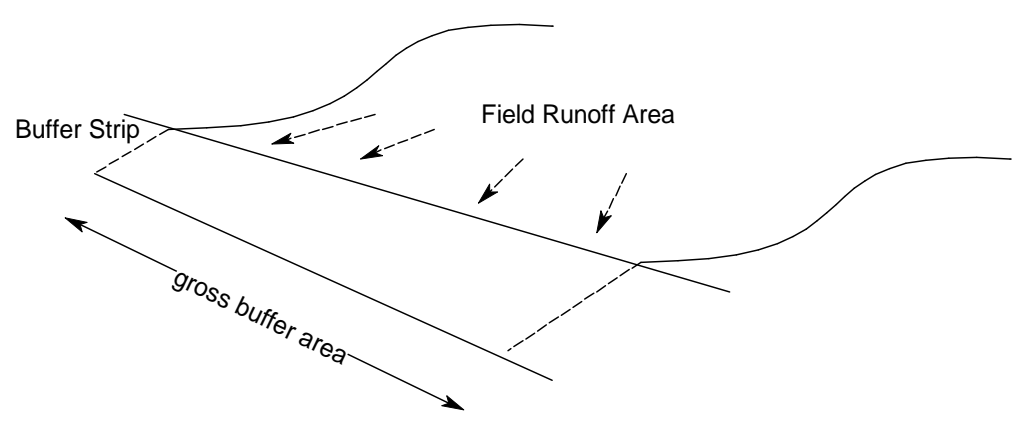

Figure 2. Ideal field-buffer contact for maximum sediment trapping efficiency

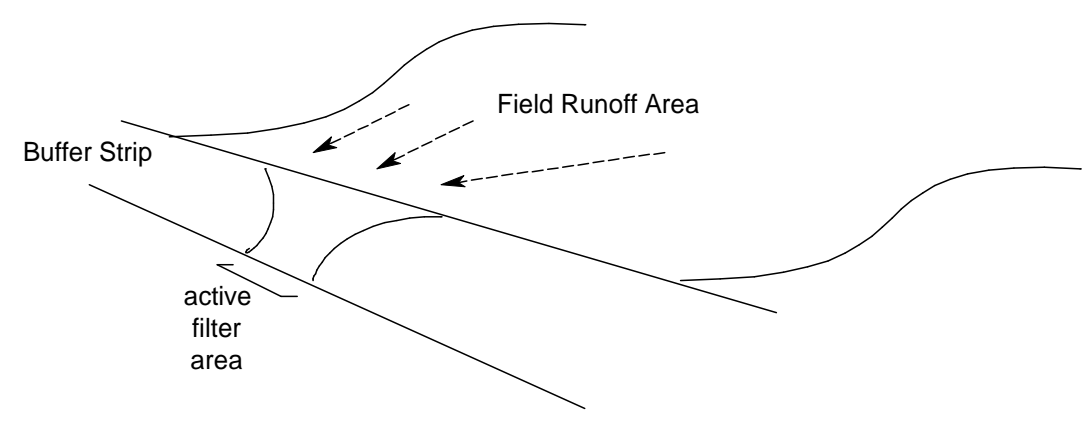

Figure 3. Active filter area when concentrated flow occurs through a field or buffer 
Dosskey et al. (2002) analyzed four test fields in Nebraska for concentrated flow and its contributing factors. Table 2 summarizes the results of their study and influencing field and buffer characteristics

Table 2. Results from Dosskey et al. (2002) on contributing factors of concentrated flow from agricultural fields

\begin{tabular}{|c|c|c|c|c|}
\hline & \multicolumn{2}{|c|}{ Field Influences on concentrated flow } & \multicolumn{2}{|c|}{ Buffer Influences on concentrated flow } \\
\hline $\begin{array}{l}\text { Farm } \\
\text { Field }\end{array}$ & $\begin{array}{l}\text { Percent length } \\
\text { of buffer in } \\
\text { contact with } \\
\text { runoff } \\
\end{array}$ & Field Characteristics & $\begin{array}{c}\text { Percent riparian area } \\
\text { where runoff exited } \\
\text { through inadequately } \\
\text { vegetated gullies } \\
\end{array}$ & $\begin{array}{c}\text { Buffer } \\
\text { Characteristics }\end{array}$ \\
\hline 1 & $8 \%$ & $\begin{array}{l}\text { Crop rows are parallel to buffer } \\
\text { length, causing runoff to flow } \\
\text { into topographic swales. Berms } \\
\text { also formed at field margins } \\
\text { causing shallow runoff to run } \\
\text { parallel before entering buffer at } \\
\text { a low point. }\end{array}$ & $71 \%$ & \multirow{4}{*}{$\begin{array}{l}\text { Sediment and } \\
\text { debris from } \\
\text { channelization } \\
\text { created high } \\
\text { areas that } \\
\text { reroute runoff to } \\
\text { low areas and } \\
\text { breakthrough } \\
\text { points. Gullies } \\
\text { also received } \\
\text { erosion from the } \\
\text { stream into the } \\
\text { buffer. }\end{array}$} \\
\hline 2 & $11 \%$ & $\begin{array}{l}\text { Crop rows are parallel to buffer } \\
\text { length, causing runoff to flow } \\
\text { into topographic swales. }\end{array}$ & $40 \%$ & \\
\hline 3 & $28 \%$ & $\begin{array}{l}\text { Berms also formed at field } \\
\text { margins causing shallow runoff } \\
\text { to run parallel before entering } \\
\text { buffer at a low point. }\end{array}$ & $38 \%$ & \\
\hline 4 & $99 \%$ & $\begin{array}{l}\text { Furrow system used where rows } \\
\text { run perpendicular to buffer } \\
\text { length. }\end{array}$ & $27 \%$ & \\
\hline
\end{tabular}

The contributions of these studies are important for understanding upland and riparian functions that influence water quality. Scientists are taking research a step further by using remote sensing technology to map these features into a geographic information system. If user's were able to input "real world" parameters with better spatial resolution for the current watershed or riparian models, outputs would better represent what's occurring in the watershed. This, in effect, allows for better land use and riparian management. 


\section{Monitoring Riparian Vegetation}

Conventional approaches for recording vegetation classes in riparian zones have predominately involved collecting aerial photographs and conducting extensive field studies. The field data collection, although useful, is time-consuming, expensive, and calls for several personnel for surveying. In addition, traditional vegetation mapping normally involves digitizing ${ }^{1}$ vegetation boundaries from the aerial photographs. Digitizing is time consuming, especially if data needs to be updated or new research questions arise, it requires an individual to re-digitize the photographs. The cost and time-commitment of this procedure is often too high to be practical for large study areas (EPA \& FTG, 2004; RESAC, 2003; Franklin and Dickson, 2001; Coulter et al., 2000; Black et al., 2003).

Remote sensing ${ }^{1}$ technology has been advancing since the 1960 s and research progress continues to allow monitoring of the earth's vegetation. A key undertaking for scientists is to continue to realize the potential promises of this technology (Biondini, 1999). Remote sensing has offered an alternative to extensive fieldwork for collecting vegetation data with the advantage of its ability to collect an immense amount of data in a small amount of time over large areas.

Traditionally, satellite sensors ${ }^{1}$, such as Landsat TM or SPOT, were used to accrue land data layers, and some researchers attempted to use this data to extract information for riparian areas. However, the coarseness of the resolution inhibited sensing riparian areas 
in much detail or very accurately (Klemas, 2001; Congalton et al., 2002; Lattin, 2004). The 30-meter by 30-meter pixel $^{1}$ size of Landsat TM was not able to detect many of the smaller riparian areas that were less than 30 meters wide, which is the case in a number of agricultural landscapes including Goodwin Creek Watershed.

In the situation where a user needs a smaller pixel size to examine a narrow, diverse land sector (i.e. riparian zone), the resolutions previously mentioned in the satellite systems are not sufficient. Multispectral ${ }^{1}$ aerial photography is an alternative that provides a higher resolution to evaluate land conditions. Several companies, including Space Imaging Corp (DAIS), provide flights over an area of interest (Lutes, 2002). Airborne multispectral scanners' spatial resolution can range from 0.3-meters to 1-meter (Wulder et al., 2004). Other studies that have used multispectral aerial photography include Black et al. (2003), Congalton et al. (2002), Lattin et al. (2004), and Coulter et al. (2000). Although the spatial resolution is high for airborne photography, satellite remote sensing with high spatial resolution sensors are sometimes more cost-efficient depending on the study area and can often be obtained more quickly than scheduling a flight (EPA \& FTG; correspondence with Space Imaging Corp, 6/2004).

Another alternative is hyperspectral aerial photography. The hyperspectral spectral resolution is high, covering 224 wavebands as opposed to the five bands in multispectral images. This gives detailed information on vegetation types but also requires a large amount of processing power, storage and more advanced calibration and interpretation techniques (Richards and Jia, 1999). 
Quickbird satellite imagery (Digital Globe) is currently the highest resolution commercially-available satellite sensor. The recent launch of Quickbird has allowed scientists to use the technology to satisfy needs of higher multispectral spatial resolution. Its applications in characterizing riparian zones are highly beneficial in monitoring the riparian widths and general vegetation types. Given such a high spatial resolution, satellite images are now comparable to aerial photographs (Nale, 2002). Figure 4 shows the apparent improvement on sensing riparian zones with Quickbird resolution over Landsat and SPOT pixel resolution.

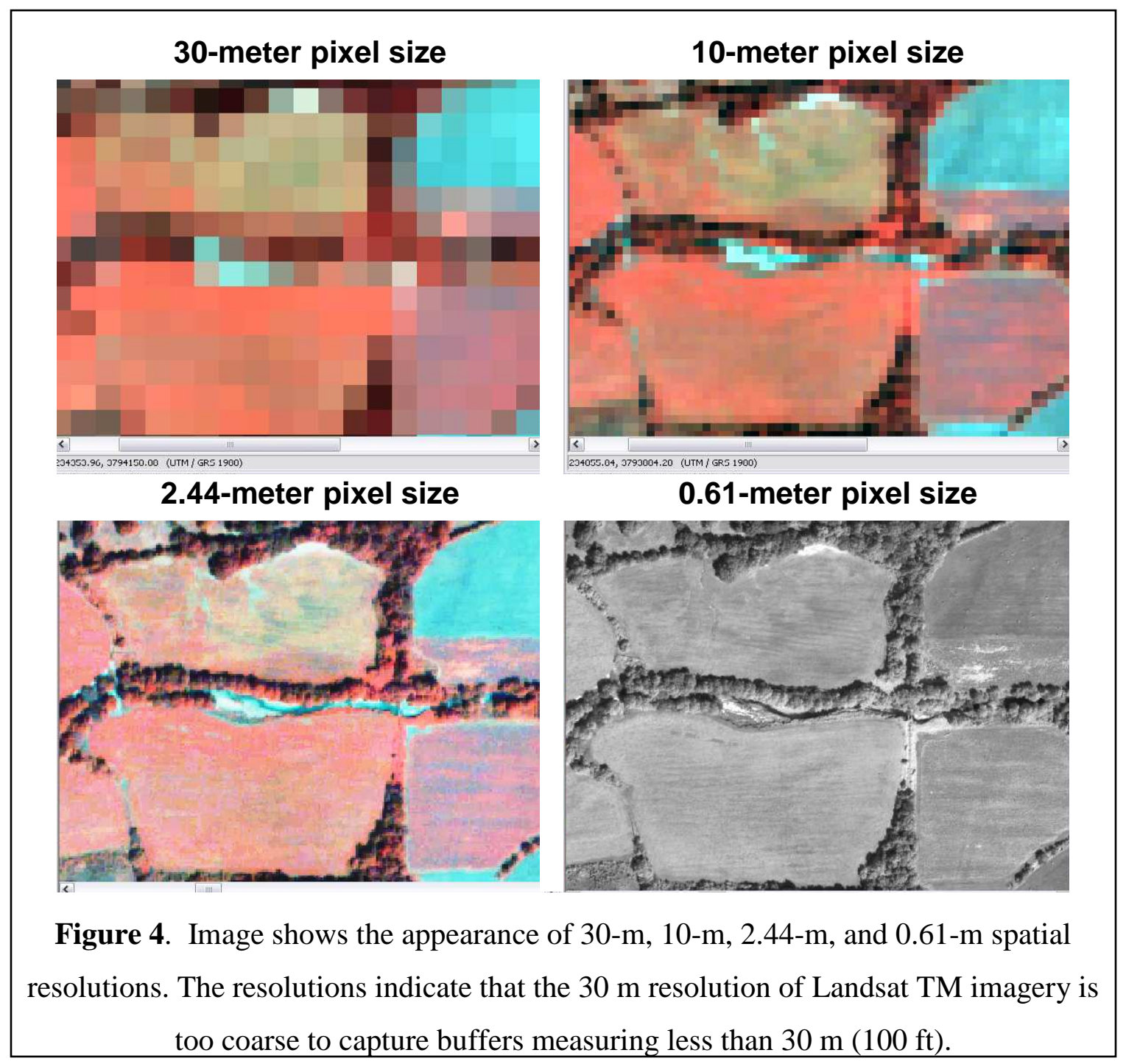




\section{Methods}

The Goodwin Creek Watershed is an experimental watershed set up by the USDA-ARS National Sedimentation Lab in Oxford, MS (Figure 5). Goodwin Creek is located within

Panola County in the Yazoo River Basin where there has been excessive erosion and bank instability. The problems caused by erosion in the loess based landform are similar to problem areas in other parts of the United States, making the watershed an ideal location for research. In addition, Goodwin Creek has easy road access and diverse land use, sediment source areas, and channel conditions (Blackmarr, 1995).

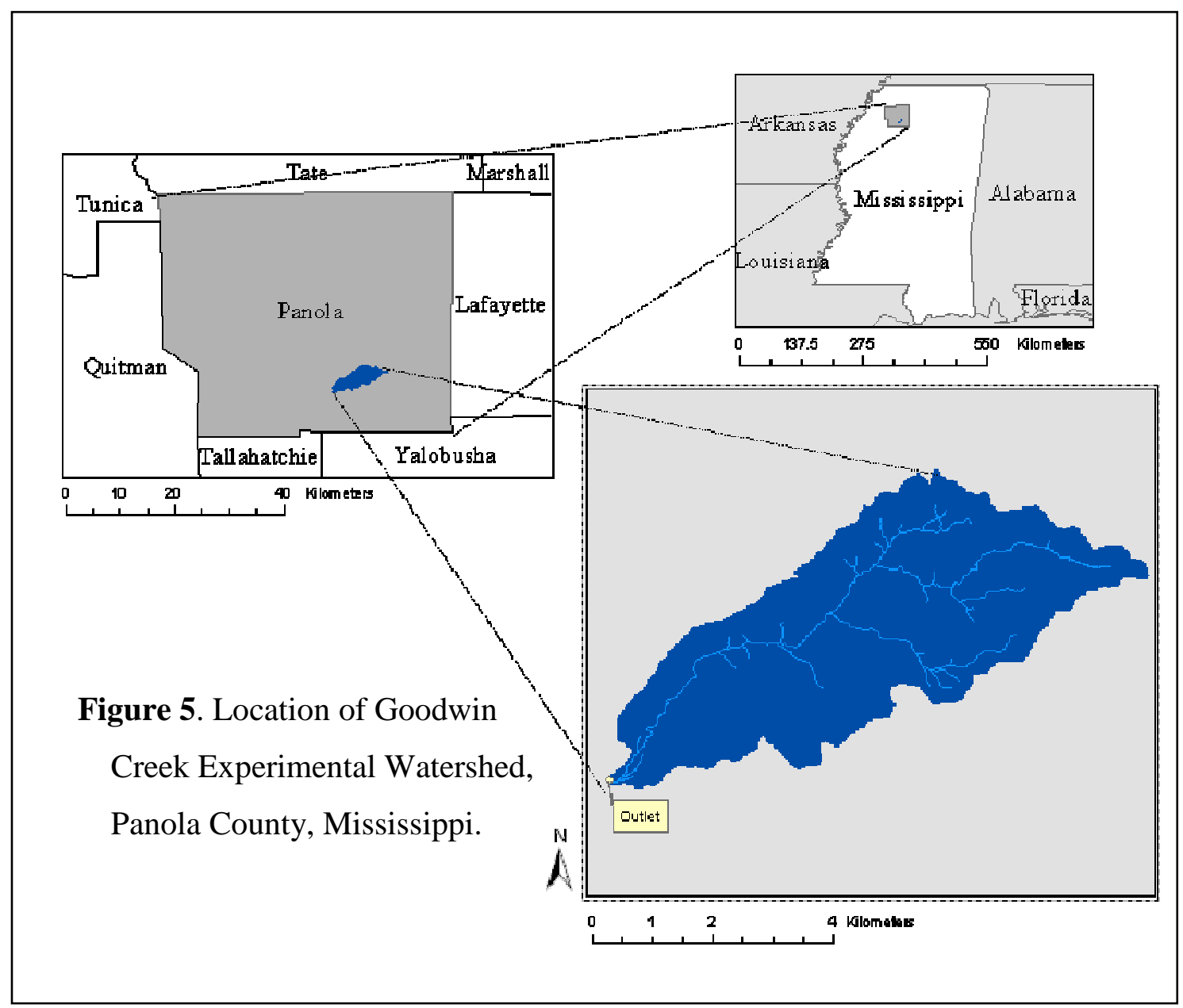


The Goodwin Creek leads into Long Creek, which flows into the Yocona River, a main channel in the Yazoo River Basin. The total drainage area of the study watershed is 8.26 $\mathrm{mi}^{2}\left(21.4 \mathrm{~km}^{2}\right)$ and predominantly consists of cotton and soybean agriculture, pastures, hayfields, and planted deciduous forest. The NRCS (Natural Resources Conservation Service) surveyed and mapped the soil properties in Goodwin Creek in 1963 (Blackmarr, 1995). The governing soil type in Goodwin Creek is silt loam, and ranges in infiltration rates from poor to fair. Elevation within the watershed ranges from 200-m to 400-m according to the 10-m digital elevation model from the Mississippi Automated Resource Information System (MARIS, 1996).

Most of the natural riparian land in Goodwin Creek was cleared for agriculture and now consists of small strips of deciduous trees and shrubs. The most serious erosion comes from bank instability in the lower parts of the watershed, along the main channels. On the other hand, in the higher branches of the watershed, sediment comes from upland sources where the slope is steeper and the lower-ordered streams transport runoff to main streams. These are riparian areas with the most impact in reducing sediment from upland runoff.

Orthorectified Quickbird images were obtained from Digital Globe on September 9, 2004 and provided a study area of $100 \mathrm{~km}^{2}$ surrounding Goodwin Creek Watershed. Quickbird multispectral imagery consists of four bands in the electromagnetic spectrum (blue, green, red and infrared) with a pixel resolution of 2.44-m. Panchromatic imagery is one band (black and white) with a resolution of 0.61-m. Appendix B contains both Quickbird 
images and Appendix C includes the Quickbird specifications. Ground truth data was recorded with a GPS to classify the multispectral image.

\section{Data Collection}

For collecting field data, a Trimble GPS Pathfinder ProXRS receiver and Contour xlr Lasercraft rangefinder were used to identify location coordinates of the training ${ }^{1}$ and accuracy $^{1}$ sample sites (Figure 6). The GPS Pathfinder system used differential GPS ${ }^{1}$ positioning which provided a sub-meter horizontal accuracy.

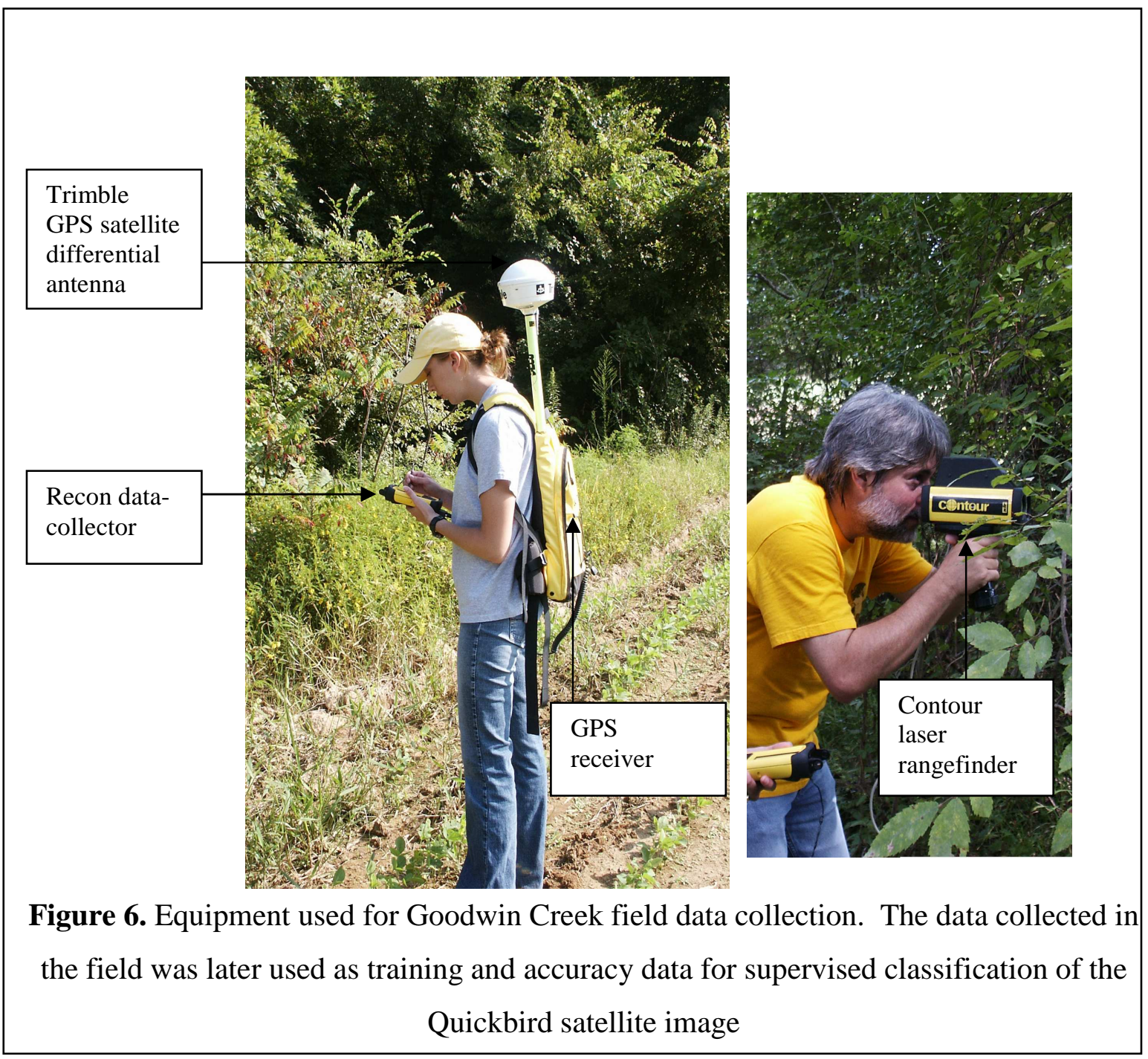


Polygons covering the entire homogeneous area of the vegetation class were documented in a TDS Recon Data Collector using the program, Solofield. The Recon's software, Solofield, calculated the location of the plot based upon the reference point and the compass/distance recorded by the laser. The appropriate characteristics of the plot were entered into the data-collector and the plot was recorded. Plots were recorded between the dates of July 22, 2004 and August 10, 2004, giving the total number of days required for collection to be approximately ten days.

According to Brogaard and Ólafsdóttir (1997) a good way to calculate field sample unit size is:

Area unit size $=[\text { pixel size }(\text { meters }) \times(1+2 \times \text { geometric accuracy }(\text { pixels }))]^{2}$

The geometric accuracy of a Quickbird multispectral image is one pixel. The result is a polygon that contains one or more $3 \times 3$ pixel squares to use for classifying and accuracy assessments $^{1}$ in the image analysis (Congalton, 1999; Brogaard and Ólafsdóttir, 1997). For the Quickbird image, one multispectral pixel is $2.44 \times 2.44$ meters giving a sampling unit of $7.32 \times 7.32$ meters. This eliminated any difficulty in finding a single pixel on the ground and matching it with the image by allowing for any geometric inaccuracies. Large polygon sample sites that contained more than one sample unit, were far enough apart to minimize correlation (Congalton, 1999). The sample units were divided randomly between training ${ }^{1}$ and accuracy ${ }^{1}$ units. It was critical that the training and accuracy data be independent. This was done by stratifying the data by map class and 
then randomly selecting accuracy and training samples for each class (Congalton, 1999). An image of the frequency of ground data taken in the study area is pictured in Figure 7.

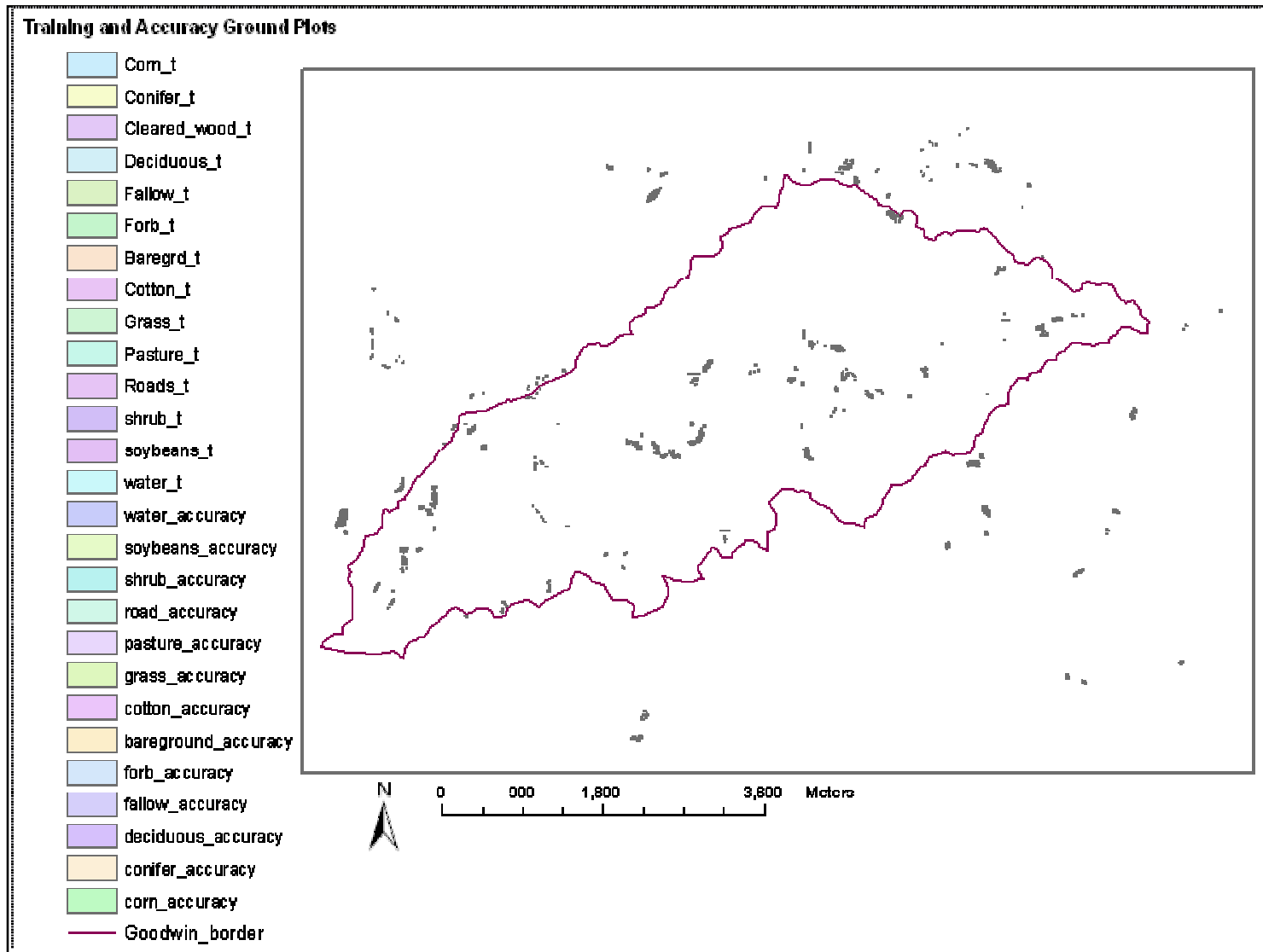

Figure 7. Scatter of stratified random field plots for training and accuracy data within the extent of the Quickbird coverage.

The minimum number of sample units for each class was chosen to be 50 units for accuracy assessment and 40 units for training data. Having a minimum of 50 units for the accuracy assessment was necessary to achieve an acceptable confidence interval and represent true error rates (Congalton, 1999; Hay, 1979). The number of training sites should be 10 times the number of bands in the image. Given the Quickbird image contains four bands, the minimum sample size number was 40 units per class (Jensen, 
1996). Given the time-frame of this study, a minimum total of 90 sample units was a feasible goal. Sampling frequency was, for some vegetation classes, limited due to accessibility and homogeneous unit availability. Obtaining plots with individual homogeneous riparian vegetation proved to be difficult considering most riparian vegetation is well mixed and many of the water-loving plants that grow in abundance along streams do not grow by themselves in open upland areas that are easier to access and detect with a satellite image. The most difficult class to obtain sufficient sample units of was shrubs. They often grew in small bunches and were rarely in the open, away from tree interference.

The vegetation classification system chosen was based partly on the National Vegetation Classification Standard designed by the Federal Geographic Data Committee (FGDC, 1997) and then adapted and modified to apply to the research problem and study area. The modified classification system was designed based on the riparian filter definition and Goodwin Creek watershed vegetation characteristics observed in pilot studies.

Watershed vegetation characteristics included the land use of riparian bordering fields such as cultivated land, pasture, idle fields, bare ground due to harvesting or construction, and non-riparian forest. The bordering land characteristics were important in determining the riparian buffer functionality for that location and determining the sediment source. Typical riparian vegetation consisted of grass, forbs, shrubs and/or trees. Unlike natural riparian areas where an edge effect occurs, most of the Goodwin Creek riparian area was 
no longer naturally occurring, but rather maintained or removed by the adjacent

landowner.

The initial training vegetation classes collected in the field are listed in Table 3. Classes included the dominant bordering land use classes as well as the dominant riparian vegetation classes. Anything more detailed was avoided since the satellite only sensed four bands; this maintained a higher spectral accuracy given the image source. Even so, the high-resolution spatial characteristic of the image was useful to determine the location of the general vegetation classes with higher spatial accuracy.

Table 3. Vegetation classes and associated properties used to classify the riparian and upland areas of Goodwin Creek Watershed (FGDC, 1997).

\begin{tabular}{|c|c|c|c|}
\hline $\begin{array}{c}\text { Vegetation } \\
\text { Type }\end{array}$ & Description & Vegetation Type & Description \\
\hline Deciduous Trees & $\begin{array}{c}\text { Homogenous grouping of mature } \\
\text { trees that seasonally loose their } \\
\text { leaves }\end{array}$ & $\begin{array}{l}\text { Agriculture- } \\
\text { Soybean }\end{array}$ & Cultivated soybean field \\
\hline Coniferous Trees & $\begin{array}{c}\text { Homogenous grouping of mature } \\
\text { trees with green leaves (needles) } \\
\text { all year round }\end{array}$ & $\begin{array}{l}\text { Agriculture- } \\
\text { Cotton }\end{array}$ & Cultivated cotton field \\
\hline Shrub & $\begin{array}{c}\text { Woody plants greater than } 0.5-5 \\
\text { meters in height, with a bushy } \\
\text { appearance }\end{array}$ & Agriculture- Corn & Cultivated corn field \\
\hline Grass & $\begin{array}{c}\text { Includes meadow, lawn, and hay } \\
\text { grasses }\end{array}$ & Fallow & $\begin{array}{c}\text { Abandoned agricultural } \\
\text { land }\end{array}$ \\
\hline Bare ground & Non-vegetated & Pasture & $\begin{array}{l}\text { Grassland for the purpose } \\
\text { grazing }\end{array}$ \\
\hline Idle Land & $\begin{array}{l}\text { Pastures with little to no grazing } \\
\text { or maintenance }\end{array}$ & Asphalt Road & $\begin{array}{l}\text { Consists of main roads } \\
\text { and bridges }\end{array}$ \\
\hline Forbs & $\begin{array}{l}\text { Broad-leaved herbaceous plant } \\
\text { (includes Kudzu) }\end{array}$ & Dirt Road & Secondary roads \\
\hline Water & Includes lakes, ponds and streams & & \\
\hline
\end{tabular}


In addition to vegetation field observations, locations where erosion occurred before or within the riparian filter were observed and recorded with the GPS. For each erosion occurrence, the degree of erosion was recorded as well as the source of the runoff.

\section{Image Processing and Classification}

The image analysis was done with the ERDAS Imagine 8.7 software package (Earth Resources Data Analysis System). ERDAS Imagine provided the ability to import field data, run supervised or unsupervised classification routines, perform an accuracy assessment of the classification, and classify at a higher level by including other GIS layers in the Knowledge Engineer classifier.

The first step in the image analysis process entailed the preprocessing, ortho-rectification ${ }^{1}$, of multispectral and panchromatic images. This step was completed by Digital Globe as part of the purchasing package. Another preprocessing option is pansharpening ${ }^{1}$, which merges the multispectral with the panchromatic ${ }^{1}$ for image enhancement purposes. While this sharpens the multispectral image, this process should not be done before classification. Pansharpening falsifies the spectral properties and modifies the spectral statistics, complicating classification due to poor separability (Repaka et al., 2004). A second preprocessing step was to remove the areas obscured by clouds and their shadows. The shadows and clouds were traced and clipped out of the image by setting their cell values to zero. This step eliminated any spectral confusion between clouds and other land classes during the classification process. 
Training data assigns a statistical spectral signature ${ }^{1}$ to the corresponding data class, including the mean vector and covariance matrix. The spectral separability of the data classes were tested with the transformed divergence algorithm and a contingency matrix. The transformed divergence assigned a statistical measure of distance between two data classes through the use of the maximum likelihood decision rule. Since this is the same rule applied the maximum likelihood classification (MLC) it is a good predictor of the result of the classification. A separability matrix in Table 4 was formed from the transformed divergence formula based on a quick classification of the training data. Distance values can range from 0-2000, where 2000 implies complete spectral separability. According to Jenson (1996), distance values greater than 1900 indicate the two classes are separable, distance values less than 1700 mean separation is poor. The contingency matrix in Table 5 is an error matrix based on a maximum likelihood classification of the training data. The contingency matrix also displays the total number of training pixels per class used in the classification algorithm (column total).

Based on several iterations to produce the best spectral separability, the flowchart in Figure 8 shows the transition from the original classes to the final adaptations. The signature analysis matrices for the final set of thirteen classes are shown in Table 4 and 5 . 
Table 4. Best minimum separability matrix using Transformed Divergence for the final classification scheme (performed with ERDAS Imagine software package).

\begin{tabular}{|r|c|c|c|c|c|c|c|c|c|c|c|c|c|}
\hline & 1 & 2 & 3 & 4 & 5 & 6 & 7 & 8 & 9 & 10 & 11 & 12 & 13 \\
\hline 1 & - & 1865 & 2000 & 2000 & 2000 & 2000 & 2000 & 1563 & 1600 & 1897 & 1998 & 2000 & 2000 \\
\hline 2 & - & - & 2000 & 2000 & 2000 & 2000 & 2000 & 1994 & 1950 & 2000 & 1986 & 2000 & 2000 \\
\hline 3 & - & - & - & 2000 & 2000 & 2000 & 2000 & 2000 & 2000 & 1987 & 2000 & 2000 & 2000 \\
\hline 4 & - & - & - & - & 2000 & 2000 & 2000 & 2000 & 2000 & 1990 & 2000 & 2000 & 2000 \\
\hline 5 & - & - & - & - & - & 2000 & 2000 & 2000 & 2000 & 2000 & 2000 & 2000 & 2000 \\
\hline 6 & - & - & - & - & - & - & 1536 & 2000 & 1999 & 2000 & 1936 & 2000 & 2000 \\
\hline 7 & - & - & - & - & - & - & - & 2000 & 1830 & 1999 & 1383 & 2000 & 2000 \\
\hline 8 & - & - & - & - & - & - & - & - & 1705 & 1834 & 1996 & 2000 & 2000 \\
\hline 9 & - & - & - & - & - & - & - & - & - & 1886 & 1592 & 2000 & 2000 \\
\hline 10 & - & - & - & - & - & - & - & - & - & - & 2000 & 2000 & 2000 \\
\hline 11 & - & - & - & - & - & - & - & - & - & - & - & 2000 & 2000 \\
\hline 12 & - & - & - & - & - & - & - & - & - & - & - & - & 2000 \\
\hline
\end{tabular}

$1=$ cotton, $2=$ kudzu, $3=$ grass -2 (cut or sparse), $4=$ asphalt road, $5=$ corn, $6=$ tree shadows, $7=$ conifer trees, $8=$ soybeans, $9=$ shrub, $10=$ grass -1 (tall or dense), $11=$ deciduous trees,

$12=$ bare ground, $13=$ water

Table 5. Contingency Error Matrix using maximum likelihood algorithm for the final classification scheme (made with ERDAS Imagine software).

\begin{tabular}{|c|c|c|c|c|c|c|c|c|c|c|c|c|c|c|}
\hline & \multicolumn{10}{|c|}{ Reference Pixels (Training Pixels) } & \\
\hline $\begin{array}{c}\text { Classified } \\
\text { Pixels }\end{array}$ & 1 & 2 & 3 & 4 & 5 & 6 & 7 & 8 & 9 & 10 & 11 & 12 & 13 & $\begin{array}{c}\text { Row } \\
\text { Total }\end{array}$ \\
\hline 1 & 3827 & 16 & 0 & 0 & 1 & 0 & 0 & 8 & 38 & 59 & 0 & 0 & 0 & 3949 \\
\hline 2 & 53 & 412 & 0 & 0 & 0 & 0 & 0 & 82 & 0 & 0 & 0 & 0 & 0 & 547 \\
\hline 3 & 0 & 0 & 1372 & 9 & 0 & 0 & 0 & 0 & 0 & 204 & 0 & 0 & 0 & 1585 \\
\hline 4 & 0 & 0 & 14 & 139 & 1 & 0 & 0 & 0 & 0 & 1 & 0 & 3 & 21 & 179 \\
\hline 5 & 0 & 0 & 0 & 0 & 2267 & 0 & 1 & 0 & 0 & 0 & 0 & 0 & 0 & 2268 \\
\hline 6 & 0 & 0 & 0 & 0 & 0 & 528 & 500 & 0 & 0 & 0 & 15 & 0 & 0 & 1043 \\
\hline 7 & 0 & 0 & 0 & 0 & 8 & 28 & 6116 & 0 & 9 & 0 & 96 & 0 & 0 & 6257 \\
\hline 8 & 289 & 11 & 20 & 0 & 6 & 0 & 0 & 2640 & 6 & 103 & 6 & 0 & 0 & 3081 \\
\hline 9 & 251 & 0 & 0 & 0 & 0 & 0 & 42 & 226 & 53 & 61 & 55 & 0 & 0 & 688 \\
\hline 10 & 118 & 0 & 22 & 4 & 14 & 0 & 28 & 298 & 2 & 4363 & 0 & 0 & 0 & 4849 \\
\hline 11 & 0 & 1 & 0 & 0 & 0 & 7 & 651 & 39 & 17 & 0 & 1085 & 0 & 0 & 1800 \\
\hline 12 & 0 & 0 & 0 & 1 & 2 & 0 & 1 & 0 & 0 & 3 & 0 & 331 & 0 & 338 \\
\hline 13 & 0 & 0 & 0 & 0 & 0 & 0 & 0 & 0 & 0 & 0 & 0 & 0 & 5861 & 5861 \\
\hline Column & 4538 & 440 & 1428 & 153 & 2299 & 563 & 7339 & 3293 & 125 & 4794 & 1257 & 334 & 5882 & 32445 \\
\hline Total & & & & & & & & & & & & \\
\hline
\end{tabular}

$1=$ cotton, $2=$ kudzu, $3=$ grass -2 (cut or sparse), $4=$ asphalt road, $5=$ corn, $6=$ tree shadows, $7=$ conifer trees, $8=$ soybeans, $9=$ shrub, $10=$ grass -1 (tall or dense), $11=$ deciduous trees, $12=$ bare ground, $13=$ water 


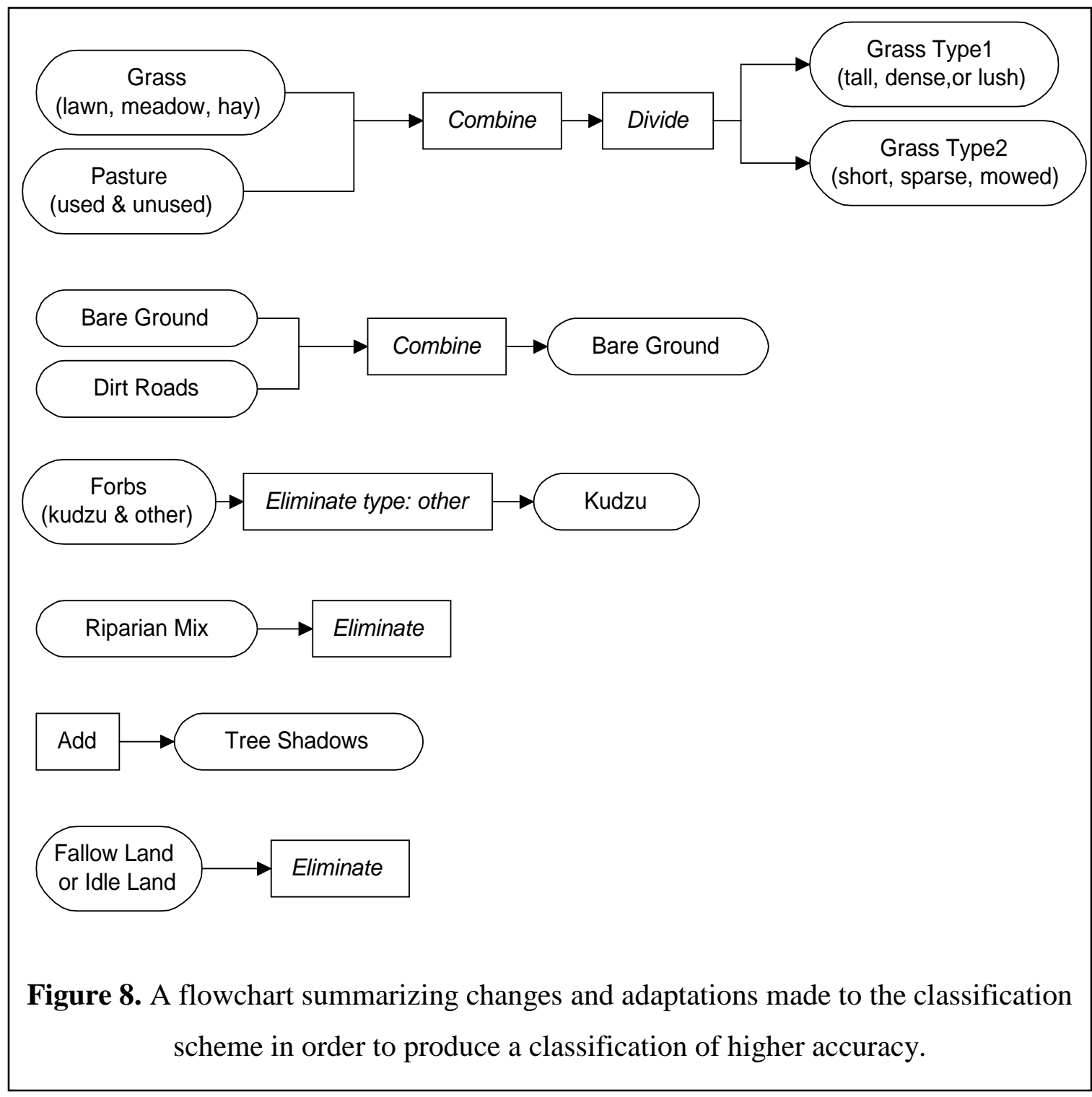

Once the signatures were created from the training data and adapted to produce the best separability, the classification routine was initiated. The most common supervised statistical algorithm is maximum likelihood classification (MLC), and tends to be most accurate in areas with high surface variability (Repaka, 2004). The algorithm is based on the probability that a pixel vector belongs to a class. A pixel vector consists of the band values (BV) for that pixel. 


$$
\text { Pixel vector }=\left[\begin{array}{c}
\mathrm{BV}_{1} \\
\mathrm{BV}_{2} \\
\mathrm{BV}_{3} \\
\mathrm{BV}_{4}
\end{array}\right]
$$

Given the pixel vectors for the training data, the mean vector and covariance matrix are calculated and used within the algorithm. The covariance matrix is a $4 \times 4$ matrix consisting of the variances and covariances of the four bands in a pixel. The covariance allows the spectral variability of a class to be taken into account. Based on Baye's Theorem of conditional probability ${ }^{1}$, the maximum likelihood algorithm establishes the weighted distance of a pixel vector to the statistical measurements of the training classes. The pixel is then assigned to the class with the lowest distance (ERDAS, 1999).

The last step of the image analysis is the classification accuracy assessment. The accuracy is judged by comparing the ground $\operatorname{truth}^{1}$ field data to pixels classified by the supervised algorithm. The standard error evaluation is done with a classification error matrix, also known as a confusion matrix. The error matrix produces a measurement of classification performance and is summarized with derivations including the overall accuracy, user's accuracy, producer's accuracy, and the Kappa coefficient. The overall accuracy is calculated by dividing the sum of the diagonal values by the total number of samples. Accuracy assessments of each individual class are represented by the producer and user accuracies. The producer's accuracy confirms the portion of pixels in the ground truth data that are correctly classified by the MLC classifier. The user's accuracy computes the percent classified by the classifier that agree with the ground truth data. User's accuracy represents the likelihood that a pixel is classified correctly. Finally, the 
kappa coefficient makes use of all data in the matrix, rather than only diagonal data. The purpose of kappa is to denote the percent errors that the classifier is avoiding given what a random classification would generate. Kappa is essentially removing chance agreement. If the classes are correctly assigned, Kappa equals one (Tso and Mather, 2001). Each of these error measures will be presented in the results chapter.

\section{Higher Level Classification and Erosion Detection}

The Knowledge Engineer classifier in ERDAS Imagine was used to detect riparian areas of poor runoff infiltration and dispersion properties. The Knowledge Engineer provides the interface for a user with knowledge of the data and its applications to determine variables, rules, and output classes through a hierarchical decision tree (ERDAS, 1999). A simple, general decision tree is shown below in Figure 9.

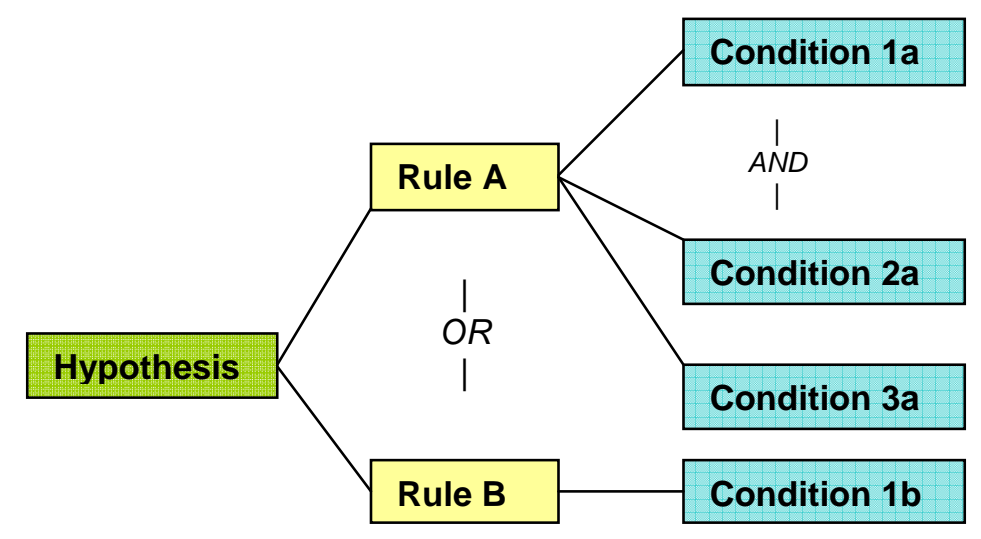

Figure 9. General description of Knowledge Engineer's decision tree. The tree states that the hypothesis is true, given rule A or rule B exist, and the rules exist given that all of the conditions are present. 
The list of vital observations for monitoring riparian filtration, as listed in the Background section, were used to form the decision trees. First, the riparian area was delineated and clipped out from the image, in order to work only with the riparian zone. The designated riparian boundary was then applied to slope data (from DEM) and soils data (from NRCS). Riparian vegetation, soil hydrologic type, slope, and distance values from the stream were all GIS layers used as input into the Knowledge Engineer decision trees.

The actual decision trees used to develop five different riparian classes can be viewed in Appendix D. The five classes are: extremely poor riparian filtration, insufficient dispersion properties with width less than 24-m from stream, insufficient dispersion properties with width greater than 24-m from stream, insufficient settling properties with width less than 24-m from stream, and insufficient settling properties with width greater than 24-m from stream. These categories are based on riparian design specifications by Welsch (1991) through the U.S. Department of Agriculture and were described in the Literature Review section.

In conjunction with the higher-level classification, visual indicators of erosion in adjacent fields were clear using the Quickbird panchromatic image. Shadows from gully formation or areas of dead vegetation were signs of erosion formation from concentrated flow. Finally, regions where concentrated flow was entering a riparian area that had been classified as poor from Knowledge Engineer were designated as areas where concentrated flow may bypass the riparian filter. 
A summary of the methods described are shown as flowcharts in Appendix E. The results of these actions are described in the next chapter and evaluated in the Discussion section.

\section{Results}

With the purpose of classifying riparian characteristics in the Goodwin Creek Watershed, the entire Quickbird image was classified using field-training samples in the Maximum Likelihood classification algorithm. Applying the ISODATA unsupervised ${ }^{1}$ clustering $^{-1}$ algorithm on the multispectral image resulted in poor accuracy. The high variability of the image caused several multimodal ${ }^{1}$ spectral clusters/classes. Thus, supervised classification, through the use of training data, was selected as the appropriate method of classification. Appendix F displays the classified Goodwin Creek Watershed, a great improvement over the previous land use classification from 1987 using Landsat TM.

\section{Classification Accuracy for Riparian and Adjacent Land}

Due to poor spectral separability for some of the original field classes, before classification took place, classes were combined, divided, or eliminated to gain better accuracy. One major vegetation category change involved grass and pasture. Different grasses had poor spectral separability. However, if the grass was cut short or sparse (lawns and mowed hayfields), the sensor picked up soil spectral signatures- giving it a different spectral signature from tall pasture or dense wetland grasses. Tall, lush and meadow grasses were titled Type-1 grass, and short, sparse grasses were named Type-2 grass. Fallow land was removed from the information classes, and instead was detected based on the field shape and mixture of Type-1 grasses and shrubs. 
Table 6 displays the error matrix produced with the ground truth data taken from the field. The diagonals represent the pixels that were correctly classified and off diagonal values are those that were misclassified.

Table 6. Error matrix for final vegetation classes produced from the Maximum Likelihood Classifier.

Reference Data

\begin{tabular}{|c|c|c|c|c|c|c|c|c|c|c|c|c|c|c|}
\hline \multirow[b]{2}{*}{$\begin{array}{c}\text { Classified } \\
\text { Data }\end{array}$} & \\
\hline & $\begin{array}{l}\text { Agri. } \\
\text { Cotton }\end{array}$ & Kudzu & $\begin{array}{c}\text { Grass- } \\
2\end{array}$ & $\begin{array}{c}\text { Road } \\
\text { Asphalt }\end{array}$ & $\begin{array}{l}\text { Agri. } \\
\text { Corn }\end{array}$ & $\begin{array}{c}\text { Tree } \\
\text { Shadows }\end{array}$ & $\begin{array}{c}\text { Conifer } \\
\text { trees }\end{array}$ & $\begin{array}{c}\text { Agri. } \\
\text { Soybean }\end{array}$ & Shrub & $\underset{1}{\text { Grass- }}$ & $\begin{array}{c}\text { Deciduous } \\
\text { trees }\end{array}$ & Dirt & Water & Row \\
\hline Agri Cotton & 227 & 14 & 0 & 0 & 0 & 0 & 0 & 0 & 18 & 0 & 0 & 0 & 0 & 259 \\
\hline Kudzu & 0 & 95 & 0 & 0 & 0 & 0 & 0 & 1 & 0 & 0 & 0 & 0 & 0 & 96 \\
\hline Grass-2 & 0 & 0 & 115 & 0 & 0 & 0 & 0 & 0 & 0 & 0 & 0 & 0 & 0 & 115 \\
\hline Road Asphalt & 0 & 0 & 0 & 132 & 0 & 0 & 0 & 0 & 0 & 0 & 0 & 0 & 5 & 137 \\
\hline Agri Corn & 0 & 0 & 0 & 0 & 86 & 0 & 0 & 0 & 0 & 0 & 0 & 0 & 0 & 86 \\
\hline Tree Shadows & 0 & 0 & 0 & 0 & 0 & 79 & 0 & 0 & 0 & 0 & 7 & 0 & 0 & 86 \\
\hline Conifer trees & 0 & 0 & 0 & 0 & 0 & 11 & 149 & 0 & 10 & 0 & 17 & 0 & 0 & 187 \\
\hline Agri Soybean & 22 & 4 & 6 & 0 & 0 & 0 & 0 & 242 & 5 & 7 & 0 & 0 & 0 & 286 \\
\hline Shrub & 7 & 0 & 0 & 0 & 0 & 0 & 72 & 26 & 74 & 1 & 4 & 0 & 0 & 184 \\
\hline Grass-1 & 50 & 0 & 47 & 0 & 0 & 0 & 0 & 34 & 7 & 268 & 0 & 0 & 0 & 406 \\
\hline $\begin{array}{c}\text { Deciduous } \\
\text { trees }\end{array}$ & 0 & 0 & 0 & 0 & 0 & 0 & 4 & 0 & 18 & 0 & 272 & 0 & 0 & 294 \\
\hline Bare ground & 0 & 0 & 0 & 0 & 0 & 0 & 0 & 0 & 0 & 0 & 0 & 137 & 0 & 137 \\
\hline Water & 0 & 0 & 0 & 0 & 0 & 0 & 0 & 0 & 0 & 0 & 0 & 0 & 142 & 142 \\
\hline Column Total & 306 & 113 & 168 & 132 & 86 & 90 & 225 & 303 & 132 & 276 & 300 & 137 & 147 & 2415 \\
\hline
\end{tabular}

Overall, accuracy for the image $\left(80 \mathrm{~km}^{2}\right)$ was approximately 85 percent for the error matrix in Table 6. User's accuracy resulted in an average of 87.5 percent with a standard deviation of 17 percent. Accuracy results show classes with lower-than-average user 
accuracies include shrubs, grass-1, and conifers. Shrubs had the poorest producer and user accuracy, which is mainly due to the difficulty of gaining a statistically-sufficient number of homogenous field plots for training data, given that shrubs are often not apart from tree overhead interference and were rarely seen in large groups in the watershed. The final classes and a summary of their individual accuracy assessments are presented in Table 7. Accuracy is presented in three forms: producer accuracy, user accuracy and kappa coefficient, as calculated from the error matrix in Table 6.

Table 7. Summary of the Error Matrix for Vegetation Classes using Supervised Maximum Likelihood Classification

\begin{tabular}{|l|c|c|c|}
\hline \multicolumn{1}{|c|}{ Class Name } & $\begin{array}{c}\text { Producer } \\
\text { Accuracy }\end{array}$ & $\begin{array}{c}\text { User } \\
\text { Accuracy }\end{array}$ & Kappa \\
\hline Agriculture Cotton & $74.18 \%$ & $87.64 \%$ & 0.8585 \\
\hline Agriculture Corn & $100.00 \%$ & $100.00 \%$ & 1 \\
\hline Agriculture Soybean & $79.87 \%$ & $84.62 \%$ & 0.8241 \\
\hline Road Asphalt & $100.00 \%$ & $96.35 \%$ & 0.9614 \\
\hline $\begin{array}{l}\text { Dirt (roads and bare } \\
\text { ground) }\end{array}$ & $100.00 \%$ & $100.00 \%$ & 1 \\
\hline Tree Shadows & $87.78 \%$ & $91.86 \%$ & 0.9155 \\
\hline Conifer trees & $66.22 \%$ & $79.68 \%$ & 0.7759 \\
\hline Deciduous trees & $90.67 \%$ & $92.52 \%$ & 0.9146 \\
\hline Shrub & $56.06 \%$ & $40.22 \%$ & 0.3676 \\
\hline $\begin{array}{l}\text { Grass-1 (pasture, tall } \\
\text { grass, or dense grass) }\end{array}$ & $97.10 \%$ & $66.01 \%$ & 0.6162 \\
\hline $\begin{array}{l}\text { Grass-2 (lawn, mowed } \\
\text { hay, or sparse grass) }\end{array}$ & $68.45 \%$ & $100.00 \%$ & 1 \\
\hline Kudzu & $84.07 \%$ & $98.96 \%$ & 0.9891 \\
\hline Water & $96.60 \%$ & $100.00 \%$ & 1 \\
\hline
\end{tabular}

A summary of the vegetation composition in the riparian area is displayed in Table 8. Vegetation was divided into three zones that involve three different functions, all of which contribute to a riparian area's filtration effectiveness (Welsch, 1991). For the zone 
closest to the stream, bank stabilization is the dominant function. In Goodwin Creek, Zone One is made of predominately deciduous and coniferous trees. In the sediment settling zone, the percent composition of grass and shrubs increased from Zone One, and some agriculture starts creeping into this zone. In the last zone, grass is needed more than shrubs and trees to disperse concentrated flow before settling. In Goodwin Creek, within the Third Zone, grass and deciduous trees are the dominant vegetation types, with soybeans not far behind.

Table 8. Vegetation area in three zones from the stream (Welsch, 1991).

\begin{tabular}{|l|c|c|c|c|}
\hline \multicolumn{1}{|c|}{ Zone purpose: } & $\begin{array}{c}\text { 1. Streambank } \\
\text { stabilization }\end{array}$ & $\begin{array}{c}\text { 2. Sediment settling } \\
\text { zone }\end{array}$ & $\begin{array}{c}\text { 3. Runoff dispersion } \\
\text { zone }\end{array}$ & $\begin{array}{c}\text { 4. Vegetation } \\
\text { beyond minimum } \\
\text { zone widths }\end{array}$ \\
\hline $\begin{array}{l}\text { Vegetation } \\
\text { Description }\end{array}$ & $\begin{array}{c}\text { Percent area } \\
\text { classified } 0-4.5 m \\
\text { from stream }\end{array}$ & $\begin{array}{c}\text { Percent area } \\
\text { classified } 4.5-22.5 \\
\text { from stream }\end{array}$ & $\begin{array}{c}\text { Percent area } \\
\text { classified } 22.5-28.5 \\
\text { from stream }\end{array}$ & $\begin{array}{c}\text { Percent area } \\
\text { classified } 28.5-60 m \\
\text { from stream }\end{array}$ \\
\hline $\begin{array}{l}\text { Agriculture } \\
\text { Cotton }\end{array}$ & $1.31 \%$ & $2.97 \%$ & $4.68 \%$ & $7.07 \%$ \\
Agriculture & $3.81 \%$ & $7.70 \%$ & $10.44 \%$ & $1.68 \%$ \\
Soybean & $3.31 \%$ & $1.52 \%$ & $1.24 \%$ & $2.31 \%$ \\
Asphalt Road & $1.65 \%$ & $1.34 \%$ & $1.15 \%$ & $1.23 \%$ \\
Dirt (roads and & & $5.69 \%$ & $4.57 \%$ & $3.51 \%$ \\
bare ground) & $9.67 \%$ & $20.90 \%$ & $15.92 \%$ & $13.88 \%$ \\
Tree Shadows & $27.78 \%$ & $28.78 \%$ & $20.27 \%$ & $11.11 \%$ \\
Conifer Trees & $30.83 \%$ & $15.74 \%$ & $15.27 \%$ & $16.23 \%$ \\
Deciduous Trees & $13.85 \%$ & $10.02 \%$ & $21.30 \%$ & $25.28 \%$ \\
Shrub & $3.66 \%$ & $0.69 \%$ & $1.88 \%$ & $16.11 \%$ \\
Grass-1 & $0.36 \%$ & $4.28 \%$ & $2.99 \%$ & $1.06 \%$ \\
Grass-2 & $1.84 \%$ & & & \\
Kudzu & & &
\end{tabular}

Once the entire Quickbird image was classified, the riparian area along visible streams were delineated and clipped from the image. The visible streams included both ephemeral and perennial streams. Perennial streams were visible at the time the image was taken due to a particularly wet summer. The panchromatic image proved to have sufficient detail for delineating the riparian boundary between adjacent fields and riparian 
vegetation. Figure 10 displays the riparian zone in Goodwin Creek Watershed clipped out of the entire Quickbird image.

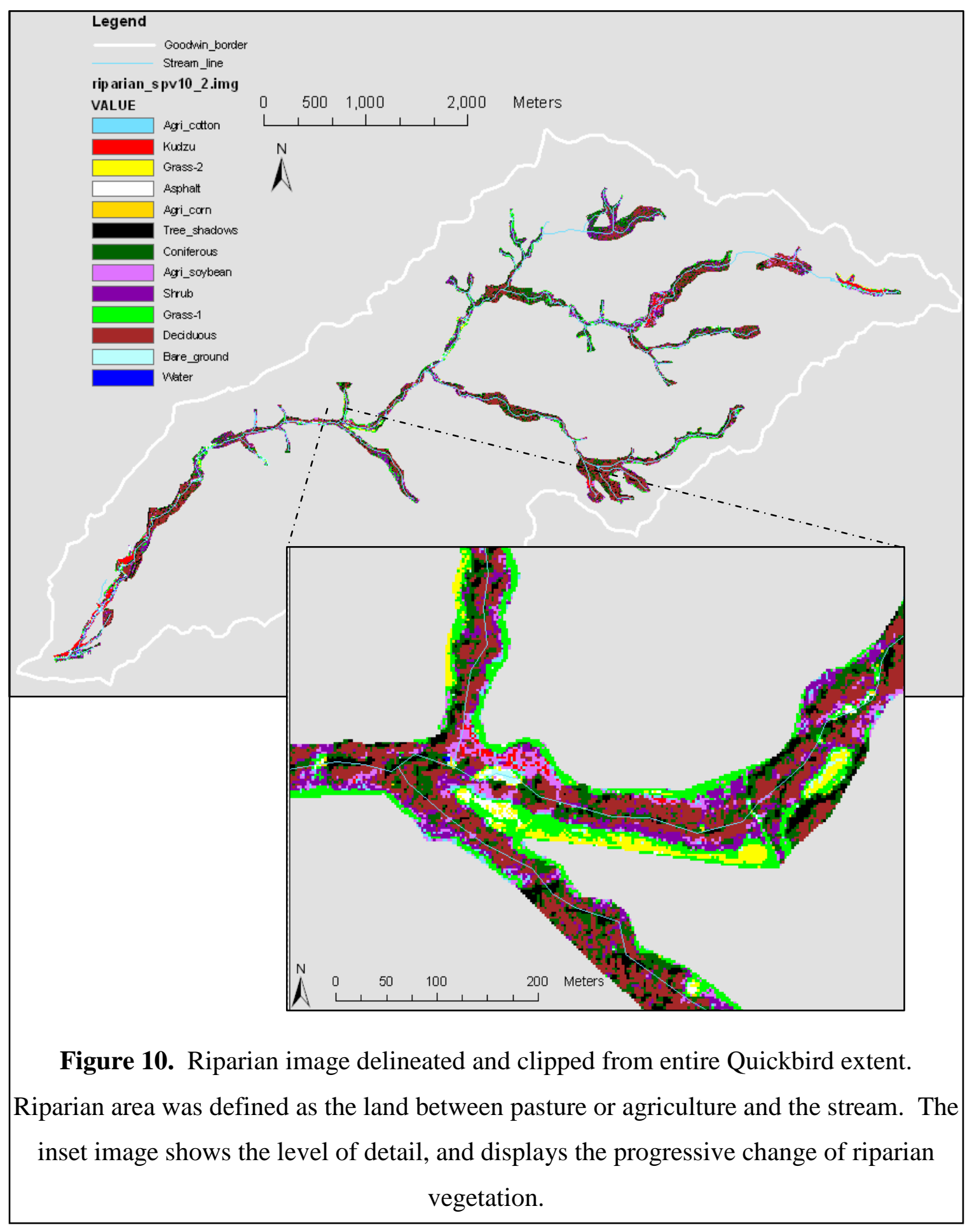




\section{Evaluating Riparian Filtration Effectiveness}

In order to evaluate areas where the vegetation types and widths fall short of the ideal; adjacent land use, direction of the crop rows and visible gully erosion from the adjacent fields were recorded. Since the satellite image was taken in late summer, there were limitations in sensing all gully erosion observed in the field due to the dense vegetation cover. The more serious erosion, however, took place over bare ground visible in the panchromatic image. The DEM did not aid in concentrated flow detection. The DEM's coarse resolution, in comparison to the Quickbird images, merely aided in revealing approximate locations of flow conditions and their contributing areas. Figure 11 focuses on a subset of the image to illustrate the results of digitizing field boundaries, row direction, concentrated flow, and riparian vegetation classification. These GIS data layers were used as input into a higher-level classifier, ERDAS Imagine's Knowledge Engineer, to determine if the concentrated flow was dispersed upon entering the riparian zone. 


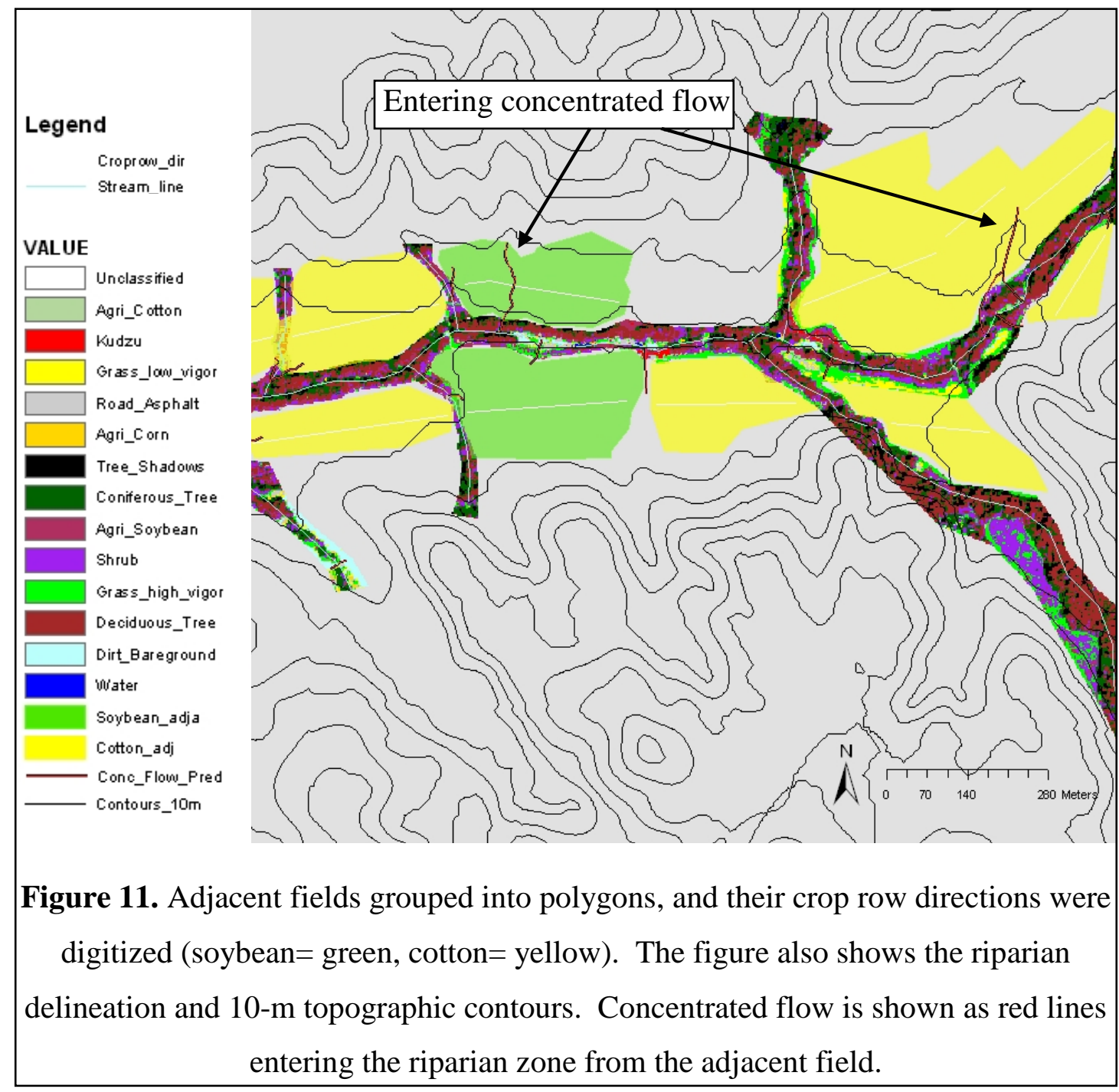

Riparian filter regions with poor characteristics for filtering incoming flow were queried using the Knowledge Engineer classifier. Criteria included slopes greater than 15 percent, soil hydrologic types $\mathrm{C}$ and $\mathrm{D}$, poor vegetative properties consisting of bare ground, agriculture, kudzu, and type 2 grass. Another set of criteria were selected to determine locations where good vegetation was present, but insufficient width of the vegetation existed in addition to slopes greater than 15 percent and soil hydrologic types $\mathrm{C}$ and D. By querying areas with poor conditions in the riparian filter, the adjacent lands 
to these areas were observed for concentrated flow that may enter at those points. An example is pictured in Figure 12.

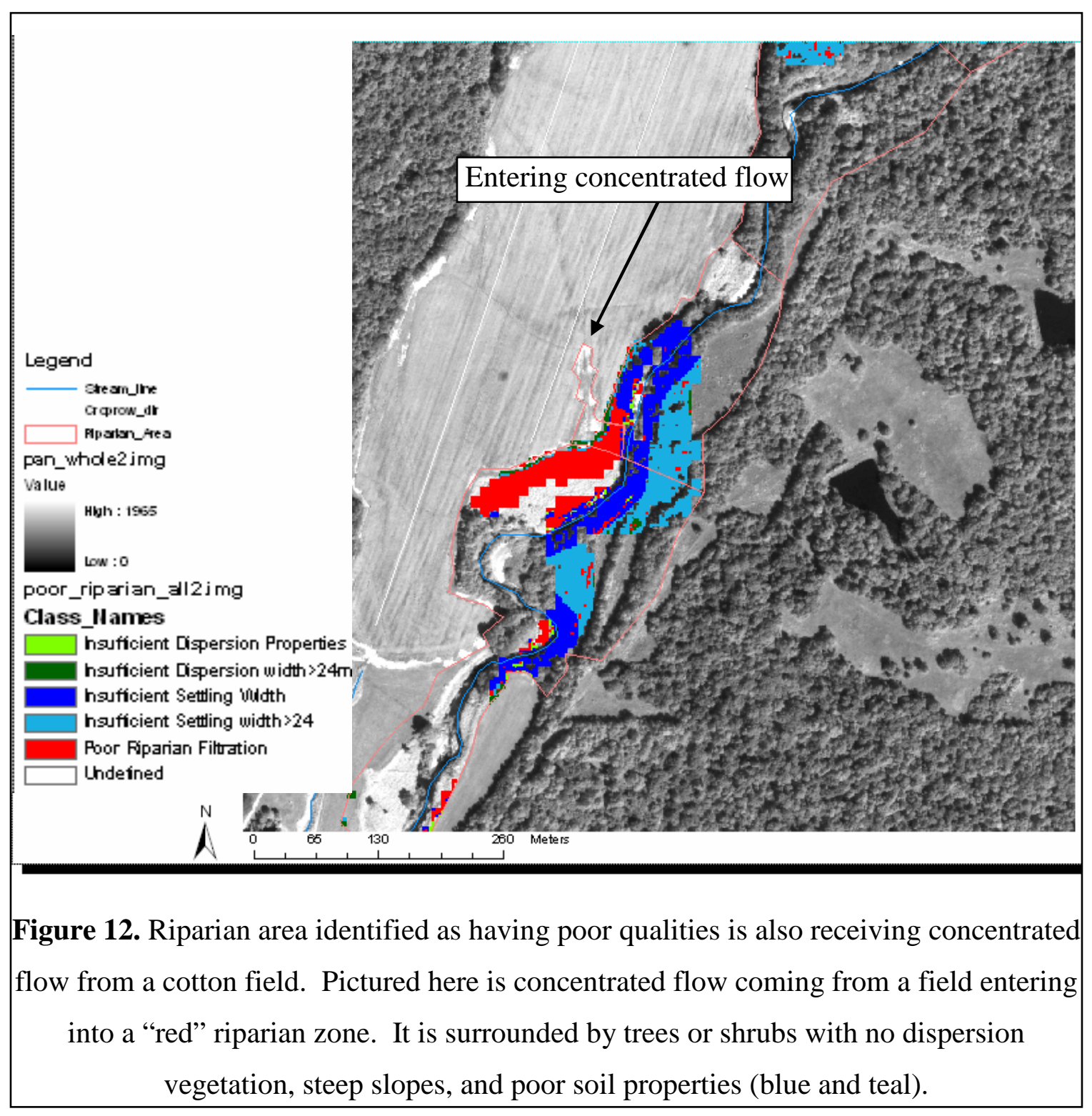

Using these criteria lead to the detection of four riparian zones within Goodwin Creek Watershed with poor riparian filtration characteristics and incoming concentrated flow (Figure 13). 


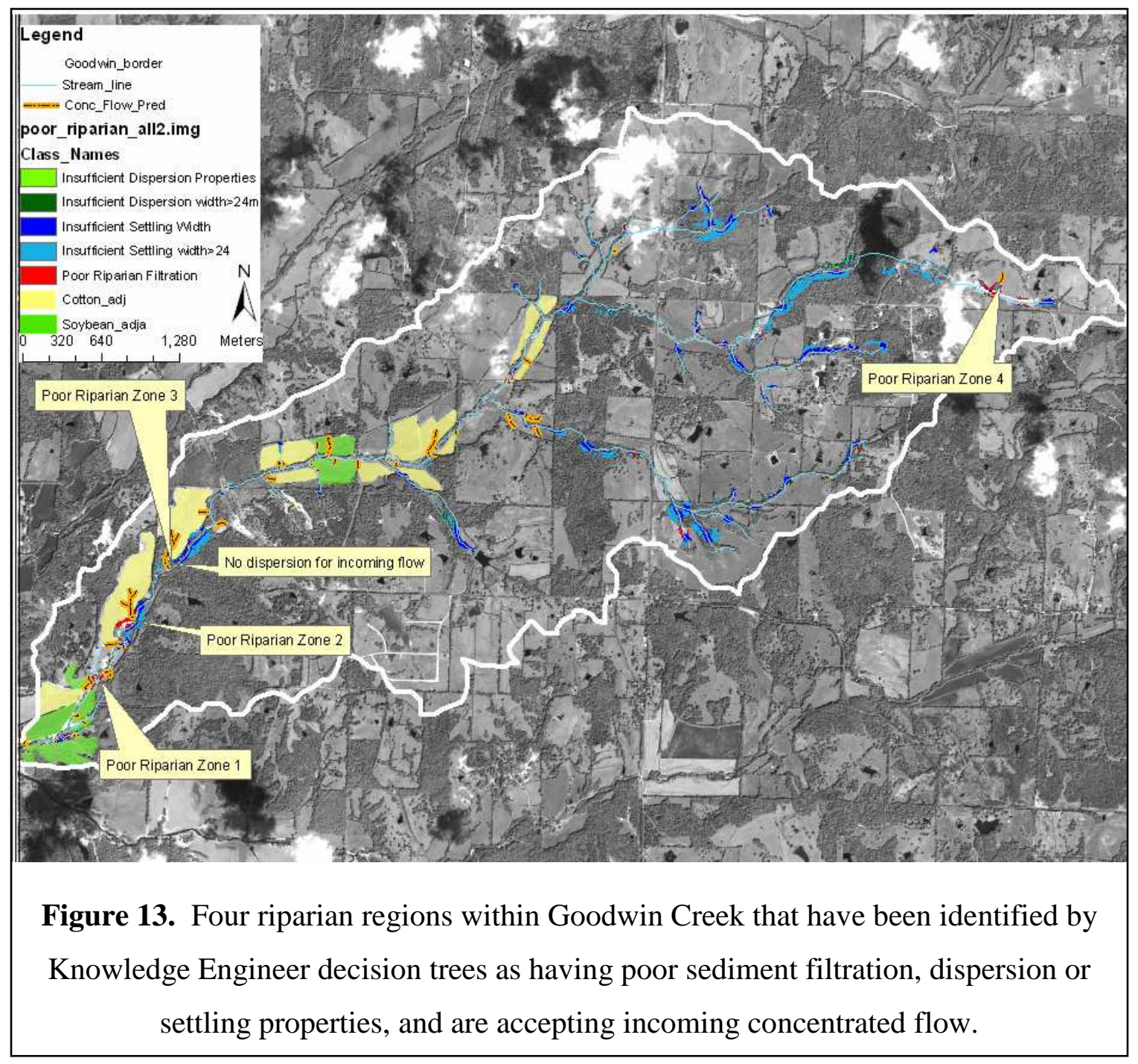

Each of the four poor riparian filtration regions is shown in detail in Appendix G (Figures

$28 \mathrm{~g}-31 \mathrm{~g})$. These are the areas that are most likely to have sediment runoff bypassing the riparian filter. However, there are other areas along the riparian zone where entering runoff was visually detected, and the knowledge classifier did not select the riparian zone as poor. One cause of some misclassification in poor riparian conditions is that the slope was calculated from the 10-m DEM, which is a coarse resolution in comparison to the satellite image. These areas should also be inspected with an onsite field follow-up. An 
example of a poor riparian filtration zone omitted by the knowledge engineer classifier is exposed in Figure 14.

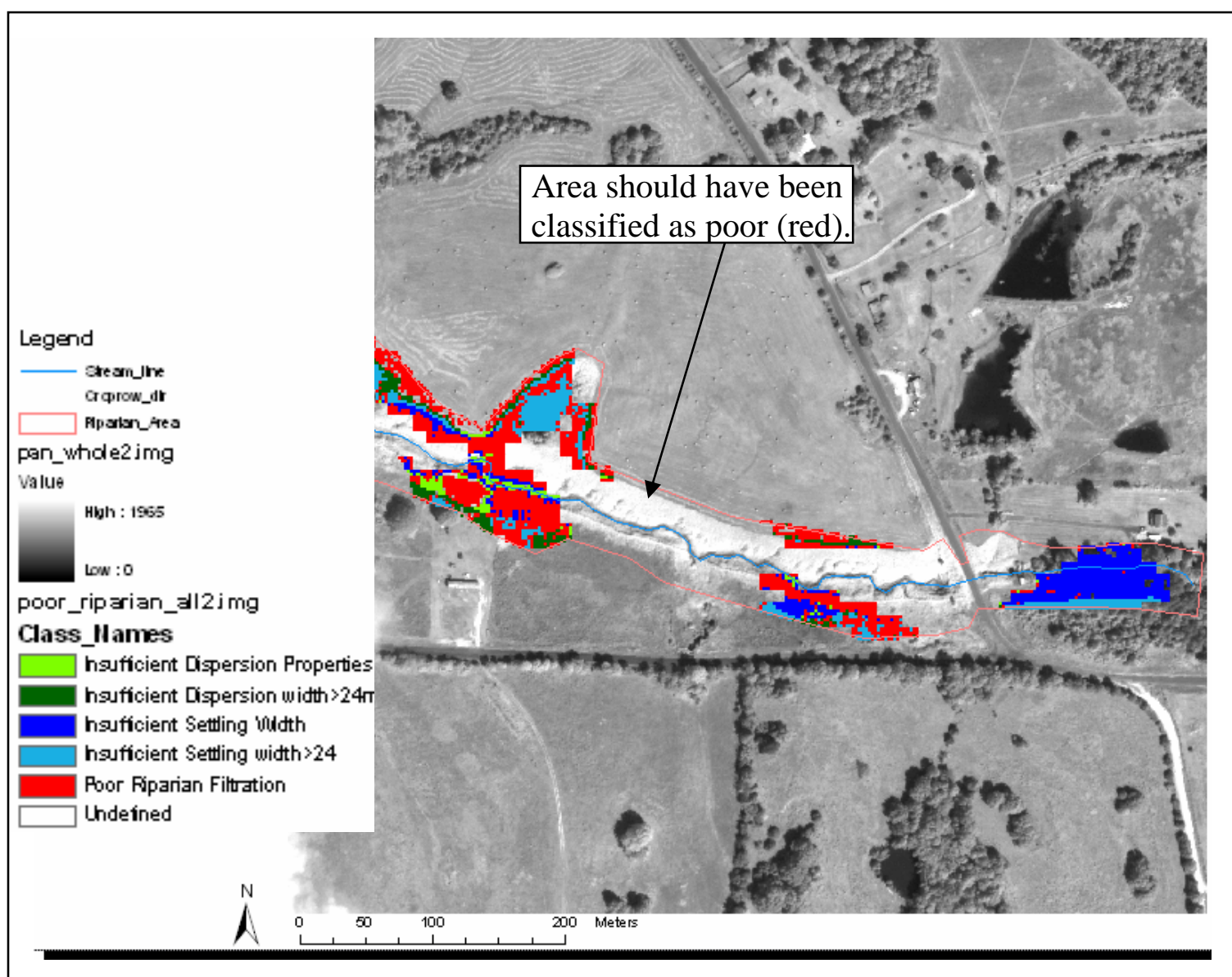

Figure 14. Kudzu covered riparian area with steep slopes, not detected with Knowledge Classifier. The steep slopes observed in the field did not appear in the 10-m DEM and slope calculation. In effect, this classification method is not suitable for detecting narrow, steep channel erosion.

These results show a few of the possibilities of applying high-spatial resolution satellite imagery to riparian management. The next section will discuss the benefits and drawbacks of these applications. 


\section{Discussion}

Medium resolution imagery has been used to characterize riparian vegetation in the past with mediocre to poor results (Repaka, 2004; Congalton, 2002). In addition, most riparian studies that attempt to monitor riparian zones with higher accuracy go no further than plot or field-sized study areas. The use of high spatial resolution imagery provides the opportunity for researchers and land managers to study a large area in a short amount of time with a high level of detail.

This study aimed to classify riparian and adjacent land vegetation types in Goodwin Creek Watershed with methods that would be applicable to other agricultural watersheds. The study used Quickbird multispectral and panchromatic imagery along with elevation and soil GIS layers with the intent of finding ineffective filter areas in a cost-effective manner. Data could ultimately be used by land managers as input into riparian and watershed models. For this case, the use of the data was demonstrated simply with the Knowledge Engineer classifier.

The results of this study indicate that the high spatial resolution of Quickbird satellite imagery is useful in characterizing riparian and adjacent land use in an agricultural watershed even in a worse-case scenario of summer dense vegetation. The clarity of observing concentrated flow, however, is reduced due to the time of year the image was taken, as well as the coarse 10-meter resolution of the digital elevation model. In addition, the high variability of riparian vegetation combined with the high spatial 
resolution limited the accuracy of the classification. The following section will discuss the usefulness of Digital Globe's Quickbird satellite imagery in evaluating the riparian filter area of Goodwin Creek Watershed.

\section{Benefits and Drawbacks of Multispectral High-Spatial Resolution Imagery}

After conducting the fieldwork to obtain training and accuracy data for the image, it was obvious that characterizing the riparian zone with fieldwork alone would have been a huge undertaking. Dense brush and forest, as well as poor accessibility to agricultural areas were convincing enough to evaluate an alternative monitoring method. The Quickbird satellite imagery provides four bands of multispectral data and a panchromatic image for the characterization of the Goodwin Creek watershed and riparian area. The four bands (blue, green, red and near-infrared) are sufficient for classifying general vegetation categories in the watershed. The Landsat TM riparian classification study performed by Congalton et al. (2002) only produced an overall accuracy of 30\%, with most of the error attributed to mixed pixels. The accuracy of this study's classification is a noticeable improvement. This experiment's $85 \%$ accuracy is also comparable to other studies using high-spatial resolution imagery with accuracies ranging from $74 \%$ to $86 \%$ (Khorram et al., 2003; Goetz et al., 2003).

Categories that are too specific result in poor spectral separability and usually have to be combined with another similar spectral class or eliminated (Franklin and Dickson, 2001). One example of this is the fallow agriculture land category. While fallow land could be considered its own category of land use, the composition of fallow land is usually a 
mixture of grasses and shrubs. Due to the high spatial resolution of the image, the sensor detected a speckled grouping of grasses and shrubs, rather than an average of the spectral signature unique to fallow land. Eliminating fallow land as a class, and allowing the classification algorithm to classify the areas as a mix of grass and shrub produced better accuracies. This requires taking a different approach for classifying than how one would approach a coarser resolution image, such as Landsat TM.

The Type- 1 and Type- 2 grass categories are also the result of pasture and grass field categories not being accurate spectral categories. Grass training data were classified as meadow grass, pasture grass, hay, and lawn grass. After making a contingency matrix to show spectral separability between classes, there was a significant spectral difference between grasses that were dense or tall (Type-1) and grasses that were recently mowed or sparse (Type-2). This indicates that the sensor is able to detect soil through the grasses that are cut or sparsely spaced. Because of this, dividing grasses into these two categories produced better accuracies.

An added unexpected effect of the multispectral high spatial resolution was the sensor's ability to pick up small variations in the health of vegetation in agricultural fields. While this is an exceptional characteristic to pick up, it leads to some inaccuracies in classifying homogenous soybean or cotton fields. The result is a speckled look to the classification, confusing unhealthy agriculture with shrubs. Even so, the shape of the field is visually obvious from the image, so the dominant agricultural classification determines the field's category (Hirose et al., 2003; Loechl et al., 2001). 
One other drawback to any remotely-sensed image is cloud cover. Digital Globe's policy is that the image is considered good enough if clouds cover $20 \%$ or less of the image (Digital Globe, 2004). In the image received, there was some cloud cover over Goodwin Creek and parts of the riparian area. Including clouds and their shadows in the classification routine produced results with very poor accuracy for water, asphalt, and tree shadows due to spectral confusions. Because of this, the areas impacted by the clouds and their shadows were "clipped" (brightness values set to zero) from the image and not included in any of the remaining analysis.

Evaluating the classification with an error matrix is helpful in understanding which classes have poor accuracy (Congalton, 1991). However, a limitation of the error matrix is that it does not give the user an idea of spatial error. For example, a class may have extremely poor accuracy at specific parts of the watershed such as around field edges, at low saturated points in a field, or areas of vegetation covered by kudzu vines. Instead, the error matrix assumes the errors are random and not related. Knowing the spatial association with the errors would have provided a more complete understanding of the accuracy (Tso and Mather, 2001).

\section{Benefits and Drawbacks of Panchromatic High-Spatial Resolution Imagery}

Use of the panchromatic image indicates it is valuable in delineating the riparian zone and visible streams. Riparian boundaries, natural and human-induced, were delineated based on vegetation edges rather than a set arbitrary width (McKee et al., 1996). Streams 
were also delineated for both ephemeral and perennial streams. The greatest limitation for accuracy and visibility is vegetation density and tree overhang. These problems could be improved by introducing satellite images from different seasons (Wulder et al., 2004; Turner et al., 2003).

Visual indicators of gully erosion in adjacent fields and riparian borders were also digitized using the panchromatic image. Pictures taken in the field were used to compare to erosion seen in the satellite image. Figure 15 is a picture of erosion visible in the panchromatic image.

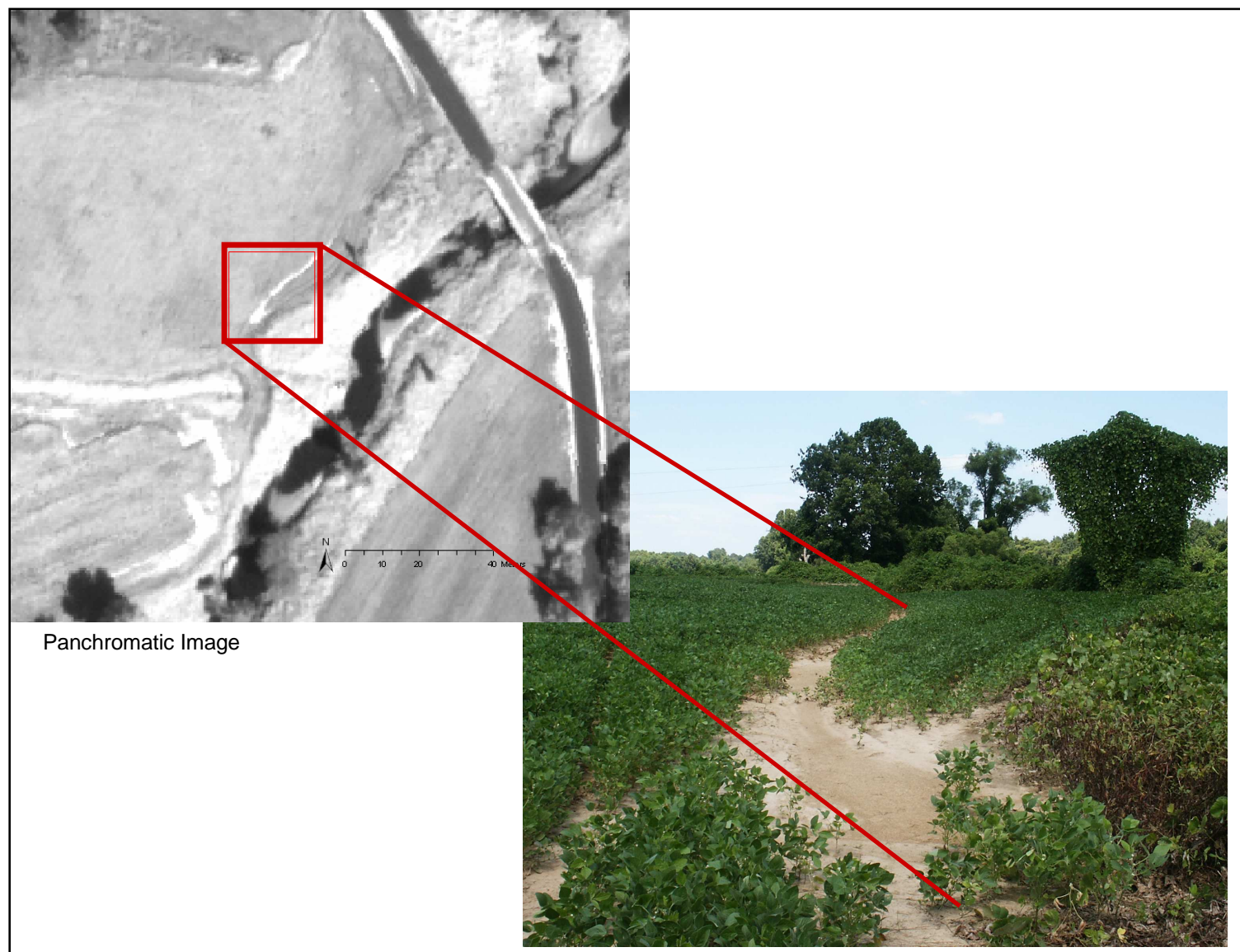

Figure 15. Erosion visible in panchromatic image and field due to lack of vegetation. 
Dense vegetation due to the summer season eliminated the ability to view erosion within the riparian area. Furthermore, what appeared to be erosion in the panchromatic image was, at times, only machinery tracks. Machinery tracks, however, can contribute to gully formation during heavy rainfall events.

A beneficial result of the high resolution is the ability to see detail in the land. According to Souchere et al. (1998), the crop row direction, slope and aspect help determine where field runoff will be directed. Crop row direction is visible in the panchromatic image. On the other hand, slope and aspect, as well as flow conditions based on topography, had its limitations because they were derived from the 10-meter digital elevation model. The flow conditions were compared to the visible flow conditions in the panchromatic image, and results showed spatial discrepancies between the two. The coarse resolution of the DEM shows the error in the topographic derived flow predictions. These inaccuracies made it difficult to correlate visible gully formation or stream formation with predicted flow. It also brought into question the accuracy of flow prediction in forested areas of the watershed, where the small streams were not visible due the tree cover. The differences between the flow predictions and the satellite image, indicate the value of Quickbird imagery for checking model outputs (Biondini, 1999).

\section{Locating Areas of Poor Riparian Filtration}

Since the satellite image showed that flow and erosion are not visible within the riparian area, additional riparian characteristics based on GIS layers and Quickbird-derived layers were used to indicate riparian effectiveness. Therefore, riparian vegetation, hydrologic 
soil conditions, slope, and width were used to predict if the entering concentrated flow, which was visible in the panchromatic image, would disperse or short-circuit the riparian strip.

ERDAS Imagine's Knowledge Engineer classifier was used to query areas within the riparian strip that fall short of ideal filtration attributes. Criteria included slopes greater than 15\% (English et al., 2002), soil hydrologic types C and D (Prosser et al., 2000b; Welsch, 1991), and poor filtration and dispersion vegetation consisting of bare ground, agriculture, kudzu, and sparse grass. Kudzu is of particular importance in the South because of its devastating effects on bank stability and erosion. The invasive vine covers riparian vegetation and kills it by blocking sunlight. The effect is dead riparian species and a gap between the Kudzu vines and the ground, which provides a barrier-free zone for water and sediment to runoff. The use of satellite data to locate areas with Kudzu growth is useful for the land monitoring- especially in areas not visible from the road. Although Kudzu is specific to Southern watersheds, the impact of invasive species on riparian filtration effectiveness is a global problem that satellite imagery can monitor (Wadsworth et al., 2000).

Another set of criteria queried in Knowledge Engineer detected riparian areas of healthy vegetation, but with slopes greater than $15 \%$ and soil hydrologic Types $\mathrm{C}$ and $\mathrm{D}$. These healthy vegetation categories were divided into vegetation for runoff dispersion (grass Type 1) and vegetation for allowing sediment settling time (trees and shrubs). These categories were again divided into areas less than and greater than 24-meters from the 
stream to detect the extent of poor dispersion and settling conditions. These categories were adapted from Welsch's (1991) recommendation for ideal riparian conditions.

Noticeably, the majority of the four poor riparian regions (Figure 13) took place in the lower section of the watershed, along the main channel. Unfortunately, the source of sediment along the main channel is predominantly from bank erosion, and the role of riparian zones as filters is insignificant in comparison. This is a weakness in using Goodwin Creek as the study area. Riparian filters have more impact in reducing sediment in areas of agriculture along lower-ordered streams ${ }^{1}$; however, in Goodwin Creek pastureland makes up most of the adjacent land along those streams. The methods devised in this study are still applicable to watersheds where monitoring sediment filtration from agricultural runoff is a priority.

While the use of Knowledge Engineer is a simple example of using information provided by satellite imagery and digital elevation models, it does not include several other complicated aspects that influence riparian function as noted in the models described in the literature review chapter. Nonetheless, it does indicate the potential to use high spatial resolution imagery as input or calibration for riparian models, especially those that may be more complicated such as REMM (Lowrance et al., 1998) and VFSMOD (Munoz-Carpena et al., 1999), or watershed models such as AnnAGNPS (Bingner and Theurer, 2001).

The results of the Knowledge Engineer classification aid land managers in investigating locations of the riparian zone that need to be monitored for poor filtration. The use of the 
broad large-scale analysis is useful in focusing on smaller-scaled projects in watersheds (McKee et al., 1996).

\section{Cost Effectiveness of High-Spatial Resolution Satellite}

One aim of this study was to provide a method for monitoring riparian filtration in a costeffective and timely manner. Using satellite imagery instead of aerial photographs provides the user with multispectral layers that do not have to be digitized, and can be obtained more conveniently than scheduling plane flights. Satellite multispectral options include both IKONOS and Quickbird. While IKONOS provides a similar product to Quickbird, IKONOS is the more expensive option. Table 9 provides a summary of several remote sensing tools, products, and costs.

Other forms of satellite data can be attained depending on the spectral and spatial resolution needed for monitoring, usually at a higher cost. One option is to obtain finer resolution DEM's from radar, however, the high-cost of radar imagery (LIDAR) would have to be taken into account in a cost-benefit analysis by the user. If a more detailed species delineation or soil data were significant to the user, the higher bandwidths available in hyperspectral imagery would make this possible. However, the cost and high-computational requirements would have to be weighed. For the purpose of this study, Quickbird proved to be the most useful for the price of the images. 
Table 9. Price comparison of remote sensing products as of 2004.

\begin{tabular}{|c|c|c|c|c|}
\hline Imagery & Reference & Resolution & Product Type & Price Range \\
\hline Aerial Photo & Finely, 2003 & $1-m$ & Color & $\$ 4,000-\$ 5,000$ per scene \\
\hline $\begin{array}{l}\text { IKONOS } \\
(1: 4,800)\end{array}$ & Finely, 2003 & $\begin{array}{l}1-\mathrm{m} \\
4-\mathrm{m}\end{array}$ & $\begin{array}{c}\text { Precision } \\
\text { Panchromatic } \\
\text { Multispectral }\end{array}$ & $\$ 80$ per km² \\
\hline Quickbird & $\begin{array}{c}\text { Digital Globe, } \\
2004\end{array}$ & $\begin{array}{l}0.61-\mathrm{m} \\
2.44-\mathrm{m}\end{array}$ & $\begin{array}{l}\text { Orthorectified } \\
\text { Panchromatic } \\
\text { Multispectral }\end{array}$ & $\$ 40$ per km ${ }^{2}$ \\
\hline LIDAR & 3001 Inc., 2004 & $1-\mathrm{m}$ & DEM & $\$ 30,000$ for $20 \mathrm{~km}^{2}$ \\
\hline Hyperspectral & $\begin{array}{l}\text { CSA, 2003; } \\
\text { Tukianinen, } \\
2002\end{array}$ & $3-10 \mathrm{~m}$ & $\begin{array}{l}126 \text { bands } 450- \\
2450 \mathrm{~nm}\end{array}$ & $\$ 150-\$ 500$ per $\mathrm{km}^{2}$ \\
\hline
\end{tabular}

\section{Further Recommendations}

Subsequently, the time frame for this study limited a few possible directions to continue this research topic. For instance, only agriculture was accounted for in this study, yet cattle-trodden pastures are also non-point pollution sources. A survey of the pastureland management practices would also aid in effective riparian management (Donaldson and Swanson, 2000).

An additional suggestion to enhance the results of the classification would be to perform a field test follow-up. The secondary field data collection would improve the classification and allow detailed categories to be added to the classification scheme. As mentioned previously, temporal satellite monitoring would also improve the classification accuracy, especially during early spring when plants leaf at different times. Detection of concentrated flow may also be easier during off-leaf season. 
Finally, if cost was not a factor, a high resolution DEM from LIDAR would ultimately provide the information needed to detect smaller topographic changes that often contribute to concentrated flow formation. High-resolution DEM's would also contribute to sensing smaller streams in forested riparian regions. 


\section{Conclusions}

Quickbird high-spatial resolution multispectral imagery proved to be useful for characterizing vegetation, and is superior to traditional satellites such as Landsat TM. By means of the supervised maximum likelihood classification algorithm, the result was an overall accuracy of $84 \%$. With the exception of shrubs, the accuracy of the vegetation categories within the classified image was satisfactory for the purpose of this study.

In identifying other properties that determine the efficiency of riparian filters, the satellite imagery was beneficial for some and not for others. Tables 10 and 11 summarize major findings that answer the research question regarding the ability to sense riparian and adjacent land attributes for the identification of ineffective filter areas.

Table 10. Identification of riparian land characteristics to aid in identifying areas of ineffective riparian filtration.

\begin{tabular}{|l|l|l|}
\hline \multicolumn{1}{|c|}{ Attribute } & \multicolumn{1}{|c|}{ Resource } & \multicolumn{1}{c|}{ Result } \\
\hline $\begin{array}{l}\text { Riparian distance from } \\
\text { channel }\end{array}$ & $\begin{array}{l}\text { Panchromatic \& } \\
\text { Multispectral Image }\end{array}$ & $\begin{array}{l}\text { Yes, boundary delineated between } \\
\text { land use and stream. Forested areas } \\
\text { more difficult to delineate. }\end{array}$ \\
\hline Vegetation Classes & $\begin{array}{l}\text { Supervised (MLC) } \\
\text { Multispectral Image }\end{array}$ & $\begin{array}{l}\text { Yes, if classes remained general. } \\
\text { Acceptable accuracy of 84\%. }\end{array}$ \\
\hline Soil Infiltration Type & NRCS Soil Survey & $\begin{array}{l}\text { Usefulness limited to identifying } \\
\text { four major hydrologic groups: A, B, } \\
\text { C, D at 30-m resolution. }\end{array}$ \\
\hline Elevation and Slope & $\begin{array}{l}\text { Digital Elevation } \\
\text { Model }\end{array}$ & $\begin{array}{l}\text { 10-meter resolution was too coarse } \\
\text { for identifying small topographic } \\
\text { changes. }\end{array}$ \\
\hline $\begin{array}{l}\text { Evidence of } \\
\text { Concentrated Flow } \\
\text { through Filter }\end{array}$ & $\begin{array}{l}\text { Panchromatic Image, } \\
\text { Knowledge Engineer } \\
\text { Classifier }\end{array}$ & $\begin{array}{l}\text { Not visible in areas of dense } \\
\text { vegetation. Had to be predicted } \\
\text { with Knowledge Engineer. }\end{array}$ \\
\hline
\end{tabular}


Table 11. Identification of adjacent land use characteristics to aid in identifying areas that contribute to ineffective riparian filtration.

\begin{tabular}{|l|l|l|}
\hline \multicolumn{1}{|c|}{ Attribute } & \multicolumn{1}{|c|}{ Resource } & \multicolumn{1}{c|}{ Result } \\
\hline $\begin{array}{l}\text { Adjacent Land Use } \\
\text { Vegetation Classes }\end{array}$ & Multispectral Image & $\begin{array}{l}\text { Yes, although a field was } \\
\text { speckled with other classes, the } \\
\text { major land type could be seen } \\
\text { and applied. }\end{array}$ \\
\hline Crop Row Direction & Panchromatic Image & $\begin{array}{l}\text { Yes, direction could be seen and } \\
\text { applied to where runoff may } \\
\text { accumulate. }\end{array}$ \\
\hline $\begin{array}{l}\text { Adjacent Soil Infiltration } \\
\text { Type }\end{array}$ & NRCS Soil Survey & $\begin{array}{l}\text { Usefulness limited to identifying } \\
\text { four major hydrologic groups: A, } \\
\text { B, C, D at 30-m resolution. }\end{array}$ \\
\hline Elevation and Slope & $\begin{array}{l}\text { Digital Elevation } \\
\text { Model }\end{array}$ & $\begin{array}{l}\text { lo-meter resolution was too } \\
\text { coarse for identifying small } \\
\text { topographic changes (swales). }\end{array}$ \\
\hline $\begin{array}{l}\text { Evidence of } \\
\text { Concentrated Flow } \\
\text { Entering Filter }\end{array}$ & Panchromatic Image & $\begin{array}{l}\text { Visible in several fields, unless } \\
\text { tree overhang interfered. }\end{array}$ \\
\hline
\end{tabular}

Due to the fact that concentrated flow within the riparian filter zone could not be seen, areas with poor filtration properties were queried, and then evaluated as to whether or not they were receiving upland concentrated flow. Although the results of this method are not hard-fact, results are successful in identifying areas of concern that could be contributing to sediment transport into streams. Having this information available to land managers and decision makers, will aid in narrowing down areas in need of an on-site field assessment within a large study area. In addition, as an alternative to evaluating riparian characteristics within image processing software, as this study has done, it is possible to use this data as input into watershed and riparian models or use the information to validate and check outputs of similar models. The use for high-spatial resolution data in riparian management is a practical and valuable solution for agricultural watersheds where riparian monitoring is needed. 


\section{Appendices}

\section{Appendix A. Glossary}

Accuracy Assessment: Provides a measure of classification performance. Most common method is an error matrix. The matrix is composed of columns that represent ground truth data and rows that represent pixels classified by classification algorithms. The overall accuracy is found by dividing the sum of the matrix diagonals by the total number of samples.

ADAR imagery: Airborne Data Acquisition and Registration. This aerial multispectral imagery provides more accurate data than those derived from scanned aerial orthophotographs (Coulter et al., 2000).

Barfield's zone concept: The first zone occurs when the sediment and runoff first enter the vegetated riparian area and the sediment creates a wedge. The wedge continues to increase with time until it reaches the maximum height of vegetation in that zone, where sedimentation in this zone discontinues. In the next zone, the sediment wedge flattens in the direction of the river or channel. Within the third zone, sediment covers the irregularities on the soil surface and in the fourth zone, only suspended material is left to be transported (Frede, 2002). Figure 16a depicts the process of sediment transport through each of the four zones in a grass filter.

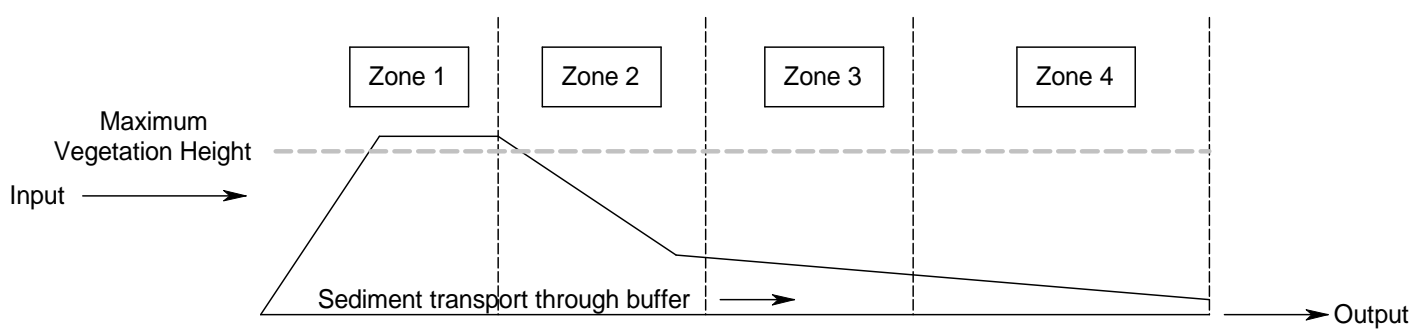

Figure 16a: Sediment transport through vegetated riparian zone (according to Barfield et al., 1979)

Baye's Theorem of conditional probability: Baye's theorem states that $\mathrm{P}\left(\mathrm{C}_{\mathrm{i}} \mid \mathrm{x}\right)=$ $\left[\mathrm{P}\left(\mathrm{x} \mid \mathrm{C}_{\mathrm{i}}\right)^{*} \mathrm{P}\left(\mathrm{C}_{\mathrm{i}}\right)\right] / \mathrm{P}(\mathrm{x})$. Given that $\mathrm{x}$ is the pixel vector and $\mathrm{C}_{\mathrm{i}}$ is class $\mathrm{i}$. The $\mathrm{P}\left(\mathrm{x} \mid \mathrm{C}_{\mathrm{i}}\right)$ can be expressed with the covariance and mean from the training data which determines the likelihood for $\mathrm{C}_{\mathrm{i}}$ given $\mathrm{x}$. $\mathrm{P}\left(\mathrm{C}_{\mathrm{i}}\right)$ is assumed to be normally distributed and the classes are weighted equally. $\mathrm{P}(\mathrm{x})$ is equal to one, being a normalizing constant (Tso and Mather, 2001).

Digitizing: Encodes map coordinates into digital form.

Differential GPS: Differential Global Positioning System (GPS) is a satellite-based positioning system operated by the U.S. Department of Defense. The beacon receiver uses all-digital signal processing to track signals from DGPS radiobeacons. Differential 
GPS requires two or more receivers, with one being a reference station. (www.trimble.com)

Ecotone: Ecotones represent environmental gradients that affect flows of energy, matter, and organisms; biodiversity related to spatial location; and landscape management. Riparian areas can be one ecotone at large scale, as well as two ecotones (aquatic and upland) at a smaller scale (Malanson, 1993)

Electromagnetic Spectrum: A remote sensor will first detect electromagnetic waves through the atmosphere and record it as an analog electric signal. When the electromagnetic waves strike a surface, the wave can be reflected, transmitted, or scattered. Each target the wave comes in contact with has a characteristic spectrum based on the chemical composition of that material that determines what wavelengths are absorbed by the chemical bonds and what is reflected back to the sensor (ERDAS, 1999).

Ephemeral channels: Flow only occurs during and after a storm event, there is no base flow.

Forbs: A broad-leaved herbaceous plant

Ground truth site: These sites will be used to test the accuracy of the classification. See also Accuracy Assessment.

Multi-modal Classes: Spectral classes or signatures containing more than one information or data class.

Multispectral Classes: See Table 12a below for a list of the four bands, their wavelengths and associated characteristics.

Table 12a: Characteristics of Spectral Bands in Quickbird Images (Digital Globe, 2004; Jensen, 1996)

\begin{tabular}{cll}
\hline Band & \multicolumn{1}{c}{ Color (wavelength) } & \multicolumn{1}{c}{ Characteristics } \\
\hline Band 1 & $\begin{array}{l}\text { Blue } \\
(0.45 \text { to } 0.52 \text { micro-meters })\end{array}$ & $\begin{array}{l}\text { Supports analysis of land use, soil, and vegetation } \\
\text { traits. }\end{array}$ \\
Band 2 & $\begin{array}{l}\text { Green } \\
(0.52 \text { to } 0.60 \text { micro-meters })\end{array}$ & $\begin{array}{l}\text { Corresponds to the green reflectance of healthy } \\
\text { vegetation. }\end{array}$ \\
Band 3 & $\begin{array}{l}\text { Red } \\
\text { (0.63 to } 0.69 \text { micro-meters })\end{array}$ & $\begin{array}{l}\text { Reprents one the most important bands for } \\
\text { vegetation discrimination. It can also be useful for } \\
\text { soil-boundary delineations. }\end{array}$ \\
Band 4 & $\begin{array}{l}\text { Reflective Infrared } \\
(0.76 \text { to } 0.90 \text { micrometers })\end{array}$ & $\begin{array}{l}\text { This band is especially responsive to the amount } \\
\text { of vegetation biomass present. It is useful for crop } \\
\text { identification and emphasizes soil-crop and land- } \\
\text { water contrasts. }\end{array}$ \\
\hline
\end{tabular}

Nutrient absorption: Nutrients are taken up by plants and sequestered in plant tissue. 
Ortho-rectification: To geometrically correct aerial or satellite images.

Panchromatic: Black and white photographs with ultra-violet and visible wavelength information.

Pansharpening: A method that sharpens a coarse resolution image with a higher resolution image. This is often done with a multispectral image and panchromatic image.

Pixel: The smallest unit of information in a grid map.

Remote Sensing: Remote sensing revolves around the energy-matter interactions in the landscape being viewed. The energy-matter relationship is used to predict the amount of radiant flux (electromagnetic radiation) that should exit an object in specific wavelengths without actually sensing the object (Strahler and Woodcock, 1986).

Roughness: Roughness is usually quantified with Manning's roughness coefficient. The coefficients represent the surface's resistance to the flow of water over it.

Sensor Systems: There are numerous multispectral remote sensor systems available, each having different resolutions, functions and applications. Common systems for sensing watershed or riparian areas include the Landsat Thematic Mapper (TM), the SPOT chromatograph, IKONOS, Quickbird, and aerial multispectral photography. See Table 13a for a comparison of current remote sensors.

Table 13a: Summary of available remotely sensed data types (adapted from Franklin \& Dickson, 2001;

Brohman and Bryant, 2003)

\begin{tabular}{|c|c|c|c|c|}
\hline \multicolumn{5}{|c|}{ Resolution } \\
\hline $\begin{array}{c}\text { Remote Sensor } \\
\text { system }\end{array}$ & Spectral* & Spatial (meter) & Temporal (days) & $\begin{array}{c}\text { Coverage } \\
\text { (swath width) }\end{array}$ \\
\hline Aircraft & & & & \\
\hline Panchromatic film & & Variable & Variable & Variable \\
\hline Color film & $\mathrm{B}, \mathrm{G}, \mathrm{R}, \mathrm{NIR}$ & $<0.3$ & Variable & Variable \\
\hline Mulitspectral scanner & $\mathrm{B}, \mathrm{G}, \mathrm{R}, \mathrm{NIR}$ & $0.3-2$ & Variable & Variable \\
\hline Satellite & & & & \\
\hline $\begin{array}{l}\text { Landsat Thematic } \\
\text { Mapper TM }\end{array}$ & $\begin{array}{l}\text { B, G, R, NIR, } \\
\text { MIR, TIR }\end{array}$ & 30 & 16 & $185-\mathrm{km}$ \\
\hline Panchromatic & & 15 & & \\
\hline $\begin{array}{l}\text { SPOT } 5 \text { Multispectral } \\
\text { Panchromatic }\end{array}$ & $\begin{array}{c}\text { B, G, R, NIR, } \\
\text { MIR }\end{array}$ & $\begin{array}{c}10 \\
5\end{array}$ & $<5$ & $60-\mathrm{km}$ \\
\hline $\begin{array}{l}\text { IKONOS } \\
\text { Panchromatic }\end{array}$ & $\mathrm{B}, \mathrm{G}, \mathrm{R}, \mathrm{NIR}$ & $\begin{array}{l}4 \\
1\end{array}$ & $1-3$ & $11-\mathrm{km}$ \\
\hline $\begin{array}{l}\text { Quickbird } \\
\text { Panchromatic }\end{array}$ & $\mathrm{B}, \mathrm{G}, \mathrm{R}, \mathrm{NIR}$ & $\begin{array}{l}2.44 \\
0.66 \\
\end{array}$ & $1-4$ & $17-\mathrm{km}$ \\
\hline
\end{tabular}

* $\mathrm{B}=$ blue, $\mathrm{G}=$ green, $\mathrm{R}=$ red, $\mathrm{NIR}=$ near infrared, $\mathrm{MIR}=$ mid infrared, $\mathrm{TIR}=$ thermal infrared 
Soil hydraulic groups: The SCS divided soils into four groups (A, B, C, D) representing different infiltration rates. Soil group $\mathrm{A}$ has the highest infiltration rate (lowest runoff potential) and group D has the lowest infiltration rate (highest runoff potential).

Stream order: Stream order classifies streams according to their position in the channel network. According to Strahler's order system, a first order stream has no tributaries. A second order stream is the joining of two first order streams and so on.

Supervised Classification: The identification of land cover using classification algorithms and a priori knowledge from fieldwork.

Topographic swales: Depressions in the topography of the land. Often where runoff will be directed to, and form concentrated flow.

Training sites: Sites within the study area that represent homogeneous areas of each of the vegetation classes. This provides the a priori knowledge necessary for supervised classification.

Unsupervised Classification: The identification of land cover without a priori knowledge. Generally, clustering algorithms are used to separate spectral characteristics into classes. 
Appendix B: Quickbird Multispectral and Panchromatic Images

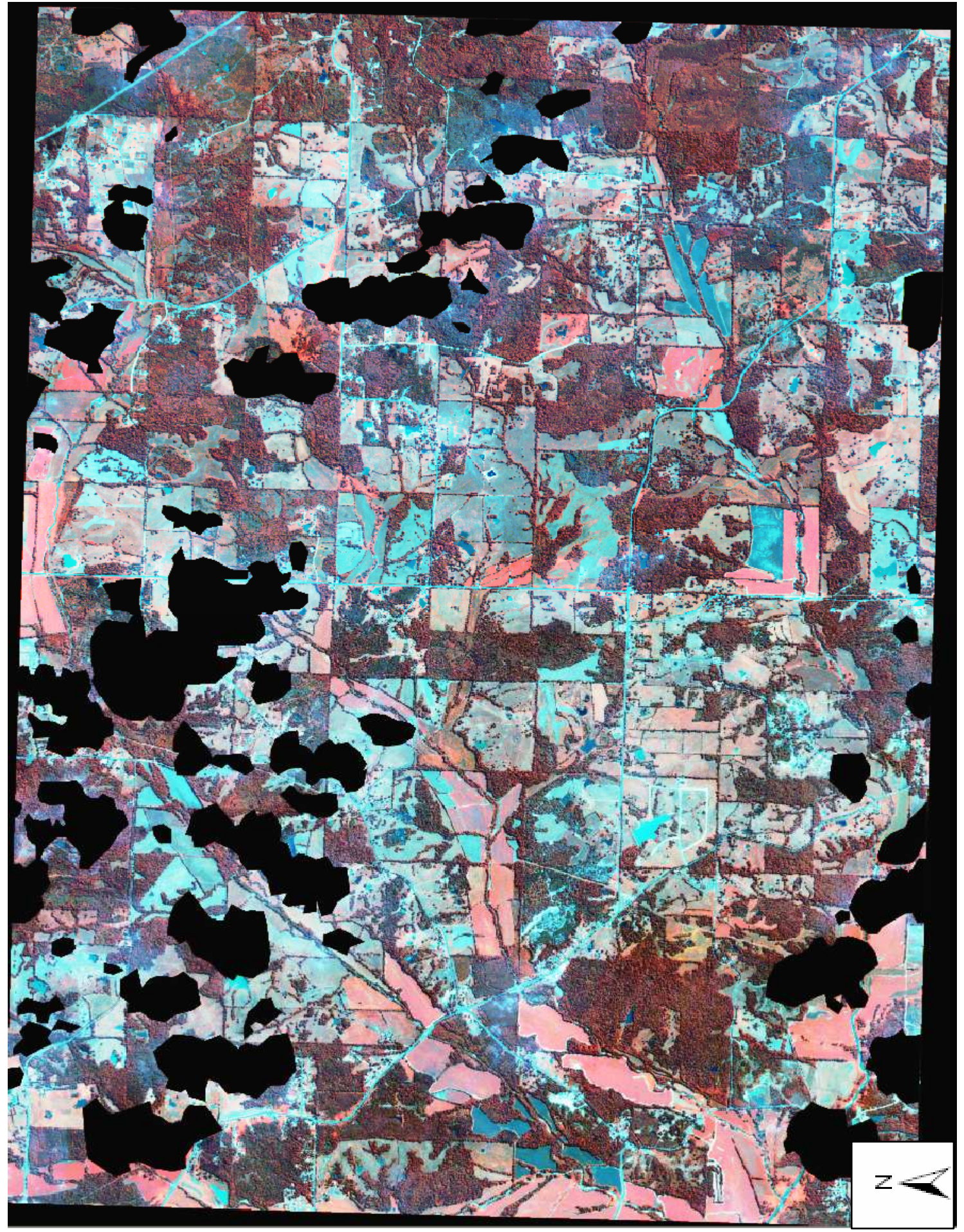

Figure 17b. Quickbird multispectral image $\left(80 \mathrm{~km}^{2}\right)$, showing blue, green and infrared bands with clouds removed (Sept. 9, 2004). 


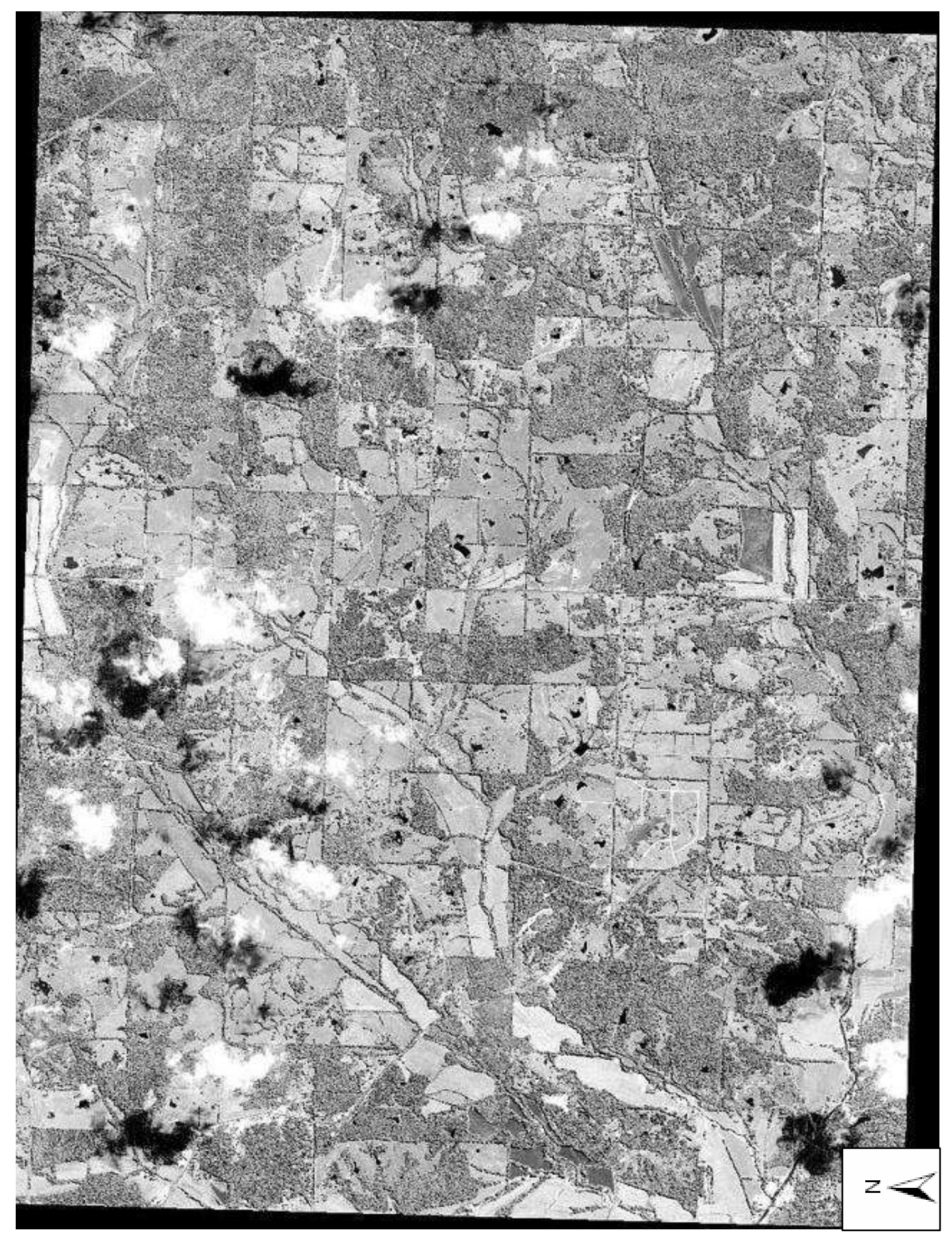

Figure 18b. Quickbird panchromatic image $\left(80 \mathrm{~km}^{2}\right)$ (Sept. 9, 2004). 


\section{Appendix C. Quickbird Specifications}

Table 14c. Quickbird Features and Benefits (Digital Globe, 2004)

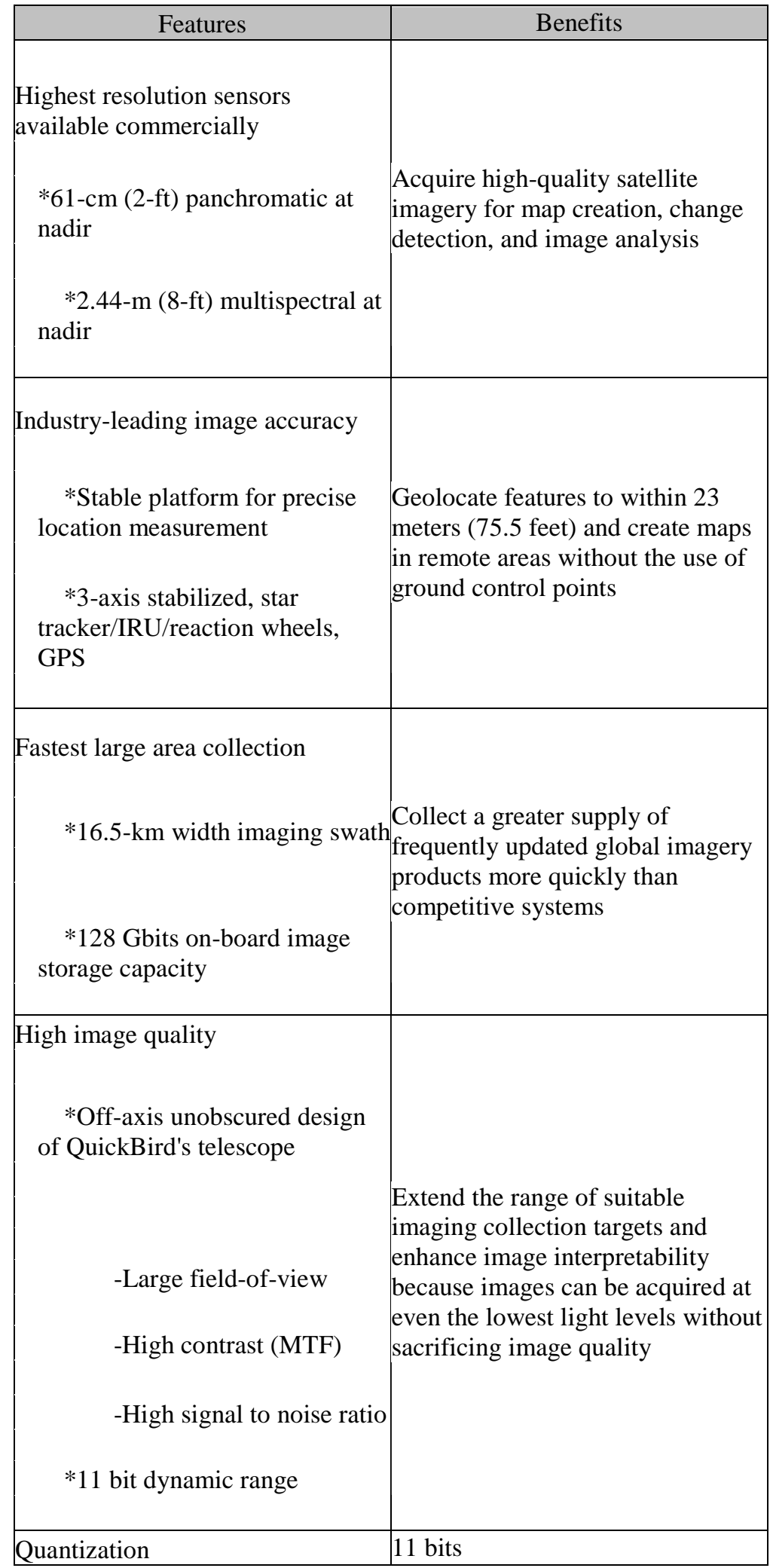


Table 15c. Quickbird Design and Specifications (Digital Globe, 2004)

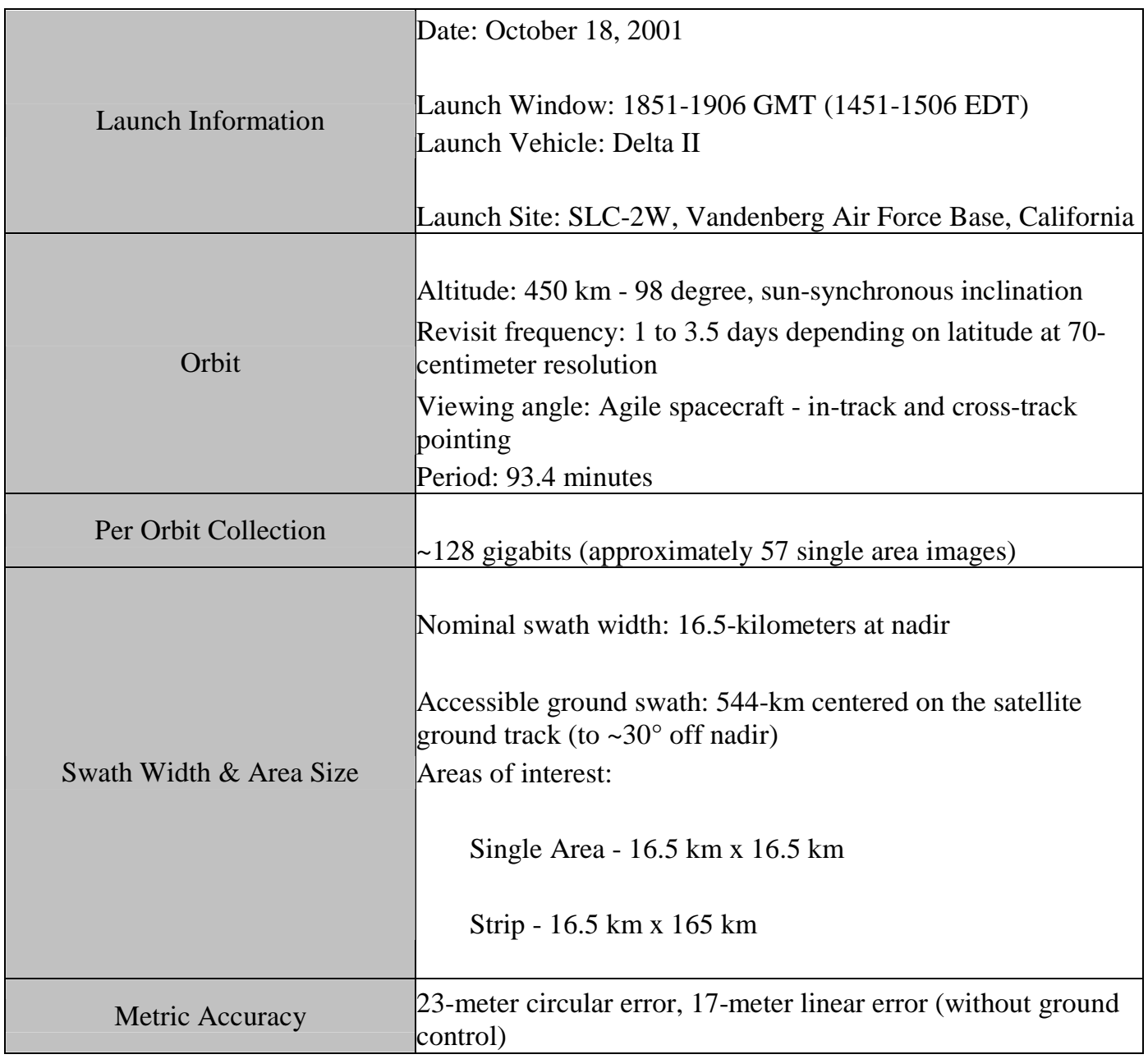


Table 16c. Quickbird Design and Specifications continued (Digital Globe, 2004)

\begin{tabular}{|c|c|c|}
\hline $\begin{array}{c}\text { Sensor Resolution \& Spectral } \\
\text { Bandwidth }\end{array}$ & $\begin{array}{l}\text { Panchromatic: } \\
\text { 61-centimeter GSD (Ground } \\
\text { Sample Distance) at nadir } \\
\text { Black \& White: } 445 \text { to } 900 \\
\text { nanometers }\end{array}$ & $\begin{array}{l}\text { Multispectral: } \\
\text { 2.44-meter GSD } \\
\text { at nadir } \\
\text { Blue: } 450 \text { to } 520 \\
\text { nanometers } \\
\text { Green: } 520 \text { to } 600 \\
\text { nanometers } \\
\text { Red: } 630 \text { to } 690 \\
\text { nanometers } \\
\text { Near-IR: } 760 \text { to } \\
900 \text { nanometers }\end{array}$ \\
\hline Dynamic Range & \multicolumn{2}{|l|}{ 11-bits per pixel } \\
\hline Communications & 320 Mbps X-band & \begin{tabular}{|} 
Housekeeping \\
X-band from 4, 16 \\
and $256 \mathrm{Kbps}$ \\
$2 \mathrm{Kbps}$ S-band \\
uplink
\end{tabular} \\
\hline ADCS Approach & \multicolumn{2}{|c|}{ 3-axis stabilized, star tracker/IRU/reaction wheels, GPS } \\
\hline Pointing and Agility & \multicolumn{2}{|c|}{$\begin{array}{l}\text { Accuracy: less than } 0.5 \text { milliradians absolute per axis } \\
\text { Knowledge: less than } 15 \text { microradians per axis } \\
\text { Stability: less than } 10 \text { microradians per second }\end{array}$} \\
\hline Onboard Storage & 128 Gbits capacity & \\
\hline Spacecraft & $\begin{array}{l}\text { Fueled for } 7 \text { years } \\
2100 \text { pounds, 3.04-meters }(10-\mathrm{ft})\end{array}$ & \\
\hline
\end{tabular}


Appendix D. Knowledge Engineer Classifier Decision Trees

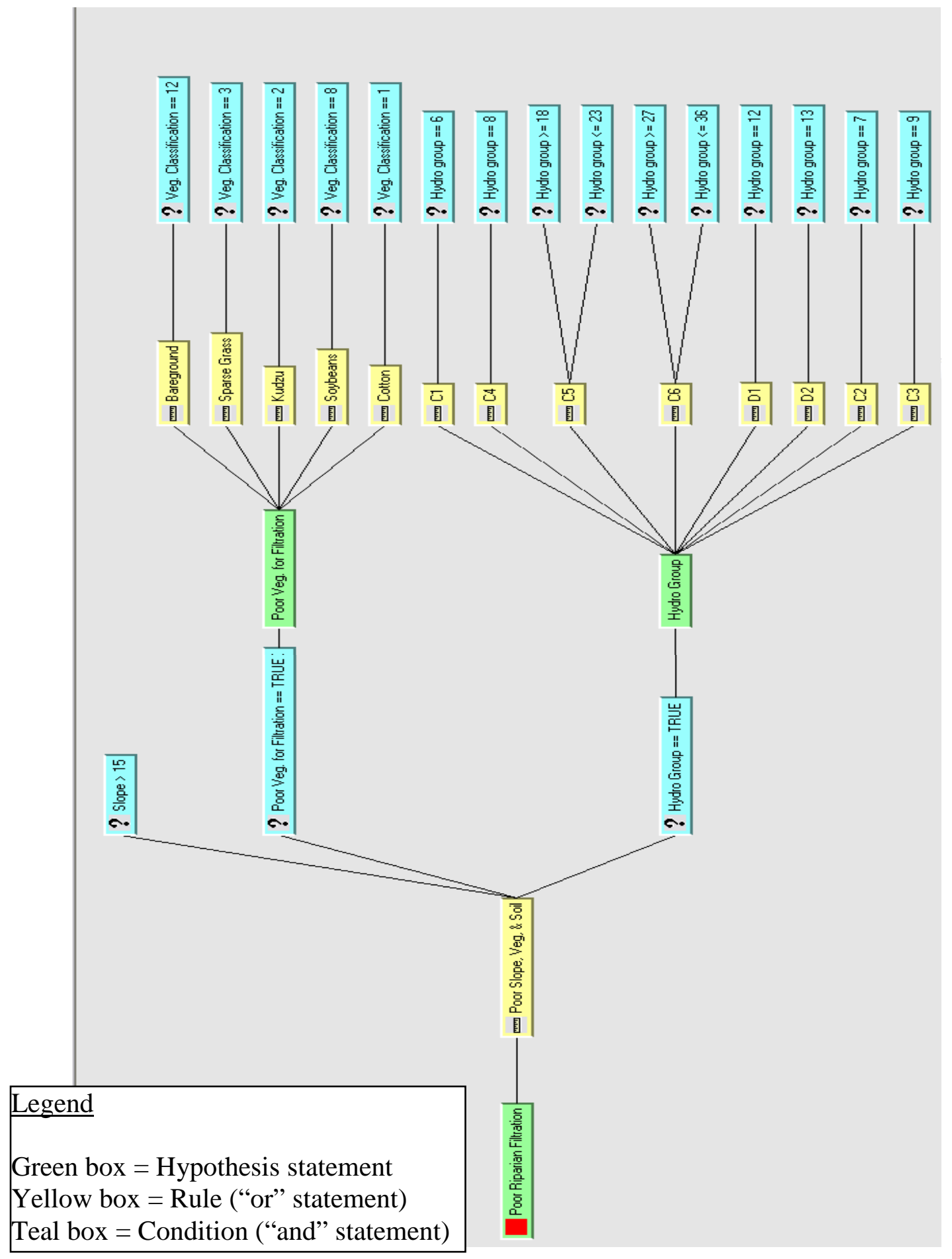

Figure 19d. Knowledge Engineer's classification of areas with poor riparian filtration (red). The areas include poor filtering vegetation, slopes greater than $15 \%$, and poor soil infiltration properties (type $\mathrm{C} \& \mathrm{D}$ ). 


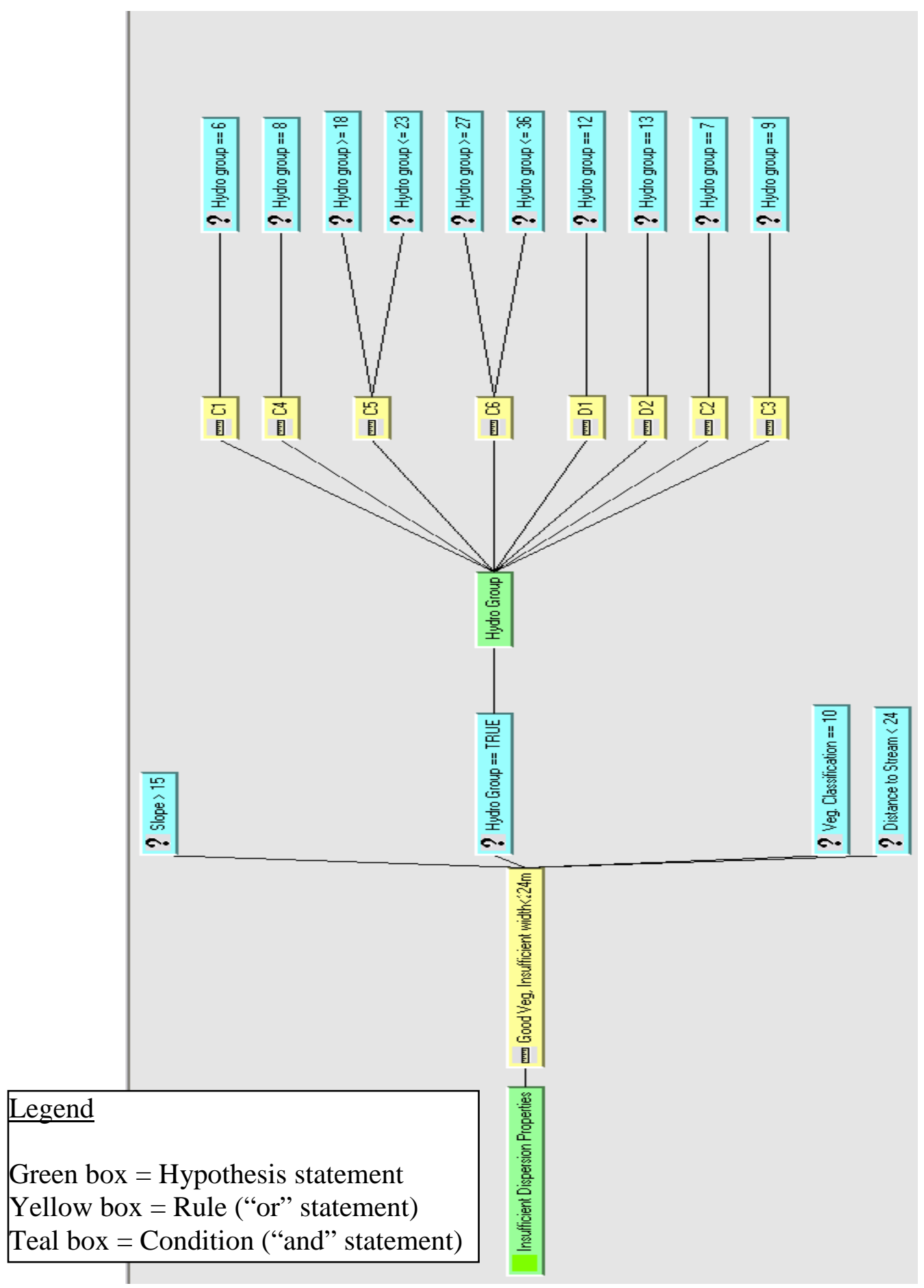

Figure 20d. Knowledge Engineer's classification of riparian areas with healthy grass (green), but other poor qualities including poor soil infiltration properties and slopes greater than $15 \%$. The classification was also limited to 24 meters from the streamline. 


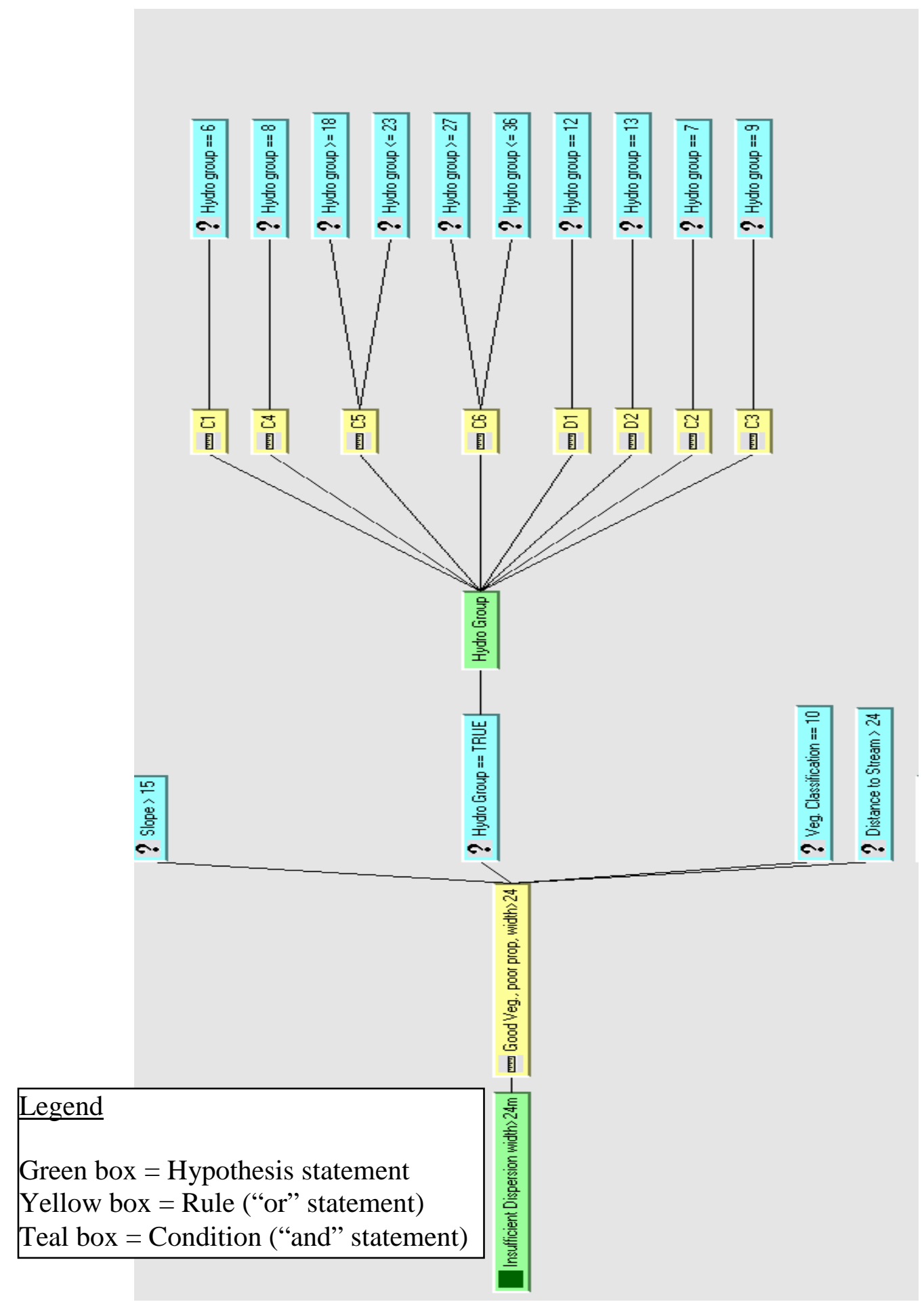

Figure 21d. Knowledge Engineer's classification of riparian areas with healthy grass (dark green), with poor qualities that limit its ability to disperse entering runoff including poor soil infiltration properties and slopes greater than $15 \%$. The classification was also limited to greater than 24 meters from the streamline. 


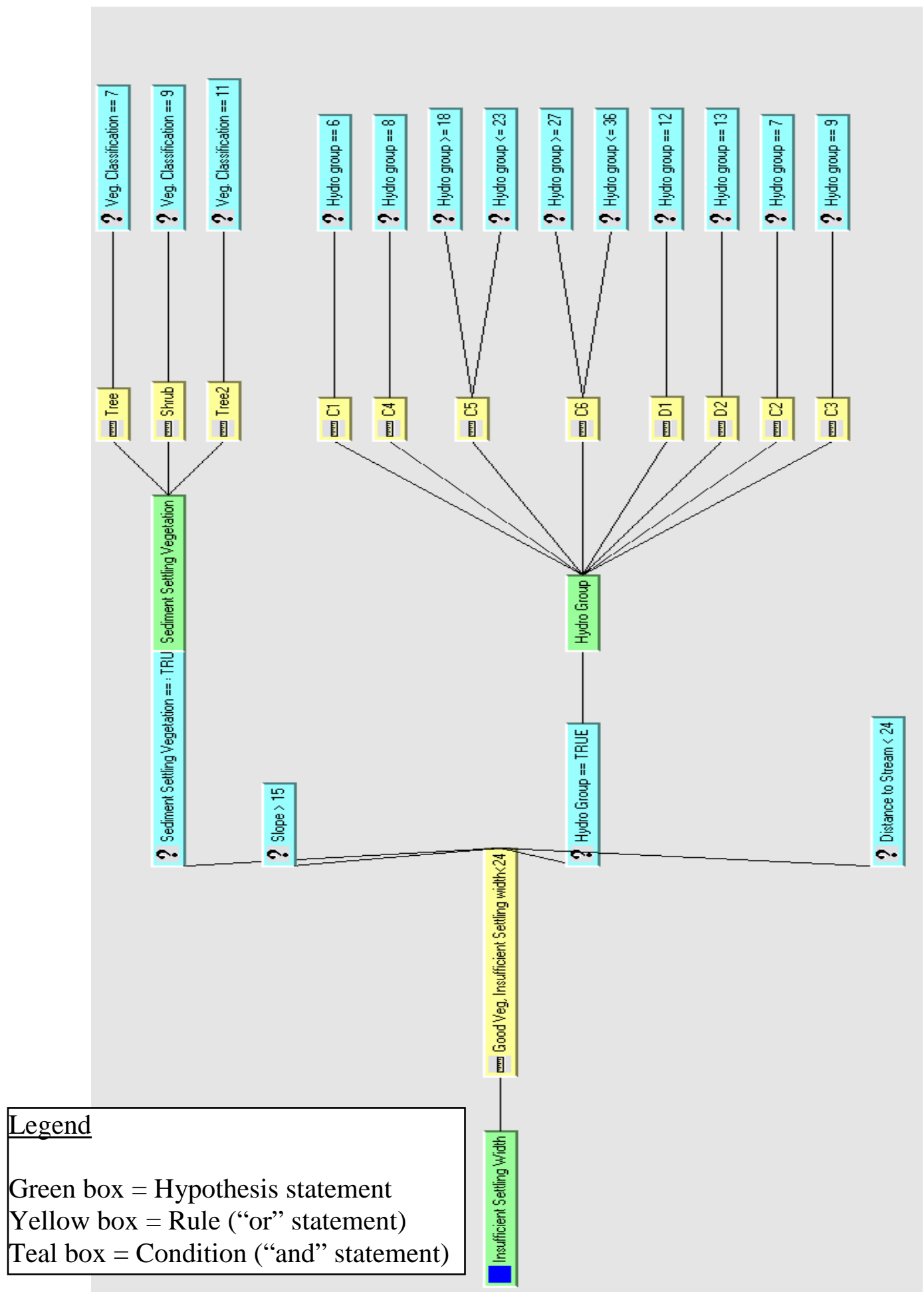

Figure 22d. Knowledge Engineer's classification of riparian areas with shrubs and trees (blue) used to increase the settling time of dispersed flow, but with other poor qualities including poor soil infiltration properties and slopes greater than $15 \%$. The classification was also limited to 24 meters from the streamline. 


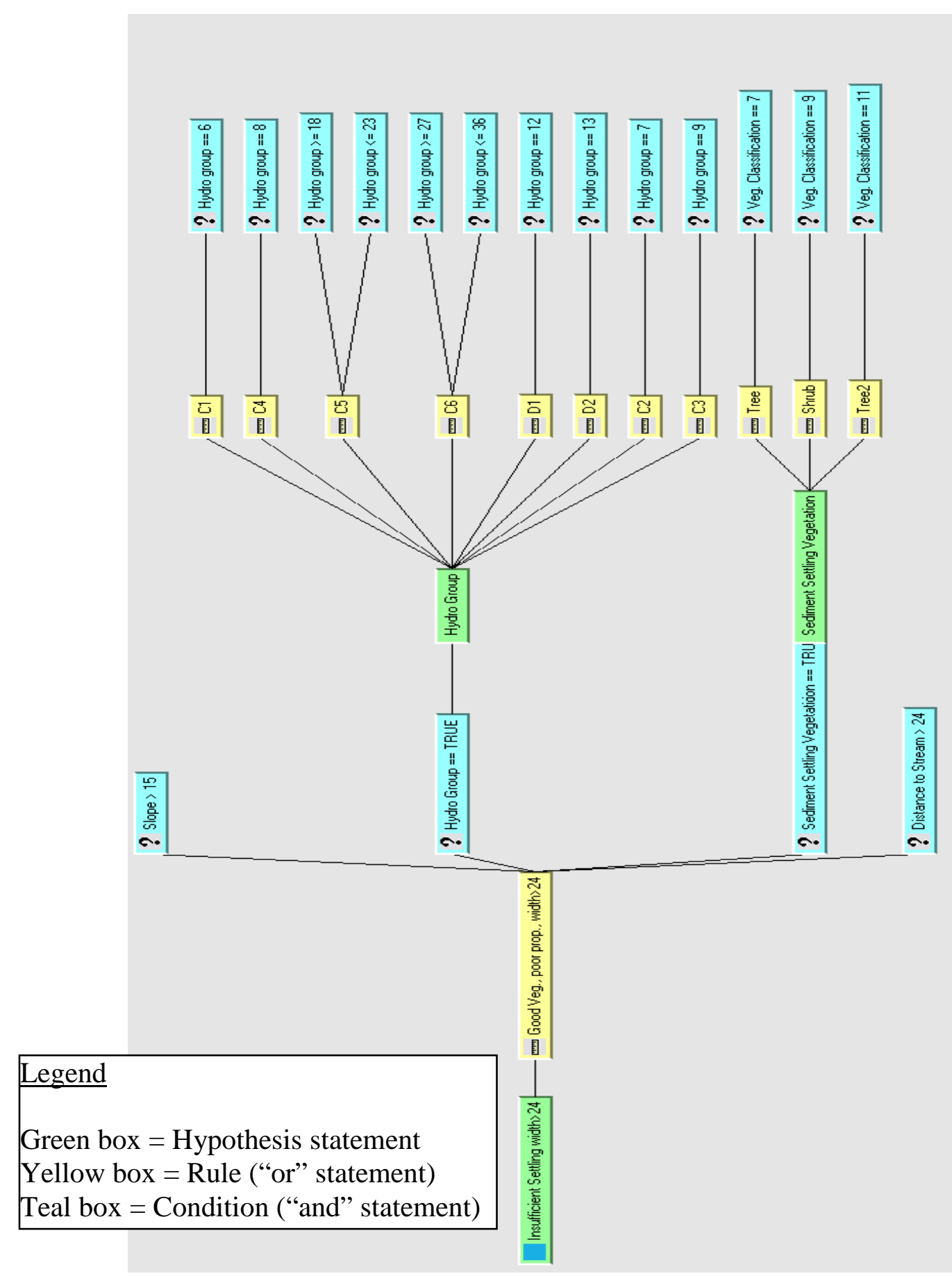

Figure 23d. Knowledge Engineer's classification of riparian areas with shrubs and trees (teal blue), used to increase the settling time of dispersed flow, but with other poor qualities including poor soil infiltration properties and slopes greater than $15 \%$. The classification was also limited to greater than 24 meters from the streamline. 


\section{Appendix E. Method Flowcharts}

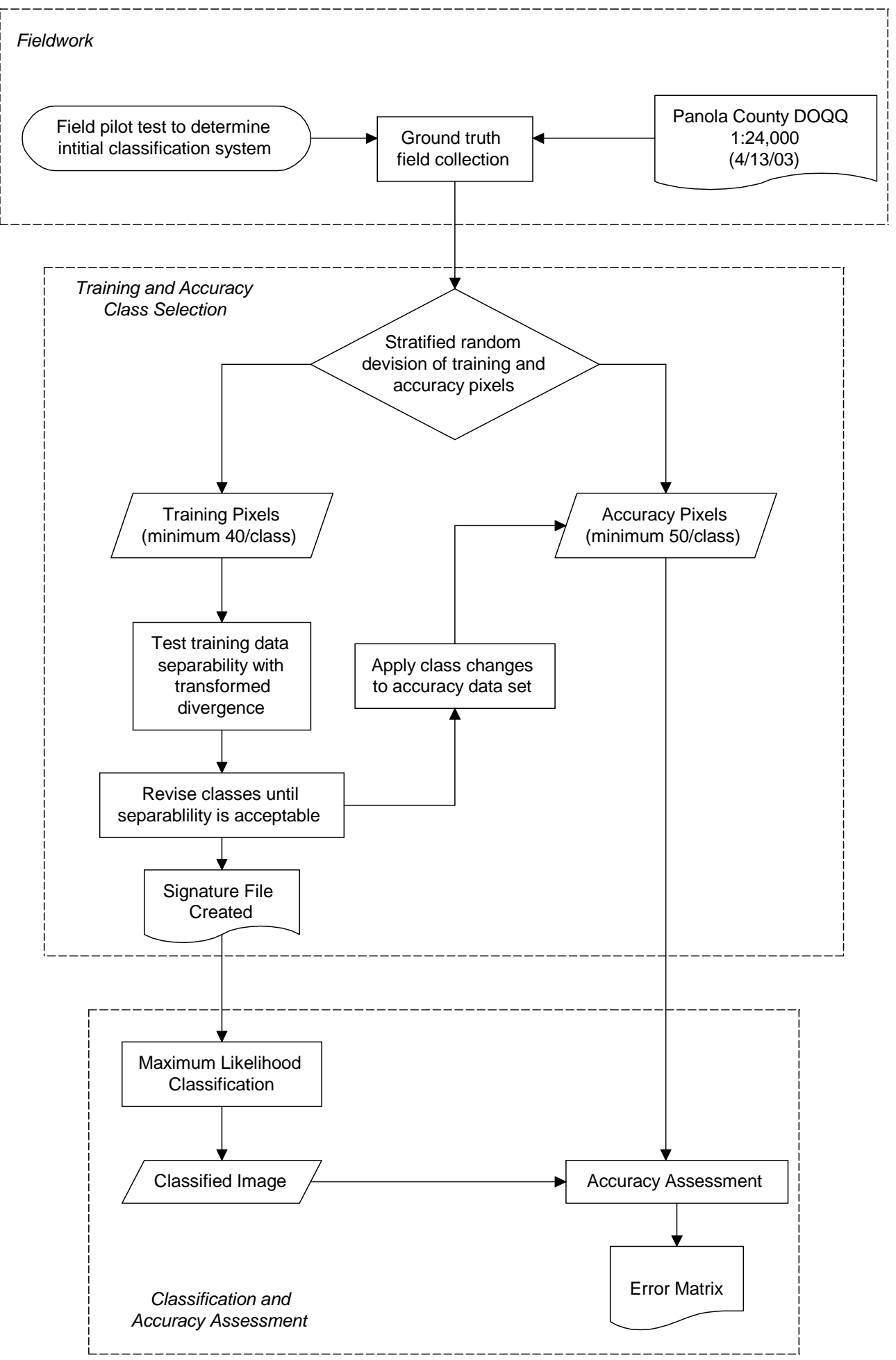

Figure 24e. Image Analysis Methods Flowchart (Tso and Mather, 2001; Franklin and Dickson, 2001; Congalton, 1999; ERDAS, 1999; Jensen, 1996; Hay, 1979). 


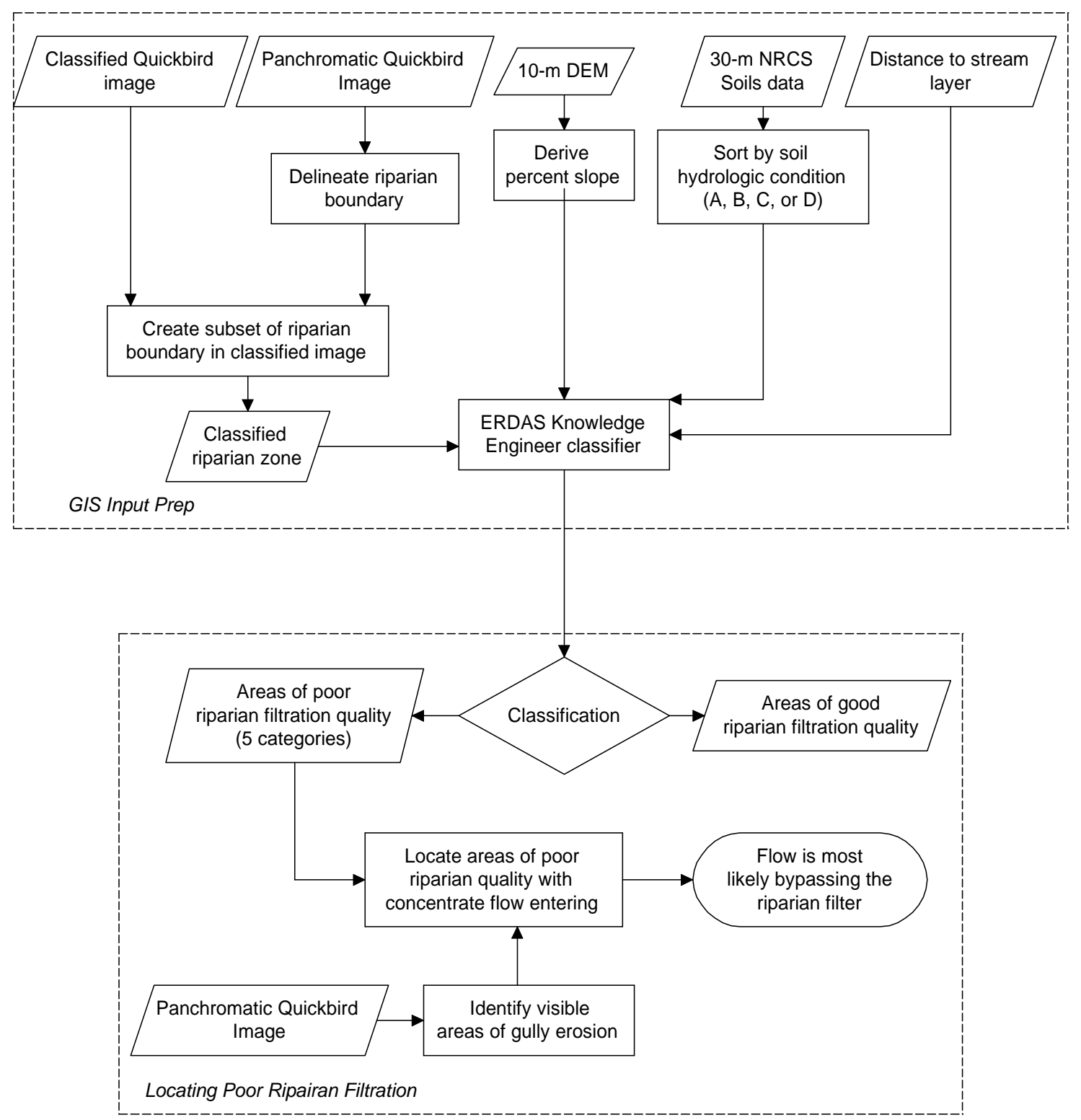

Figure 25e. GIS Methods Flowchart (English et al., 2002; Prosser et al., 2000b; ERDAS, 1999; McKee et al., 1996; Welsch, 1991). 
Appendix F. Classified Goodwin Creek Subset

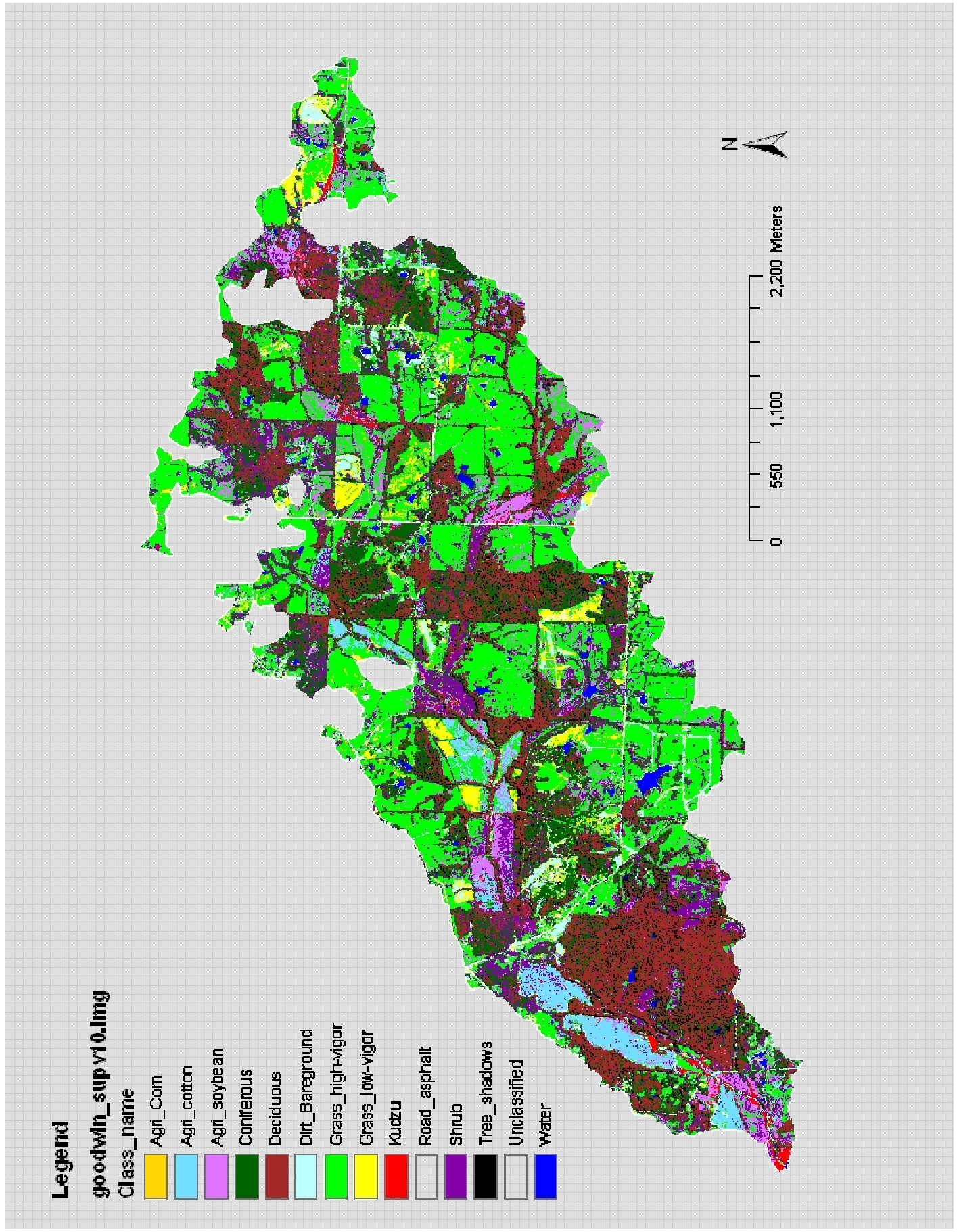

Figure 26f. Goodwin Creek Watershed classified image. Classification is a result of the Maximum Likelihood algorithm run in ERDAS Imagine. Holes in the classification are from clipping out cloud coverage. 


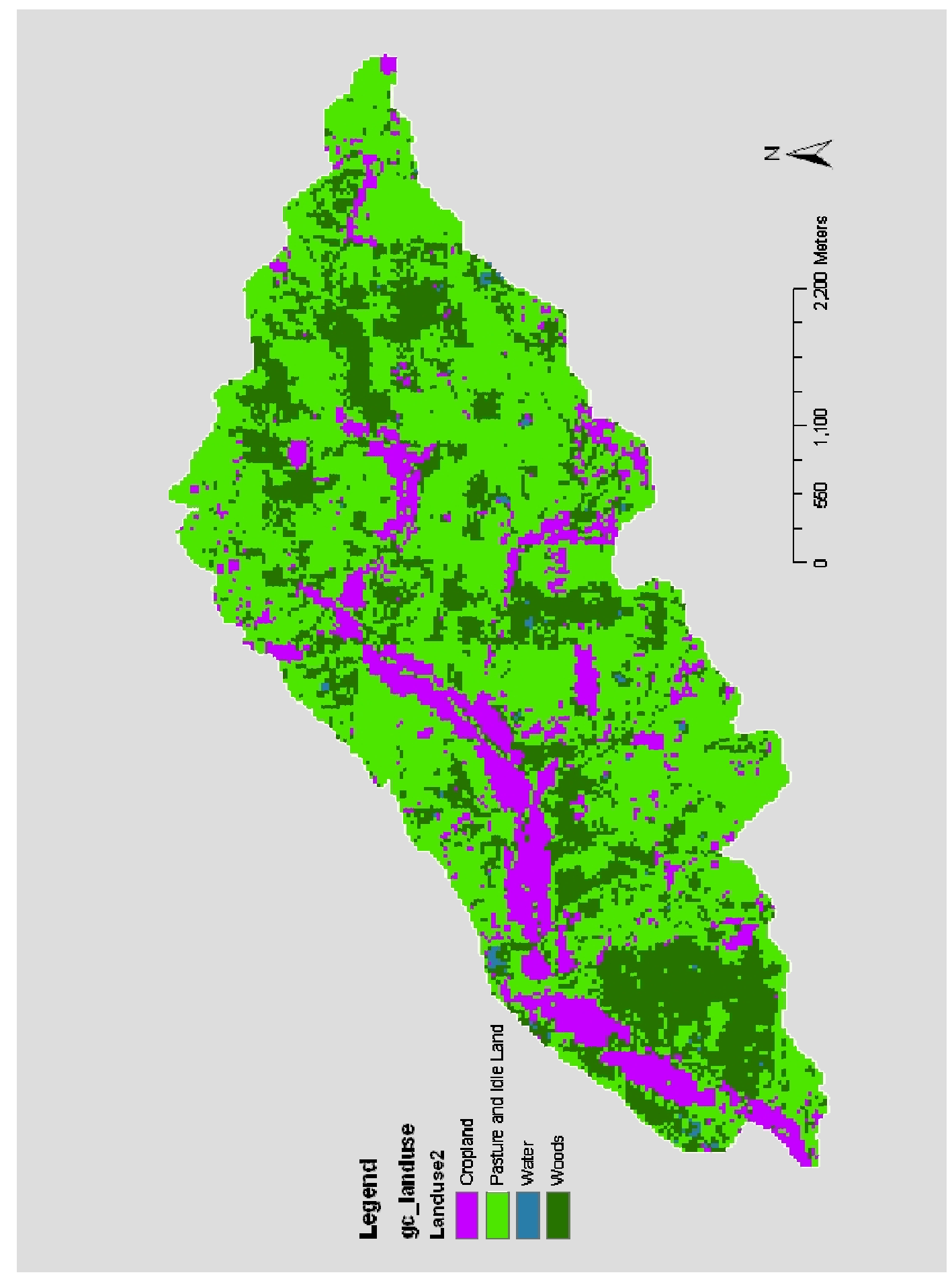

Figure 27f: 1987 land use classification used by the USDA Sedimentation Laboratory and created from a 30-m Landsat TM image. Classification includes only four classes:

Cropland, Pasture/Idle Land, Water, and Woods. 
Appendix G. Four Poor Riparian Filtration Regions of Goodwin Creek Watershed

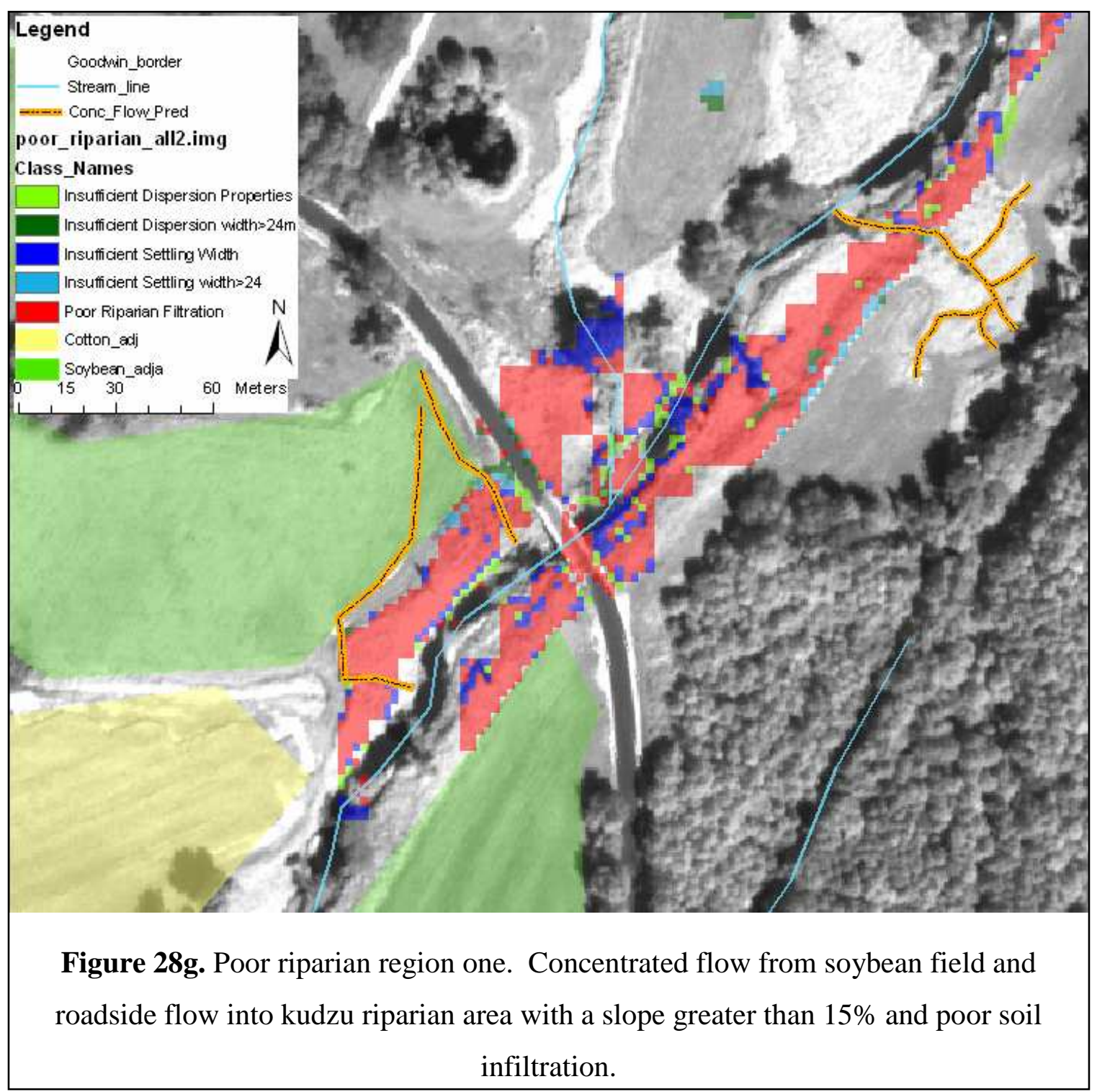




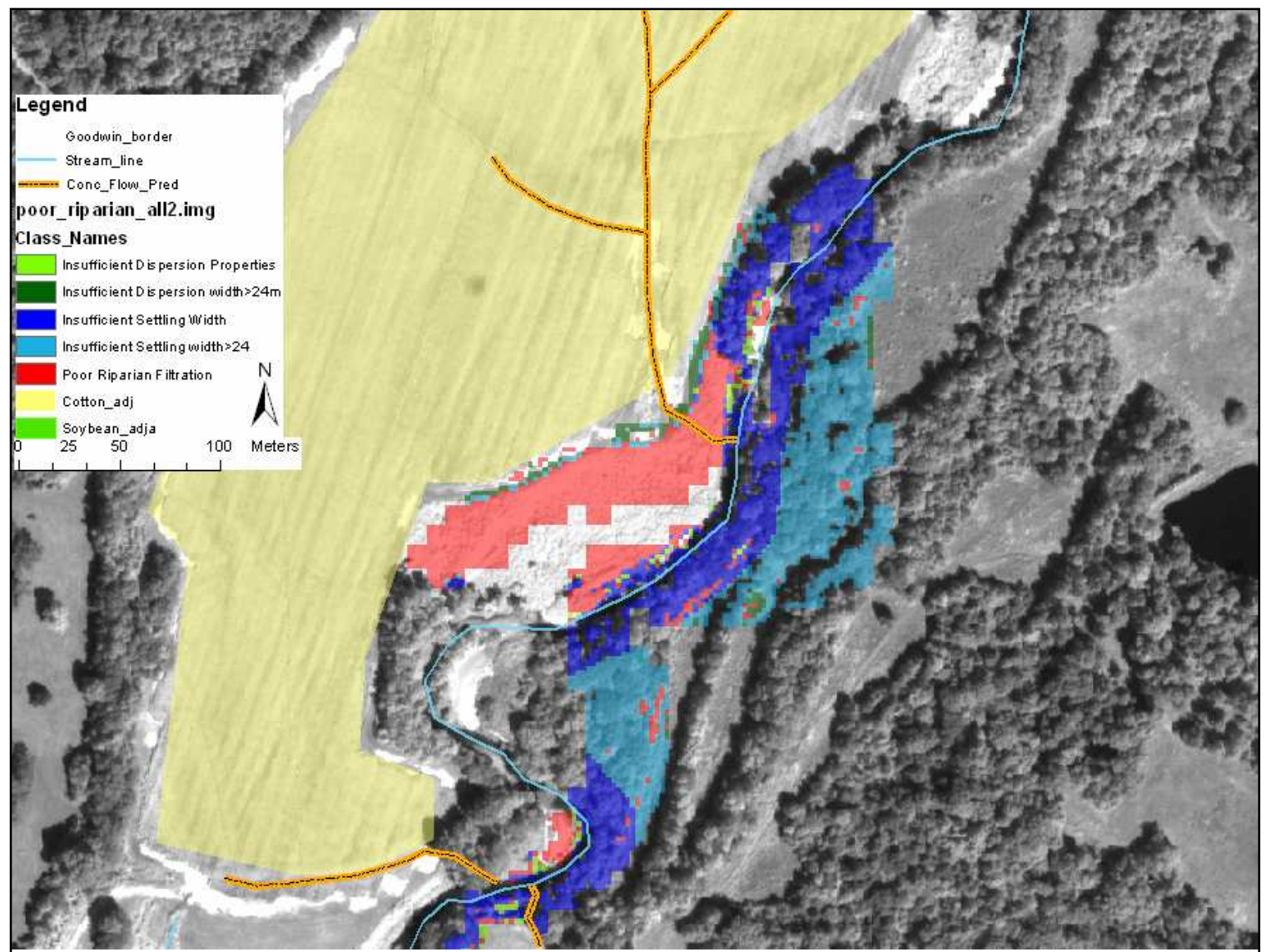

Figure 29g. Poor riparian region two. Concentrated flow coming from cotton field into Kudzu covered riparian zone with a slope greater than $15 \%$ and poor soil infiltration. 


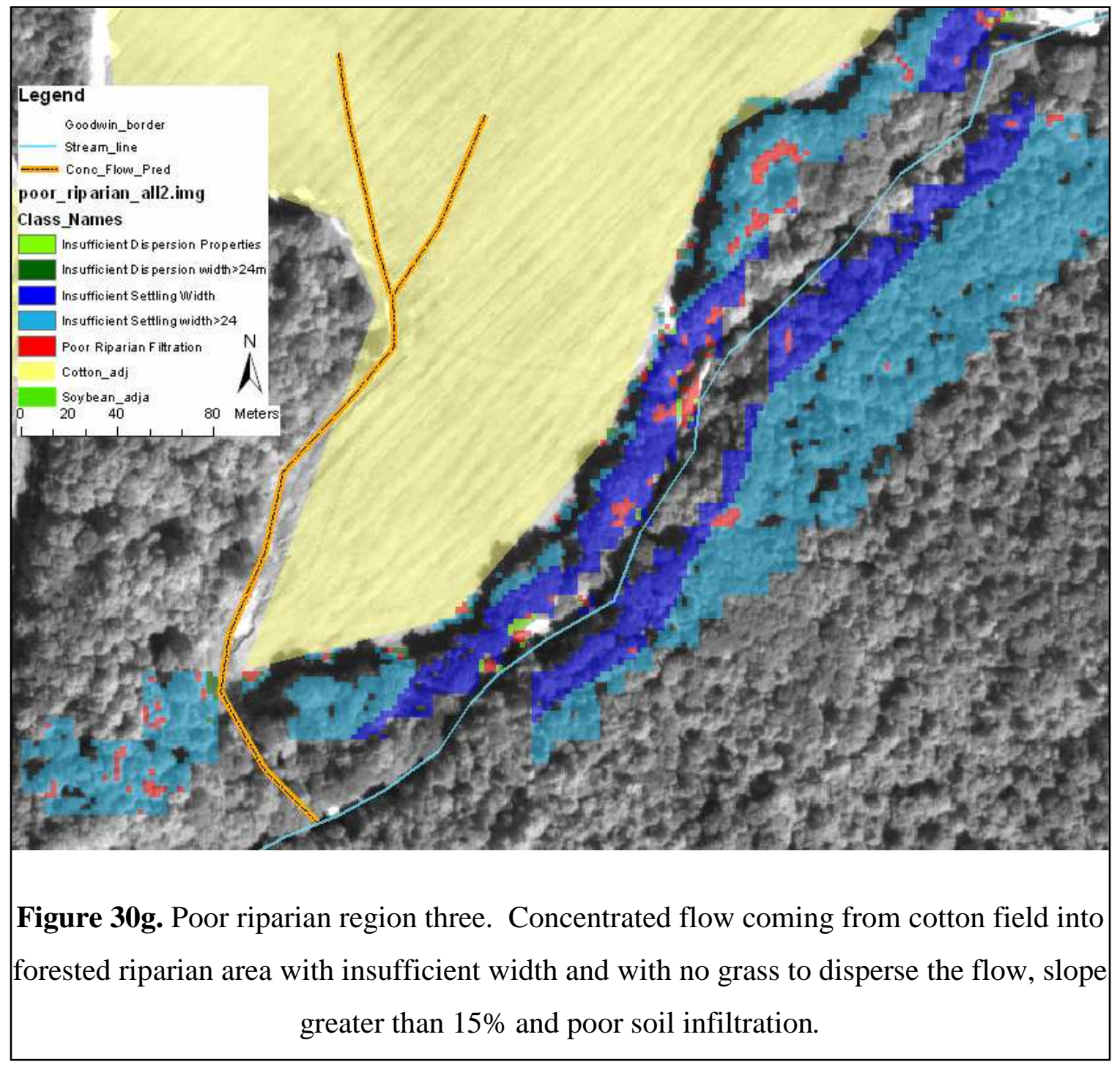




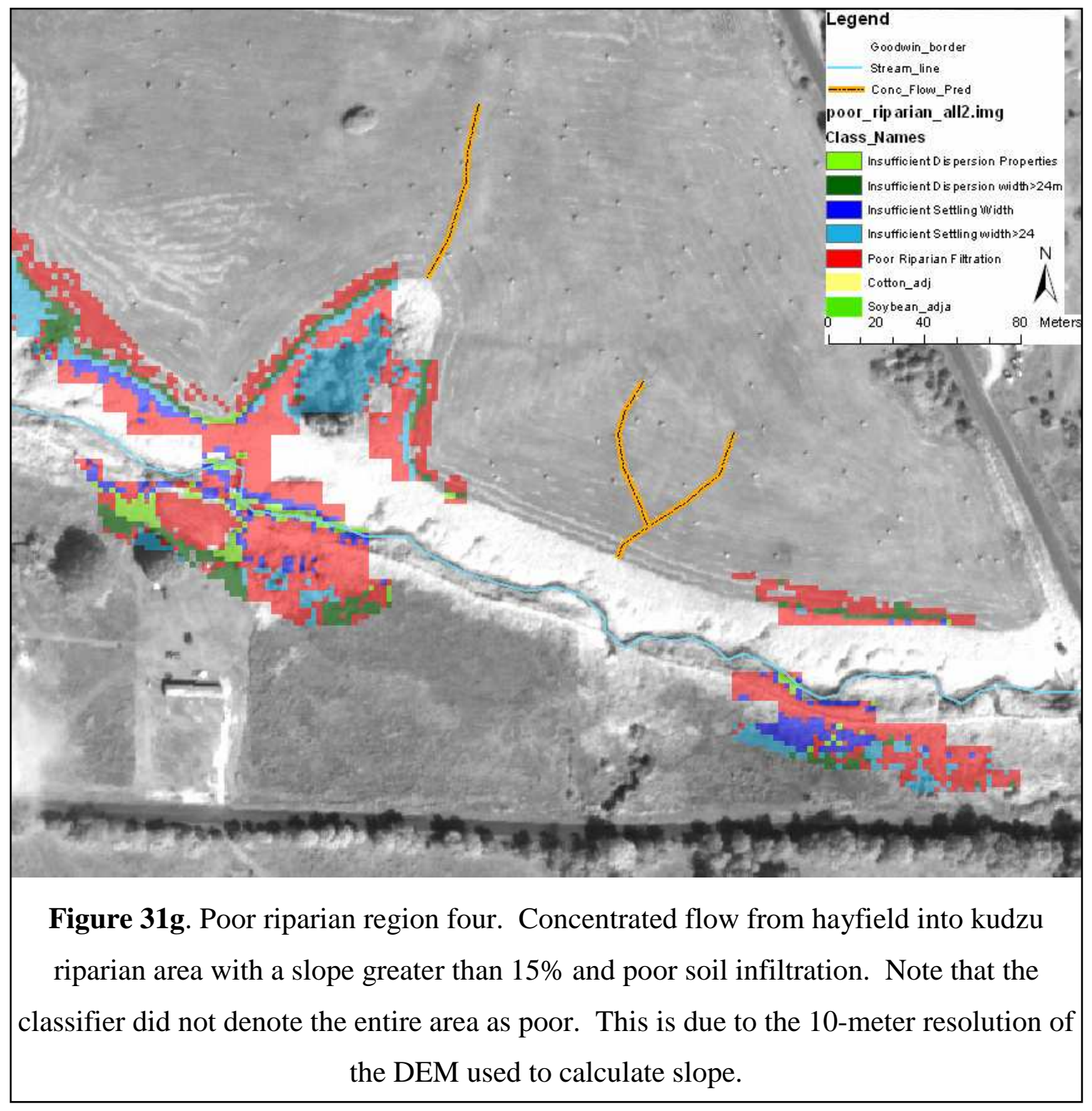




\section{References}

3001 Inc. (2004). Cost proposal for LIDAR collection and processing for the proposed watershed area between Oxford and Batesville, Mississippi. Correspondence with 3001 Inc. July 27, 2004.

Bagdon, J., R. Parker, T. Gilding, N. Poletika, and D. Fawcett. (2000) Conservation Buffers to Reduce Pesticide Losses. United States Department of Agriculture \& Natural Resources Conservation Service.

Bagnold, R.A. (1966) An approach to the sediment transport problem from general physics. U.S. Geological Survey, Prof. Paper 422-J. Reston, VA.

Barfield, B.J. E.W. Tollner and J.C. Hayes. (1979) Filtration of sediment by simulated vegetation: I. Steady-state flow with homogeneous sediment. Transaction of ASAE 22 (5): 530-545.

Bingner, R. L. and F. D. Theurer. (2001). "AnnAGNPS: estimating sediment yield by particle size for sheet \& rill erosion." In Proceedings of the Sediment: Monitoring, Modeling, and Managing, 7th Federal Interagency Sedimentation Conference, Reno, NV, 25-29 March 2001. p. I-1 - I-7.

Biondini, M. (1999). Remote Sensing in Agriculture. North Dakota State University Remote Sensing. URL: www.ndsu.nodak.edu/instruct/ biondini/ars452/rsensing.pdf Accessed: July 2004.

Black, R.W., A. Haggland, G. Crosby. (2003) Characterization of Instream Hydraulic and Riparian Habitat Conditions and Stream Temperatures of the Upper White River Basin, Washington, Using Multispectral Imaging Systems. U.S. Geological Survey Water-Resources Investigation. Report No. 03-4022.

Blackmarr, W.A. (1995) Documentation of Hydrologic, Geomorphic, and Sediment Transport Measurements on the Goodwin Creek Experimental Watershed, Northern Mississippi, for the Period 1982-1993-Preliminary Release. Channel and Watershed Process Research Unit, National Sedimentation Laboratory, ARS-USDA. Oxford, Mississippi

Bren, L.J. (1998) The geometry of a constant buffer-loading design method for humid watersheds. Forest Ecology and Management, 110: 113-125. 
Brogaard, S. and R. Ólafsdóttir (1997). Ground-truth or Ground-lies: Environmental sampling for remote sensing application exemplified by vegetation cover data. Lund Electronic Reports in Physical Geography, No. 1, October 1997. URL: www.natgeo.lu.se/Publikationer/Lerpg/1/1Article.htm. Accessed: June 28, 2004.

Brohman, R.J. and L.D. Bryant (2003). Existing Vegetation Classification and Mapping Technical Guide- Review Draft. USDA Forest Service, Washington Office, Ecosystem Management Coordination Staff.

Congalton, R.G. (1991). A Review of Assessing the Accuracy of Classifications of Remotely Sensed Data. Remote Sensing of the Environment, 37: 35-46.

Congalton, R.G. (1999). Sampling Issues for Assessing the Accuracy of Remotely Sensing Data. Fourth Annual GLOBE Conference Science Report. URL: http://www.globe.gov/fsl/html/templ_unh1999.cgi?Congalton\&lang=en\&nav=1

Congalton, R.G., K. Birch, R. Jones, and J. Schriever (2002). Evaluating remotely sensed techniquies for mapping riparian vegetation. Computers and Electronics in Agriculture, 37(1):113-126.

Coulter, L., D. Stow, A. Hope, J. O'Leary, D. Turner, P. Longmire, S. Peterson, and J. Kaiser (2000). Comparison of High Spatial Resolution Imagery for Efficient Generation of GIS Vegetation Layers. Photogrammetric Engineering \& Remote Sensing, 66(11): 1329-1335.

CSA (Canadian Space Agency) (2003). Hyperspectral Remote Sensing. CSA Sectors: Space Technology website. URL: http://www.space.gc.ca/asc/eng/satellites/hyper_geology.asp Accessed 2/1/05.

Daniels, R.B. and J.W. Gilliam (1996). Sediment and Chemical Load Reduction by Grass and Riparian Filters. Soil Science Society of America Journal, 60: 246- 251.

Digital Globe (2004). Quickbird Specifications. URL: www.digitalglobe.com/about/quickbird.html, Accessed: July 2004.

Dillaha, T.A., R.B. Reneau, S. Mostaghimi, D. Lee (1989). Vegetative Filter Strips for Agricultural Non-Point Source Pollution Control. Transactions of American Society of Agricultural Engineers, 32(2): 513-519.

Donaldson, S. and S. Swanson (2000). Managing Irrigated Pastures for Water Quality. Chapter 16 In: Kettle, R., W. Riggs, R. Torell, J. Davison, B. Bruce, and H. Glimp. Increasing Forage Production, Quality and Livestock Profitability on Irrigated Pastures and Meadows Nevada Cooperative Extension Bulletin.

Dosskey, M., D. Schultz, T. Isenhart (1998). How to Design a Riparian Buffer for Agricultural Land. Agroforestry Notes, USDA Forest Service, Rocky Mountain 
Station. URL: http://waterhome.brc.tamus.edu/projects/afnote4.htm Accessed: July 23,2004

Dosskey, M.G., M.J. Helmers, D.E. Eisenhauer, T.G. Franti, and K.D. Hoagland (2002). Assessment of concentrated flow through riparian buffers. Journal of Soil and Water Conservation, 57(6): 336-343.

Eisenhaurer, D., T. Franti, M. Dosskey, and K. Hoagland (1997). Field assessment of surface runoff patterns into riparian areas. Proceedings Vegetative Filter Strip and Riparian Buffer Research Symposium, Dec. 17, 1997. University of Nebraska, Lincoln.

English, R., T. Wilson, and B. Pinkerton (2002). Riparian Area Management Handbook for Agricultural and Forestry Lands. College of Agriculture, Forestry and Life Sciences, Clemson University, Clemson, SC. URL: http://www.clemson.edu/scg/water/riparian/ Accessed July 2004.

EPA and FTG (2004). Land Cover/Land Use Classification EPA Case Study. URL: www.ftgrp.com/content/casestudies/epa.html Accessed: July 9, 2004.

ERDAS, Inc. 1999. ERDAS Field Guide, Fifth Edition. Atlanta, Georgia.

FGDC (Federal Geographic Data Committee) (1997). Vegetation Classification Standard. U.S. Geological Survey, Reston, Virginia. URL: www.fgdc.gov/fgdc.html Accessed: June 2004.

Finely, S.R. (2003). High resolution satellite imagery and resource management. Fact Sheet 3: Remote Sensing and Geospatial Analysis Laboratory, University of Minnesota, College of Natural Resources, Dept. of forest Resources website, URL: http://rsl.gis.umn.edu. Accessed: 1/30/05.

Franklin, S.E. and E.E. Dickson (2001). Approaches for Monitoring Landscape Composition and Pattern Using Remote Sensing. Alberta Biodiversity Monitoring Program. Phase One Reports. URL: http://www.abmp.arc.ab.ca/Documents.htm

Frede, H., Z. Birgit and F. Nicola (2002) Simulation of runoff reduction and nutrient retention in riparian buffer strips. Proceedings from the $17^{\text {th }}$ WCSS, 14-21 August 2002, Thailand.

Goetz, S.J., R.K. Wright, A.J. Smith, E. Zinecker, E. Schaub (2003). IKONOS Imagery for Resource Management: Tree cover, impervious surfaces, and riparian buffer analyses in the mid-Atlantic region. Remote Sensing of the Environment, 88: 195208. 
Gowda, H.G. (1998). Agricultural Non-Point Loading Patterns in Upper Mississippi River Watersheds. USGS Project Status Reports. Last Accessed: 1-29-05. URL: http://www.umesc.usgs.gov/reports_publications/psrs/psr_1998_12.html

Hay, A.M. (1979). Sampling Designs to Test Land-Use Map Accuracy. Photogrammetric Engineering and Remote Sensing, 45(4): 529-533.

Hirose, Y., M. Mori, Y. Akamatsu, Y. Li. (2003). Vegetation Cover Mapping Using Hybrid Analysis of Ikonos Data. XXth ISPRS Congress-Commision 7, July 2004, Istanbul Turkey. URL: http://www.isprs.org/istanbul2004/comm7/papers/56.pdf Accessed 2/2/2005.

Jensen, J.R. (1996) Introductory Digital Image Processing: A Remote Sensing Perspective- $3^{\text {rd }}$ Edition. Prentice Hall series in geographic information science. Upper Saddle River, NJ.

Karr, J. R., and I. J. Schlosser (1978). Water resources and the land-water interface. Science, 201:229-234.

Khorram, S., J. Gregory, D.F. Stallings, H. Cakir (2003). High Resolution Mapping Land Cover Classification of the Hominy Creek Watershed. Center for Earth Observation, North Carolina University. CEO Technical Report 220.

Klemas, V.V. (2001). Remote Sensing of Landscape-Level Coastal Environmental Indicators. Environmental Management, 27(1): 47-57.

Langendoen, E.J., R.R. Lowrance, C.V. Alonso, R.L. Bingner, A. Simon (1998). Integration of USDA-ARS Stream and Riparian Modeling Technology, National Sedimentation Lab, Oxford, MS and USDA-ARS Southeast Watershed Research Lab, Tifton, GA.

Lattin, P.D., P.J. Wigington, T.J. Moser, B.E. Peniston, D.R. Lindeman, D.R. Oetter. (2004). Influence of Remote Sensing Imagery Source On Quantification of Riparian Land Cover/Land Use. Journal of the American Water Resources Association, Paper No. 03036.

Leckie, D., F. Gougeon, D. Hill, R. Quinn, L. Armstrong, R. Shreenan (2003). Combined high-density lidar and multispectral imagery for individual tree crown analysis. Canadian Journal of Remote Sensing, 29(5): 633-649.

Loechl, P., W. Goetz, C. Hendrix, J. Coen (2001). Integrating GIS Modeling and Remotes Sensing Classification Techniques for Mapping Vegetation on US Army Bases. 2001 ESRI International User Conference Proceedings. URL: http://gis.esri.com/library/userconf/proc01/professional/papers/pap831/p831.htm Accessed 2/2/2005. 
Lowrance, R., J.K. Sharpe and J.M. Sheridan (1986). Long-term sediment deposition in the riparian zone of a coastal plain watershed. Journal of Soil and Water Conservation, 41:266-271.

Lowrance, R. R., Altier,L.S., Williams R. G. , Inamdar S. P., Bosch, D. D., Sheridan, J. M., Thomas, D. L., and Hubbard, R. K. (1998) The riparian ecosystem management model: simulator for ecological processes in riparian zones. First Federal Interagency Hydrologic Modeling Conference, April 19-23, Las Vegas, NV, (in press)

Lutes, J. (2002). DIAS: A Digital Airborne Imaging System. Space Imaging Corp., Thorton, Colorado.

Malanson, G.P. (1993). Riparian Landscapes, Cambridge University Press, Great Britain, 287 p.

MARIS (1996) Panola County, Mississippi 10-m Digital Elevation Model. Dowloaded from: http://www.maris.state.ms.us/, 6/15/04.

McKee, A., S. Gregory, L. Ashkenas (1996). Draft Riparian Management Reference, National Forests in Minnesota, USDA Forest Service, 110 p.

Mertes, L.A. (2002). Remote Sensing of Riverine Landscapes. Freshwater Biology, 47: 799-816.

Munoz-Carpena, R., J.E. Parsons, J.W. Gilliam (1999) Modeling hydrology and sediment transport in vegetative filter strips. Journal of Hydrology, 214: 111-129.

Nale, D.K. (2002). Quickbird-Aerial Product Comparison. Prepared by EMAP International for Digital Globe. URL:

www.digitalglobe.com/product/product_docs.shtml. Accessed: September 8, 2004.

Natural Resources Conservation Service (2001). Buffer Strips: Common Sense Conservation. http://www.nrcs.usda.gov/feature/buffers/

Prosser, I., L. Karssies, R. Ogden, P. Hairsine (2002a). Using buffers to reduce sediment and nutrient delivery to streams. Riparian Land Management Technical Guidelines, Volume 2, Guideline D. URL:

http://www.rivers.gov.au/acrobat/techguidelines/tech_guide_vol2_chapd.pdf

Prosser, I., S. Bunn, T. Mosisch, R. Ogden, L. Karssies (2002b). The delivery of sediment and nutrients to streams. Riparian Land Management Technical Guidelines, Volume 1, Chapter 5. URL:

http://www.rivers.gov.au/acrobat/techguidelines/tech_guide_vol1a_chap05.pdf

Repaka, S.R., D.D. Truax, E. Kolstad, C.G. O'Hara (2004). Comparing Spectral and Object Based Approaches for Classification and Transportation Feature Extraction 
from High Resolution Multispectral Imagery. ASPRS Annual Conference Proceedings, May 2004. Denver, Colorado. URL: http://www.definiensimaging.com/documents/publications/ASPRS-2004-0204.pdf

RESAC (2003). Using IKONOS Satellite Imagery to Map Riparian Forest Buffers. MidAtlantic Regional Earth Science Applications Center. Department of Geography, University of Maryland. URL: http://www.geog.umd.edu/resac/riparian.htm Accessed: March 11, 2004.

Richards, J.A. and X. Jia (1999). Remote Sensing Digital Image Analysis: An Introduction, Springer-Verlag, New York, New York, 363 p.

Rolim, F.A. and Lingnau, C. (2002). Monitoring Riparian Areas through Object Oriented Classification in IKONOS Image. URL: http://www.definiensimaging.com/documents/um2002/poster/rolim_brasil.pdf Accessed: May 2004.

Souchere, V., D. King, J. Daroussin, F. Papy and A. Capillon. (1998). Effects of tillage on runoff directions: consequences on runoff contributing area within agricultural catchments. Journal of Hydrology, 206: 256-267.

Strahler, A.H., C.E. Woodcock, J.A. Smith (1986). On the Nature of Models in Remote Sensing. Remote Sensing of Environment, 20:121-139.

Tim, U.S., R. Jolly, and H. Liao (1995). Impact of landscape feature an dfeature placement on agricultural non-point source pollution control. Journal of Water Res. Planning and Management, 121(6): 463-470.

Tso, B. and P.M Mather (2001). Classification Methods for Remotely Sensed Data, Taylor \& Francis Inc., New York, New York, 332 p.

Tukianinen, T. (2002). Remote sensing in impact assessment and monitoring: a cost benefit analysis. Presented at the $2^{\text {nd }}$ MINEO Workshop, Orleans, France. URL: http://www.brgm.fr/mineo/workshop/2ndWorkshop/13th\%20Dec/Session\%201/costs. pdf Accessed: 2/1/05.

Turner, W., S. Spector, N. Gardiner, M. Fladeland, E. Sterling, M. Steininger (2003). Remote Sensing for Biodiversity Science and Conservation. Trends in Ecology and Evolution, 18(6): 308-314.

USDA-NRCS (1995). Riparian Forest Buffer, 391. Model State Standard and General Specifications. NRCS Watershed Science Institute. Seattle, WA.

Van Oevelen, P.J., G. Sterk (2001). Erosion Processes Modeling Using Microwave Remote Sensing at a Catchment Scale. Soil Erosion Research for the $21^{\text {st }}$ Century: Proceedings of the International Symposium, Honolulu, Hawaii. 
Wadsworth, R.A., Y.C. Collingham, S.G. Willis, B. Huntley, P.E. Hulme (2000). Simulating the spread and management of alien riparian weeds: Are they out of control? Journal of Applied Ecology, 37(1): 28.

Welsch, D.J. (1991). Riparian Forest Buffers: Function and Design for Protection and Enhancement of Water Resources. U.S. Department of Agriculture, Forest Service, Northeastern Area. Paper No. NA-PR-07-91. URL:

www.na.fs.fed.us/spfo/pubs/n_resource/riparianforests/index.htm Accessed: September 27, 2004.

Wilson, B.N., B.J. Barfield, I.D. Moore (1981). A hydrology and sedimentology watershed model, Part I, Modeling Techniques. Technical Report. Department of Agricultural Engineering. University of Kentucky. Lexington.

Wulder, M.A., R.J. Hall, N.C. Coops, S.E. Franklin (2004). High Spatial Resolution Remotely Sensed Data for Ecosystem Characterization. BioScience, 54(6): 511-521.

Young, R. A., C. A. Onstad, D. D. Bosch and W. P. Anderson (1989). AGNPS: A nonpoint-source pollution model for evaluating agricultural watersheds. Journal of Soil and Water Conservation 44(2): 168-173. 